\title{
Psychophysiological responses of older adults to an anxiety -evoking stimulus
}

Angela W. Lau

West Virginia University

Follow this and additional works at: https://researchrepository.wvu.edu/etd

\section{Recommended Citation}

Lau, Angela W., "Psychophysiological responses of older adults to an anxiety -evoking stimulus" (2000). Graduate Theses, Dissertations, and Problem Reports. 1202.

https://researchrepository.wvu.edu/etd/1202

This Dissertation is protected by copyright and/or related rights. It has been brought to you by the The Research Repository @ WVU with permission from the rights-holder(s). You are free to use this Dissertation in any way that is permitted by the copyright and related rights legislation that applies to your use. For other uses you must obtain permission from the rights-holder(s) directly, unless additional rights are indicated by a Creative Commons license in the record and/ or on the work itself. This Dissertation has been accepted for inclusion in WVU Graduate Theses, Dissertations, and Problem Reports collection by an authorized administrator of The Research Repository @ WVU.

For more information, please contact researchrepository@mail.wvu.edu. 
Psychophysiological Responses of Older Adults to an Anxiety-Evoking Stimulus

\author{
Angela W. Lau \\ Dissertation submitted to the \\ Eberly College of Arts and Sciences \\ at West Virginia University \\ in partial fulfillment of the requirements for the degree of
}

Doctor of Philosophy

in

Psychology

\author{
Kevin T. Larkin, Ph.D., Chair \\ Barry A. Edelstein, Ph.D. \\ B. Kent Parker, Ph.D. \\ Eric D. Rankin, Ph.D. \\ Joseph R. Scotti, Ph.D. \\ Department of Psychology
Morgantown, West Virginia 2000

Keywords: Older Adults, Anxiety, Heart Rate, Skin Conductance, Blood Pressure Copyright 2000 Angela W. Lau 


\begin{abstract}
Psychophysiological Responses of Older Adults to an Anxiety-Evoking Stimulus
\end{abstract}

Angela W. Lau

The purpose of this study was to clarify the relation between anxiety and physiological responses in older adults as compared to younger adults. Heart rate (HR), skin conductance level (SCL), skin conductance response (SCR), systolic blood pressure (SBP), and diastolic blood pressure (DBP) were obtained before, during, and after exposure to a Stroop color-word naming task and a snake video from 46 female younger adults (age 18-30) and 28 female older adults (age 65-80) who were designated as either snake fearful or snake nonfearful. No significant group differences were observed on physiological measures to baseline one or during the snake video. Younger adults exhibited significantly greater HR, SCL, and SCR responses relative to older adults during the Stroop Task, while older adults demonstrated significantly higher SBP and DBP during baseline and in response to the Stroop task as compared to younger adults. There also was evidence of delayed recovery on SCL and SCR in older adults as compared to younger adults following the Stroop task. Although high fear individuals endorsed greater anxiety on self-report measures during both tasks relative to low fear individuals, with the exception of an unusual Age $\mathrm{x}$ Fear $\mathrm{x}$ Interval interaction in SBP during recovery from the Stroop task, no significant fear group differences were observed on physiological variables before, during, or in recovery from the Stroop task or the snake video. Problems with the definition of the high fear sample population may explain these findings. Although this study was not able to support its major hypotheses, it replicated the psychophysiological findings of stressor-task studies of older adults and yielded some evidence to suggest that stressor tasks may not evoke an emotional response sufficient enough to be considered an anxiety- or fear-evoking stimulus. It also found evidence to suggest that older adults exhibited greater desynchrony (physiologic responses vs. self-report) than younger adults. The findings of this study also clearly indicated the need to employ methods of data collection that take into account age-associated changes in order to truly capture the experience/presentation of anxiety in older adults. 


\section{Acknowledgments}

I must express my deepest gratitude to my committee chair, Kevin Larkin, for his guidance, support, and quick turn-around time. His professionalism and positive attitude during our "teleconference meetings" helped to invigorate me and to lower my anxiety to better approximate a more optimal level of arousal so that I could complete my dissertation in a timely manner.

I would also like to give a heartfelt thanks to my other committee members, Barry Edelstein, Virginia Goetsch, Kent Parker, Eric Rankin, and Joseph Scotti, for their valuable contributions and for making this collaborative process a positive and painless experience.

Special thanks to Kevin Larkin and Joseph Scotti for their spirit of cooperation in allowing me to utilize the resources in their respective laboratories; I would not have been able to complete this study without their generosity.

I would also like to express my appreciation to Andria Black for her assistance in recruiting subjects and collecting data; her sacrificed weekends and evenings, and her enthusiasm during our quest for older adult participants were greatly appreciated.

I must also acknowledge the members of my dissertation support group, Steve, Lisa, Patty, Kristine, and Lorraine, who helped keep me on track and keep my sanity during the last leg of this long, education process.

But most of all, I must thank my family and friends for their support throughout the last five years. I drew strength from their constancy and their unwavering conviction in my abilities. I would especially like to thank my mother for instilling in me the belief that I could achieve anything I wanted to in life, and for her willingness to support me in any way possible; I could not have done this without her unconditional love and support. 
This research was supported in part by grants from the West Virginia University Department of Psychology Alumni Fund and the Eberly College of Arts and Sciences Office of Academic Affairs, and a dissertation fellowship from the Southern Regional Board of Education. 


\section{Table of Contents}

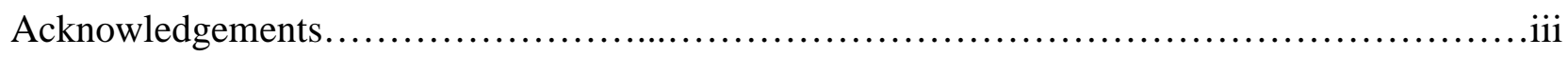

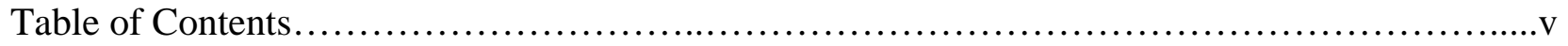

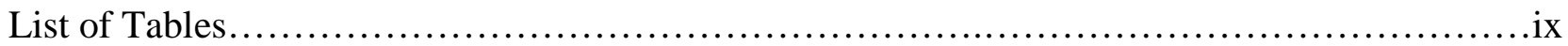

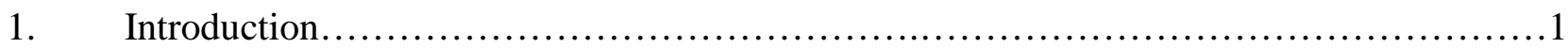

1.1 Complications in the presentation of anxiety in older adults......................2

1.2 The importance of the physiological response modality ........................

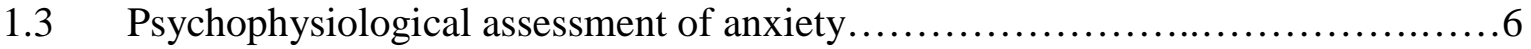

$1.4 \quad$ Developmental physiological changes with aging...............................9

$1.5 \quad$ Psychophysiological responses of older adults ................................10

1.6 Psychophysiological responses of older adults to anxiety-evoking stimuli.........13

$1.7 \quad$ Statement of the problem................................................. 19

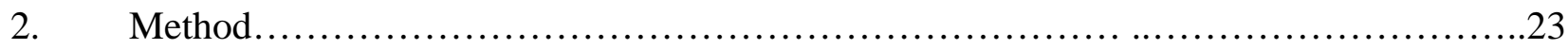

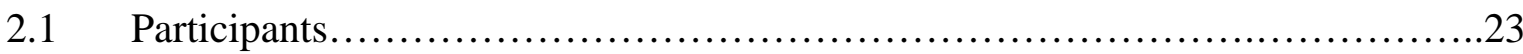

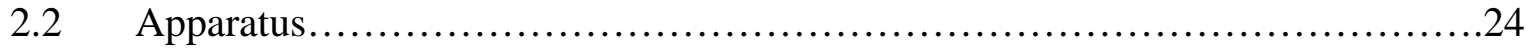

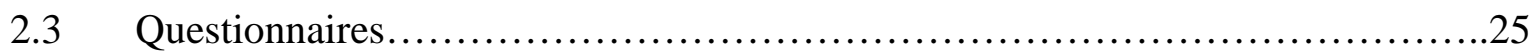

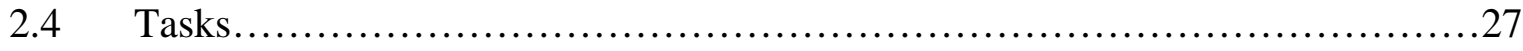

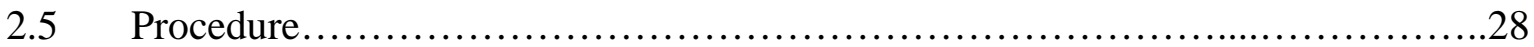

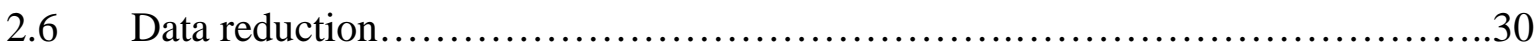

$2.7 \quad$ Statistical analysis............................................................

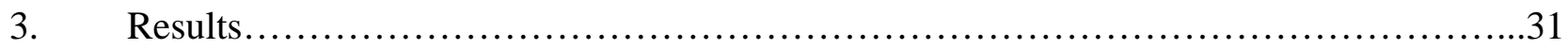

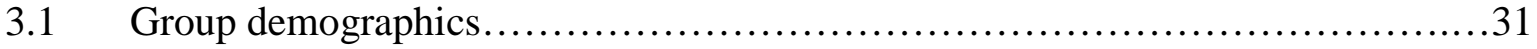

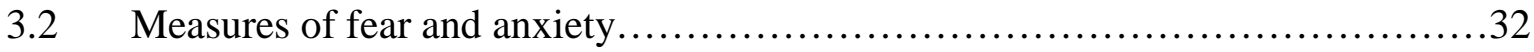


$3.3 \quad$ Task performance.........................................................

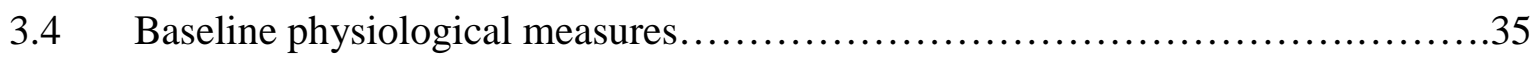

3.5 Physiological reactivity to pre-task baseline................................. 35

3.6 Physiological responses to tasks.......................................

3.7 Correlations between physiological measures and anxiety measures..............37

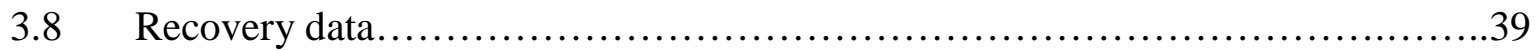

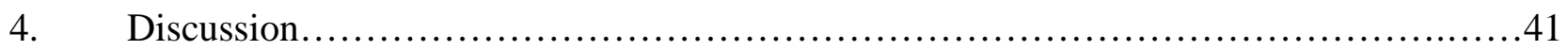

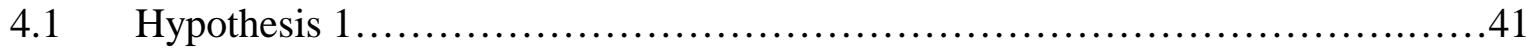

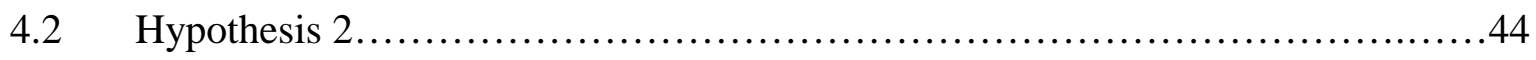

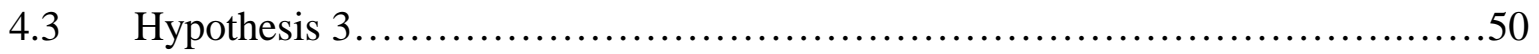

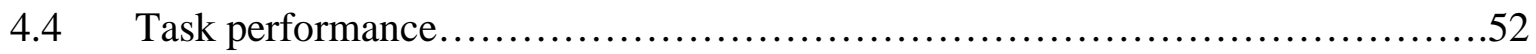

4.5 Self-report behaviors..................................................

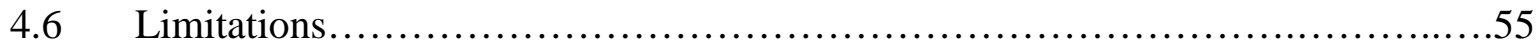

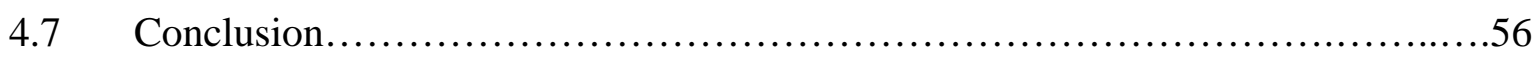

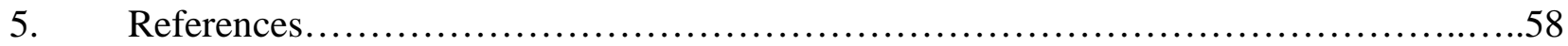

6. Appendices........................................................ $71-85$

6.1 Appendix A: Medical Screening Questionnaire $\ldots \ldots \ldots \ldots \ldots \ldots \ldots \ldots \ldots \ldots \ldots . \ldots 11$

6.2 Appendix B: Snake Video Questionnaire.................................73

6.3 Appendix C: ANOVA and ANCOVA Summary Tables.......................74

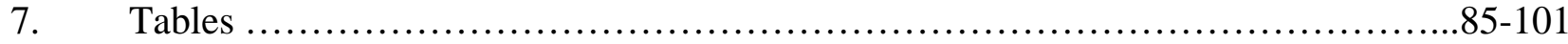

7.1 Table 1: Means (and Standard Deviations) for Age, Education, and Health Behaviors. 
7.2 Table 2: Frequencies (and Percentages) for Categorical Demographic

Information.

7.3 Table 3: Frequencies for Medical Conditions, Prescription Medication Use, Nonprescription Medication Use, and Psychiatric History

7.4 Table 4: Means for FSS Item 39 (snakes), BAI, STAI, SNAQ, and Subjective Anxiety Ratings.

7.5 Table 5: Means (and Standard Deviations) for Measures of Performance on the Stroop Task and Snake Video .92

7.6 Table 6: Means (and Standard Deviations) for Baseline One and Estimated Means (and Standard Error) for Reactivity to Snake Video and Stroop Task for Heart Rate, Skin Conductance Level, Skin Conductance Response, Systolic Blood Pressure, and Diastolic Blood Pressure .93

7.7 Table 7: Means (and Standard Deviations) for Heart Rate, Skin Conductance Level, Skin Conductance Response, Systolic Blood Pressure, and Diastolic Blood Pressure Following Stroop Task and Snake Video .95

7.8 Table 8: Correlations Between Mean Physiological variables (Baseline and Reactivity) and Measures of Fear and Anxiety

8. Figure Captions. 101

9. Figures

9.1 Figure 1: Age x Fear Interaction for Years of Education......................102

9.2 Figure 2: Age x Fear Interaction for State Trait Anxiety Inventory-State..........103

9.3 Figure 3: Age x Task Interaction for Subjective Anxiety Ratings...............104

9.4 Figure 4: Fear x Task Interaction for Subjective Anxiety Ratings................105 
9.5 Figure 5: Age x Task Interaction for Snake Video Questionnaire ..............106

9.6 Figure 6: Age x Fear Interaction for Stroop Task Error Ratio................. 107

9.7 Figure 7: Age x Task Interaction for Heart Rate Responses During Tasks........108

9.8 Figure 8: Age x Task Interaction for SCR Responses......................109

9.9 Figure 9: Fear x Task for Systolic Blood Pressure Responses During Tasks......110

9.10 Figure 10: Age x Interval Interaction for Post-Stroop Task Skin Conductance Level Recovery.......................................................... 111

9.11 Figure 11: Age x Interval Interaction for SCR Recovery following the Stroop Task.................................................................... 112

9.12 Figure 12: Age x Fear x Interval Interaction for SBP during Recovery...........113 
List of Tables

Table 1. Means (and Standard Deviations) for Age, Education, and Health Behaviors

Table 2. Frequencies (and Percentages) for Categorical Demographic Information

Table 3. Frequencies for Medical Conditions, Prescription Medication Use, Nonprescription

Medication Use, and Psychiatric History

Table 4. Means for FSS Item 39 (snakes), BAI, STAI, SNAQ, and Subjective Anxiety Ratings

Table 5. Means (and Standard Deviations) for Measures of Performance on the Stroop Task and

Snake Video

Table 6. Means (and Standard Deviations) for Baseline One and Estimated Means (and Standard

Error) for Reactivity to Snake Video and Stroop Task for Heart Rate, Skin Conductance Level,

Skin Conductance Response, Systolic Blood Pressure, and Diastolic Blood Pressure

Table 7. Means (and Standard Deviations) for Heart Rate, Skin Conductance Level, Skin

Conductance Response, Systolic Blood Pressure, and Diastolic Blood Pressure Following Stroop

Task and Snake Video

Table 8. Correlations Between Mean Physiological Variables (Baseline and Reactivity) and Measures of Fear and Anxiety 


\section{Psychophysiological Responses of Older Adults \\ to an Anxiety-Evoking Stimulus}

Anxiety is an emotional reaction to a perception of danger and is defined by a vague, diffuse feeling of uneasiness, apprehension, or impending doom (Lader \& Marks, 1971; Pettijohn, 1992). It is often accompanied by physiological arousal (e.g., increased heart rate) and fearful behaviors (e.g., avoidance, catastrophic thoughts) (American Psychiatric Association, 1994; APA). Anxiety becomes pathological when the intensity and/or duration of the anxiety response is exaggerated towards a particular stimulus (Lader \& Marks, 1971). Anxiety disorders are diagnosed when the primary focus of clinical concern evokes extreme anxiety in the individual and results in interference with daily functioning (APA, 1994). It is peculiar that despite the large number of older adults who experience a level of anxiety that causes dysfunction in their daily lives, only a small number of older adults are diagnosed with anxiety disorders (Fuentes \& Cox, 1997; Small, 1997; see Blazer, George, \& Hughes, 1991).

\section{According to findings from the National Institute of Mental Health (NIMH)}

Epidemiological Catchment Area (ECA) survey, anxiety disorders are the single largest mental health problem in the country (Regier et al., 1984). Other community-based epidemiological surveys have reported similar findings (Bland, Newman, \& Orn, 1988; Myers et. al, 1984). Despite general agreement regarding the prevalence rates for anxiety disorders in general, the prevalence rates for adults under age 65 are different from those reported for adults age 65 years and older (for reviews, see Blazer et al., 1991; Flint, 1994; Stanley \& Beck, 1998). In general, older adults have lower prevalence rates for anxiety disorders than younger adults. Regier et al. (1988) reported a one-month prevalence rate of anxiety disorders of $7.3 \%$ for younger adults as compared to a rate of $5.5 \%$ for older adults (lower than in any other age category). Bland et al. 
(1988) reported similar findings from an epidemiological survey of three communities in Canada. Blazer et al. (1991) reported the results of the ECA Wave II survey, which found a generalized anxiety disorder (GAD) prevalence rate of $4.8 \%$ in older adults, less than the $6.2 \%$ prevalence rate found in younger adults.

It should be noted that in studies that included homebound or institutionalized older adults, prevalence rates for anxiety disorders were slightly elevated in comparison to community-dwelling, ambulatory older adults (Bland et al., 1988; Bruce \& McNamara, 1992). Although reduced, the prevalence rates of anxiety disorders for older adults are still significant and indicate anxiety is of clinical concern for older adults. Moreover, close to $40 \%$ of the elderly sampled in the community and in hospitals reported experiencing enough anxiety symptomatology to warrant clinical intervention even though they did not meet full criteria for an anxiety disorder (Himmelfarb \& Murrell, 1984; Magni \& De Leo, 1984).

\section{Complications in the Presentation of Anxiety in Older Adults}

Several factors may explain the difference in prevalence rates between older and younger adults and the possible underdiagnosis of anxiety disorders in the elderly. First, there may be a cohort effect. Adults who are age 65 and older grew up in an era in which psychology and psychological disorders were stigmatized conditions. Thus, a bias towards underreporting anxiety may exist with older adults. This may help explain why, with the exception of cognitive impairment, the ECA survey found prevalence rates for all psychological disorders were lowest in adults over 65 years of age (Myers et al., 1984).

Second, co-morbidity with other psychological disorders, certain medical conditions, or the cognitive state of the older adult may complicate the presentation of anxiety in older adults because the clinical presentation of these co-morbid conditions may be identical to that of an 
anxious individual (Alexopoulos, 1991; Cohen, 1991; Flint 1994; Small, 1997; Stanley \& Beck, 1998; Yesavage \& Taylor, 1991). As a result, anxiety symptoms may not be recognized as the primary focus of clinical concern. Also related to the cohort effect, older adults may exhibit a "masked anxiety," in which the anxiety symptoms are manifested somatically and are subsequently reported as medical illnesses (Gurian \& Miner, 1991). Conversely, many older adults may have medical conditions that can cause symptoms that appear to be anxiety symptoms (Cohen, 1991). For example, individuals with diabetes may experience somatic symptoms similar to having a panic attack, such as racing heart, sweating, cold chills, hot flashes, and trembling. In addition, with additional medical, financial, and social concerns, older adults may have more "legitimate" reasons about which to worry (Shamoian, 1991).

Third, ageism also may be a factor in underdiagnosing anxiety disorders in older adults. In other words, mental health specialists may be less likely to diagnose an anxiety disorder in older adults because they believe observed or reported symptoms of worry and somatic concerns are a normal development in the aging process (Small, 1997). Fourth, it is possible that older adults experience a subsyndromal anxiety state that causes dysfunction, but does not meet full criteria for an anxiety disorder. Although older adults may be diagnosed less frequently than younger adults, studies indicate older adults experience significant distress from anxiety symptoms (Angst, Merikangas, \& Preisig, 1997; Gurian \& Miner, 1991; Shamoian, 1991; Small, 1997; Stanley \& Beck, 1998).

Fifth, it is possible that current anxiety assessment instruments lack content validity when assessing fear and anxiety in older adults. Just as children have fears that are age-specific (e.g., separation anxiety), the nature of fear in older adults may differ from those of younger adults. Liddell, Locker, and Burman (1991), Kilpatrick (1984), and Kogan (1996) found an 
inverse relation between age and the number of fear items endorsed, and between age and particular fear items on the Fear Survey Schedule-II (FSS-II). Kogan (1996) modified the FSS-II by including age-appropriate fears (i.e., falling, diminished health, being disabled, being a burden) and found four of the ten most commonly endorsed fear items were not original FSS-II items but one of these age-appropriate fears.

Finally, almost none of the anxiety assessment devices have been normed for the older adult population (Fisher, Zeiss, \& Carstensen, 1993; Hersen, Van Hasselt, \& Goreczney, 1993; Sheikh, 1991; Stanley \& Beck, 1998). As a result, if it is true that the experience and subsequent presentation of anxiety is different in older adults than in younger adults, then it may go unrecognized and/or undiagnosed because the assessment instruments fail to detect the particular constellation of anxiety symptoms seen in older adults. Flint (1994) noted that the method investigators used to diagnose older adults in various epidemiological studies (e.g., case definition, hierarchical vs. nonhierarchical approach to diagnosis, wording of questions, list of fears presented) may have influenced reported prevalence rates. Therefore, assessment methods that require self-report information or the subjective interpretation of symptoms may not be the most accurate method by which to identify anxiety disorders in older adults.

\section{The Importance of the Physiological Response Modality}

To develop a more comprehensive and objective understanding of anxiety, Lang (1968) proposed a triple response model of anxiety, which is comprised of three response modalities: overt-motor, verbal-cognitive, and somatic-physiological. Although related to one another, each response system is partially independent. In other words, each modality can influence one another, but "none of these systems hold a special controlling relationship to the others" (Lang, 1968, p. 90). Desynchrony, or differential change in fear responding across modalities following 
treatment, is frequently observed (Cone, 1979). Thus, in order to gain a more comprehensive understanding of anxiety and its disorders, it has been argued that each system should be assessed separately (Cone, 1979; Lang, 1968).

Although all three response modalities have been utilized to better understand the construct of anxiety, the proposed study will focus on the physiological response channel. Not only is it an objective measure of bodily functions, but there are three reasons why it is particularly important to study the physiological response mode (Turpin, 1991). First, physiological arousal has been implicated as a causal factor in several theories regarding the acquisition and maintenance of anxiety disorders (Barlow, 1988; Forsyth \& Eifert, 1996; Mower, 1939; see Lader \& Marks, 1971). For example, in a habituation theory posited by Lader, the lowered ability to habituate to excessive arousal predisposes an individual to anxiety (see Lader \& Marks, 1971). Thus, the individual continues to respond to aversive stimuli and continues to experience excessive physiological arousal, which facilitates the fear conditioning process.

Second, information pertaining to physiological arousal can be used to aid in the classification and diagnosis of anxiety disorders. Physiological arousal is a ubiquitous symptom in anxiety disorders, and therefore is crucial in the assessment process (Papillo, Murphy, \& Gorman, 1988; Zuckerman, 1991). Moreover, studies have found that individuals with various anxiety disorders react differently to phobic stimuli than individuals without anxiety disorders (for review, see Barlow, 1988). For example, Turner, Biedel, and Nathan (1985) found that socially anxious persons exhibited greater cardiovascular reactions to a laboratory speech task than control subjects, and Lader (1967) found group differences contrasting individuals with different types of anxiety states (i.e., social phobia, specific phobia, agoraphobia, mixed anxietydepression) on skin conductance fluctuations and response habituation to a fearful stimulus. 
Thus, psychophysiological assessments can help with diagnosing and/or classifying an anxiety disorder based on level of arousal patterns to selected stimuli.

Third, physiological assessment can aid in treatment planning and monitoring treatment process. Psychophysiological assessment can help in initially identifying the discriminative stimulus for target behaviors by assessing stimuli that evoke the greatest physiological responses from a patient (Turpin, 1991). By reviewing changes in reactivity, a clinician can evaluate the progress of a patient and assess whether a treatment plan may require readjustment (due to lack of change or exceptional improvement) (Turpin, 1991). In addition, this information could be used to formulate a comprehensive treatment plan that would limit relapse; clinical lore postulates post-treatment desynchrony among modalities is a leading predictor for relapse (see Barlow, 1988; Lang, 1993).

\section{Psychophysiological Assessment of Anxiety}

Although psychophysiological measures can range from measures of the central nervous system (CNS; e.g., electroencephalography, cortical evoked potentials) to those of the autonomic nervous system (ANS; e.g., electromyography, pupillography, electrogastrophy, cardiovascular activity, electrodermal activity), for financial and technological convenience, the most commonly used measures in research and in clinical practice are nonintrusive measures of the ANS: heart rate, blood pressure, and electrodermal activity (Anderson \& McNeilly, 1991; Fredrikson, 1991; Turpin, 1991). Moreover, they are the physiological symptoms most commonly associated with anxiety (e.g., racing or pounding heart, sweating) (Papillo et al., 1988).

Heart rate. The measurement of the activity of the heart was one of the earliest measures used to study physiological arousal (Hassett, 1978). Many aspects of the cardiovascular system 
can be studied, but heart rate (how fast the heart pumps blood) and blood pressure (the pressure within the blood vessels) are the most popular (Hassett, 1978; Stern, Ray, \& Davis, 1980).

In general, studies have found that individuals with anxiety disorders tend to have higher resting heart rate (HR) (Antony, Meadows, Brown, \& Barlow, 1994; Ehlers, Margraf, Roth, Taylor, \& Birbaumer, 1988; Lader \& Wing, 1966; Rapee, 1986; see Papillo et al., 1988) and exhibit slower HR habituation to a fearful stimulus than normal controls (McGuinness, 1973). There is inconclusive evidence regarding the pattern and magnitude of HR reactivity to presentation of a phobic stimulus. While some studies have reported a pattern of significantly greater HR reactivity towards stress- or anxiety-evoking stimuli by individuals with anxiety disorders than controls and other diagnostic groups (Antony et al., 1994; Rapee, 1985; Sartory, Roth, \& Kopell, 1992; Woods, Charney, McPherson, Gradman, \& Heninger, 1987), other studies report only trends in HR reactivity across groups after covarying resting heart rate (Asmundson, Norton, Wilson, \& Sandler, 1994; Barlow et al., 1984; Ehlers \& Breuer, 1992; Rapee, 1986). However, studies that employed nonclinically fearful or focally phobic individuals yielded more consistent findings that fearful/phobic individuals exhibited significantly greater HR responses to phobic stimuli than nonfearful individuals (Fredrikson \& Gunnarsson, 1992; Hare, 1973; see Hugahl, 1988; Rose, McGlynn, \& Lazarte, 1995; Weerts \& Lang, 1978).

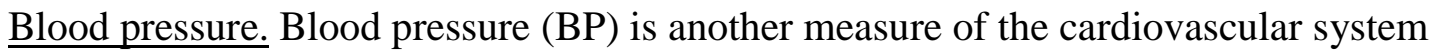
comprised of systolic blood pressure (SBP; i.e., when the heart is contracting) and diastolic blood pressure [DBP; i.e., when the heart relaxes; Hassett, 1978].

In general, because of the discontinuous measurement of BP, establishing a single response pattern for BP for anxious individuals based on psychophysiological studies has not been as forthright as that for the more continuous measures of HR or electrodermal activity. 
Overall, studies seem to indicate a pattern of elevated blood pressure, both SBP and DBP, during baseline in individuals with anxiety disorders as compared to controls (Ehlers et al., 1988; Kelly, 1980; Kelly \& Martin, 1969; Malmo, Shagass, \& Heslam, 1951; Woods et al., 1987). Although some studies were unable to find differences in the magnitude of blood pressure reactivity to stress- or anxiety-evoking stimuli between individuals with anxiety disorders and controls (Ehlers \& Breuer, 1992; Kelly \& Martin, 1969; Woods et al., 1987), other studies seem to support a pattern of hyperarousal and slow habituation for both SBP and DBP in anxious individuals when exposed to a stressor in contrast to nonanxious control participants (Ehlers et al., 1988; Ehlers et al., 1986; Malmo et al., 1951).

Electrodermal activity. Electrodermal activity (EDA) measures the changes in the ability of the skin to conduct an electrical current across and through the skin as a result of sweat gland activity (Hassett, 1978). Sweat gland activity is reflected by changes in skin potential level (SPL) or skin conductance level (SCL). EDA can also be measured by the number of momentary spontaneous fluctuations, or skin conductance responses (SCR). Studies using EDA as a dependent measure have produced more robust findings than those of heart rate and blood pressure. A pattern of elevated conductance level during rest periods, larger number of spontaneous fluctuations in response to phobic stimuli, and slower habituation rates of SCL and SCR to those stimuli in individuals with anxiety disorders as compared to normals is supported by numerous studies (Ehlers et al., 1988; Geer, 1966; Johnstone et al., 1981; Lader, 1967; Lader \& Wing, 1964, 1966; Maple, Bradshaw, \& Szabadi, 1981). However, findings of increased magnitude of SCL reactivity are equivocal (Lader, 1967; Lader \& Wing, 1966). Studies employing nonclinically fearful or focally phobic individuals also evidenced a clear pattern of increased SCR responding but equivocal SCL reactivity to a phobic stimulus (see Hugahl, 1988). 


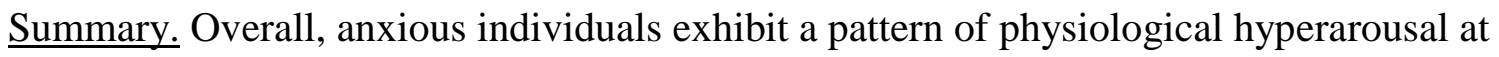
baseline and during habituation to fearful stimul, but do not always exhibit a pattern of increased physiological reactivity during the task (Ehlers et al., 1988; Lader \& Wing, 1964, 1966; Malmo et al., 1951). Although findings for significant differences in magnitude of cardiovascular reactivity to an anxiety-evoking stimulus are equivocal, there are many studies to support the existence of a pattern of cardiovascular hyperarousal (e.g., higher baseline, slower habituation) in anxious individuals as compared to non-anxious individuals at baseline and when exposed to a stimulus (Barlow et al., 1984; Malmo et al., 1951; Rapee, 1985; Woods et al., 1987). There is clear evidence that anxious individuals exhibit significantly greater arousal on EDA at rest and slower habituation to stimulus presentations than non-anxious individuals as well (Bond, James, \& Lader, 1974; Lader \& Wing, 1964, 1966). Indeed, looking more closely at a subset of the anxiety literature, there is substantial and consistent support in the fear literature for increased heart rate and SCR in fearful or focally phobic individuals as compared to non-fearful individuals in response to a phobic stimulus (see Hugahl, 1988).

\section{Developmental Physiological Changes with Aging}

The population on which these data regarding the physiological modality of Lang's triple-response model are based has been comprised of individuals between the ages of 18 and 65 (Hersen et al., 1993). Therefore, one must question whether these data are applicable to individuals over the age of 65 because it is well known that the general physiology of an individual changes over a lifetime; some of these changes being in the cardiovascular system (Lakatta, 1990). As an individual ages, arteries become less plastic, leading to greater peripheral resistance (Lakatta, 1990). In addition, weakening of cardiac muscles results in decreased efficiency in pumping blood (Lakatta, 1990). The aging process also produces changes in the 
electrodermal system (Porges \& Fox, 1986). As one ages, the density of sweat glands diminishes, the number of active eccrine sweat glands in individuals over age 65 decreases significantly, and the active sweat glands in older adults do not produce as much sweat as those of younger adults (e. g., under age 65) (Catania, Thompson, Michalewski, \& Bowman, 1980; Montagna, 1965; see Porges \& Fox, 1986).

Based on our knowledge of the developmental physiological changes with aging, one might predict lower heart rate, skin conductance level, and skin conductance response but greater blood pressure responses in older adults relative to younger adults. In fact, studies have found that older adults have a lower resting heart rate, lower skin conductance levels, and higher blood pressures at rest than younger adults (see Anderson \& McNeilly, 1991). With these developmental changes, reactivity to fear-evoking stimuli may also differ between older adults and younger adults. If this is the case, then one might argue that the somatic consequences of these physiological changes may also affect the psychophysiological presentation and experience of anxiety, and consequently, across the remaining two response modalities in older adults.

\section{$\underline{\text { Psychophysiological Responses of Older Adults }}$}

Twenty studies to date have investigated the HR, BP, and EDA reactivity of older adults (mean age over 60) to a stressor task in comparison to the reactivity of younger adults (under age 55), but the internal, external, and ecological validity of eleven of these studies were compromised to such an extent that their respective findings are difficult to interpret meaningfully (Barnes, Raskind, Gumbrecht, \& Halter, 1982; Botwinick \& Kornetsky, 1960; Ditto, Miller, \& Maurice, 1987; Eisdorfer, Doerr, \& Follette, 1980; Faucheux, Bourleire, Baulon, \& Dupuis, 1981; Furchtgott \& Busemeyer, 1979; Levenson, Carstensen, \& Gottman, 1994; Morris \& Thompson, 1969; Norris, Shock, \& Yiengst, 1953; Powell, Milligan, \& Furchtgott, 
1980; Silverman, Cohen, \& Shmavonian, 1958). For example, general exclusionary criteria and inadequate control of health behaviors may have allowed confounding variables to be introduced to the studies (e.g., use of medications that effect the ANS; medical conditions that impact the ANS) and limited their generalizability (Barnes et al., 1982; Botwinick \& Kornetsky, 1960; Ditto et al., 1987; Eisdorfer et al., 1980; Furchtgott \& Busemeyer, 1979; Levenson et al., 1994; Morris \& Thompson, 1969; Norris et al., 1953; Powell et al., 1980; Silverman et al., 1958). Generalizability was further restricted in studies that also employed participants from populations with limited generalizability to the general population (Botwinick \& Kornetsky, 1960; Norris, et al., 1953; Powell et al., 1980) or in studies that did not report participant characteristics or from where they recruited (Barnes et al., 1982; Eisdorfer et al., 1980; Silverman et al., 1958). In addition, some studies also employed stressor tasks with questionable efficacy or content validity (Barnes et al., 1982; Ditto et al., 1987; Furchtgott \& Busemeyer, 1979; Powell et al., 1980; Silverman et al., 1958). Other methodological concerns among these studies included the lack of a standardized protocol across groups and the lack of an appropriate baseline from which to calculate reactivity (Ditto et al., 1987; Faucheux et al., 1981).

Despite methodological concerns, the internal validity of the remaining nine articles were sufficiently intact to warrant discussion of reported results, albeit with caution (Boutcher \& Stocker, 1996; Capriotti, Garwood, \& Engel, 1981; Faucheux, Baulon et al., 1983; Faucheux, Dupuis, Baulon, Lille, \& Bourliere, 1983; Garwood, Engel, \& Capriotti, 1982; Jennings, Brock, \& Nebes, 1990; Shmavonian, Miller, \& Cohen, 1968, 1970; Shmavonian, Yarmat, \& Cohen, 1965). It should be noted that technically, only the findings from six studies will be discussed because three of the nine articles included duplicate reports based on data presented in one of the other studies (Capriotti et al., 1981; Faucheux, Baulon, et al., 1983; Faucheux, Dupuis, et al., 
1983; Garwood et al., 1982; Shmavonian et al., 1968, 1970). Again, the findings from these six studies should be interpreted with caution because they, too, may also have some problems with limited generalizability and the threat of confounding variables, although not as problematic as in the other eleven studies.

The majority of these studies found attenuated HR reactivity to stressors in older adults as compared to younger adults (Boutcher \& Stocker, 1996; Faucheux, Dupuis, et al., 1983;

Garwood et al., 1982; Jennings, et al., 1990; Shmavonian et al., 1970). With the exception of one study that unexpectedly reported higher HR baseline levels in older adults than younger adults (Boutcher \& Stocker, 1996), none of the studies found significant age differences on resting heart rate.

Resting BP was generally found to be higher in older adults than younger adults (Boutcher \& Stocker, 1996; Garwood et al., 1982; Jennings et al, 1990) but the findings for BP reactivity to stressful tasks were equivocal. Although one study found that older adults exhibited greater SBP to stressor tasks than younger adults (Garwood et al., 1982), two other studies did not find significant group difference in BP reactivity (Boutcher \& Stocker, 1996; Jennings et al., 1990). However, Boutcher \& Stocker (1996) employed a task that was not very challenging and therefore may not have been effective enough to evoke differential responding in their older participants. Jennings et al. (1990) also employed a task that was not equally challenging between groups. Moreover, both studies, although screening for most medical conditions and health behaviors that might affect performance, did not restrict some behaviors (e.g., caffeine use) that may have influenced cardiovascular measurement.

Age-related findings on EDA are equivocal. Shmavonian and colleagues $(1968,1965)$ reported smaller baseline values and smaller SCR from older adults as compared to younger 
adults during conditioning, and faster extinction to a stimulus than younger adults, while the study by Garwood and colleagues $(1981,1982)$ did not yield significant age effects for SPL or SCL. However, Capriotti et al. (1981) and Garwood et al. (1982) collapsed measurement responses across multiple tasks that required different coping strategies (e.g., passive vs. active). Thus, significant results in the study by Garwood and colleagues $(1981,1982)$ may have been diluted by collapsing across differing stimuli.

With indications that there are age differences in psychophysiological response to stress, but without the ability to make any conclusive statements based on these indications due to questionable methodological integrity, one is still left without truly knowing if older adults' psychophysiological responses to a stressor differ from that of younger adults. $\underline{\text { Psychophysiological Responses of Older Adults to Anxiety-Evoking Stimuli }}$

A stressor task is not necessarily an anxiety- or fear-evoking task (Krantz, Manuck, \& Wing, 1986). A psychological stressor task "demands continuous mental effort and active engagement in the task in order to achieve reasonable task completion, but minimal physical exertion" (pg. 39-40, Turner, 1994). It does not require an individual to have an emotional reaction to it or to perceive the task/stimulus as dangerous. Therefore, it is possible that the question of whether older adults differentially respond to anxiety-evoking stimuli than younger adults may be a different question than whether they respond differently to a mentallychallenging stressor task than younger adults. Moreover, studies have found that young adult anxious individuals respond differently to a stress- or anxiety-evoking stimulus than non-anxious individuals (Ehlers et al., 1988; Lader \& Wing, 1964; Rapee, 1985). In light of these findings, it is unknown whether results from psychophysiological studies on young anxious adults could be replicated with an anxious population of older adults. 
Incredibly, even though there is a paucity of literature on older adults' physiological reactivity to stressors, the number of studies investigating the relation between anxiety and older adults' psychophysiological responses to stimuli is even more scant. Only three psychophysiology studies included self-report measures of anxiety to examine the relation between physiological reactivity to a stressor and anxiety (Barnes et al., 1982; Boutcher \& Stocker, 1996; Faucheux, Baulon, et al., 1983), and only three studies reported using an anxietyevoking stimulus (Ditto et al., 1987; Levenson et al., 1991; Silverman et al., 1959). No study to date has examined the relation between physiological reactivity and anxiety by exposing both high and low anxious participants to an anxiety-evoking stimulus.

Boutcher \& Stocker (1996) administered the State Trait Anxiety Inventory-State (STAIS; Speilberger, Gorsuch, \& Lushene, 1970) prior to having participants engage in a Stroop Color-Word task. However, even though the authors reported age differences in HR and BP response during the Stroop task, they did not find any age differences on the STAI-S (young, M $=30.7$; old,$M=28.9$ ), nor did they find any age differences on a manipulation check of task difficulty. Participants' scores on the STAI-S did not indicate anxiety was beyond normal parameters, suggesting their sample was comprised of normal controls rather than anxious participants.

Barnes et al. (1982) also administered the STAI prior to a mental stressor condition (e.g., digit span and serial subtraction), but in addition to a manipulation check of task difficulty, they also administered the STAI-S at the end of the experiment. Similar to Boutcher \& Stocker (1996), the authors reported age-group differences in HR and BP responsivity to the stressor task, but did not find age differences in pre- (young, $M=31.1$; old, $M=29.4$ ) or post-test STAIS scores (young, $M=34.7$; old, $M=29.2$ ), nor did they find age differences on task difficulty 
ratings. As in Boutcher \& Stocker (1996), the STAI-S scores in Barnes et al. (1992) did not indicate participants were experiencing anxiety beyond normal parameters, suggesting that the stressor task was not anxiety-evoking. Although Barnes et al. (1982) did find a significant age difference in STAI-Trait pre-test scores (young, $\mathrm{M}=38.1$; old, $\mathrm{M}=29.4$ ), no statistical analyses were performed to investigate the relation between the anxiety measure and physiological responsivity to the two tasks.

Faucheux, Baulon, et al. (1983) administered the Welsh Anxiety Index and Internalization Ratio of the MMPI (Perse \& LeBeaux, 1977, as cited in Faucheux, Baulon, et al, 1983) and questionnaires on masked anxiety and manifest anxiety (Cattell, 1962, as cited in Faucheux, Baulon, et al., 1983) to participants at the beginning and end of each of three experimental periods: control, experimental, and recovery. Even though the authors reported significant heart rate reactivity differences between conditions, they did not find any significant age differences in self-rated anxiety, suggesting that reactivity to stressor tasks was unrelated to anxiety. The authors reported nonsignificant correlations between all anxiety measures and heart rate reactivity.

The findings from the studies mentioned above indicate that age groups did not differ on a premorbid level of anxiety, and that the tasks for each respective study were not perceived as anxiety-evoking even though they elicited physiological reactivity. The findings therefore do not contribute to our understanding of how developmental physiologic changes affect older adults' physiological response to anxiety, and imply that stress-evoking stimuli (i.e., mental stressor tasks) may not be particularly valid stimuli for anxiety research. In other words, to study the experience and behaviors of anxiety, one might have to specifically employ anxiety-evoking stimuli, rather than standard stress-evoking laboratory stimuli. Only three psychophysiological 
studies that used a sample group over age 60 also reported employing an anxiety-evoking stimulus.

Silverman et al. (1958) presented participants with phrases the authors believed were “emotionally charged" for older adults (age 60-70) and measured their SCL and SCR as compared to younger adult participants (age 20-24) who were presented with words emotionally charged for their age group. No significant differences in SCL or SCR were found. However, there were many methodological concerns that limited the interpretability of these findings. First, the authors did not report from where they recruited their older adult participants. Second, they did not report any exclusionary criteria. Thus, it is unknown whether individuals had medical conditions that would interfere with EDA reactivity, whether they had auditory impairments, or were using substances (e.g., drugs) that might interfere with EDA reactivity. The premorbid anxiety level and psychiatric condition of the participants is also unknown. Third, it is unknown whether health behaviors that could influence EDA (e.g., exercising) were restricted prior to the experimental session. Fourth, the authors did not report how the phrases were selected, nor did they employ a manipulation check to assess for task effectiveness. Thus, it is possible the stimuli were not potent enough to elicit differential responding. With threats to generalizability and the ample opportunities for the introduction of confounding variables to this study, the results from this study are difficult to interpret.

Ditto et al. (1987) instructed participants to imagine an anxiety-eliciting situation that they had experienced for two minutes. While younger adults (age 17-28) exhibited significant HR, SBP, and DBP increases in response to the anxiety-imagery task, there was no significant difference in HR change scores between baseline and the anxiety-imagery task among older adults (age 60-96), although there were differences in SBP and DBP reactivity scores. However, 
as was mentioned in a previous section, the Ditto et al. (1987) study contains some methodological problems that limit the interpretability of reported results.

First, although participants were screened for medical conditions and medication use that could affect cardiovascular responding, psychiatric conditions and premorbid level of anxiety were not assessed, nor were health behaviors that could affect cardiovascular responding (e.g, exercising, caffeine, nicotine) restricted prior to the experimental session. Second, potential confounding variables were introduced because the authors had their groups engage in different task protocols, conducted the experiment in various locations according to group affiliation (e.g., in-lab for younger adults but in-home for older adults), and also used different psychophysiological recording equipment depending on group affiliation. Third, the authors did not employ a manipulation check to determine whether the tasks were truly anxiety-evoking for the participants, or that the participants were performing the task accurately (e.g., not distracting or avoiding). Fourth, the authors employed several tasks in their experimental protocol (e.g., serial subtraction, imagining an anxiety-eliciting and an anger-eliciting situation), but did not counterbalance the tasks. Therefore, reported findings may have been confounded by an order effect. Finally, the age range of the participants in the group classified "older adult" was extremely large (age 60-96). Presently, it is not known whether "young-old" adults respond differently than "old-old" adults. Thus, the heterogeneous nature of the older adult age group employed by Ditto et al. (1987) may have diluted the ability to identify developmental differences in reactivity.

Without naming the emotion, Levenson et al. (1991) directed participants (age 71-83) on how to construct various facial configurations to create the universal expression of six emotions (anger, disgust, fear, happiness, surprise, sadness). They were then asked to hold the 
configuration for 10 seconds while physiological measures were recorded. In a second task, participants were prompted with an antecedent condition (i.e., anticipating injury) to recall a time they had experienced the emotional reaction elicited by the antecedent condition. For each emotion, the participant was asked to describe the situation, and was directed to "relive" for 15 seconds, the moment in which the emotion was experienced in the situation. The authors found a main effect for emotion on HR and skin conductance level after restricting the data to trials in which participants rated having felt at least moderate emotional intensity during the task. However, instead of reporting significant change scores from baseline per emotion, they reported significant differences in change scores as compared to other emotions per measure (e.g., anger, sadness). Thus, although the participants showed an increase in heart rate, it is uncertain whether they exhibited significant HR or EDA responses to fear-related tasks.

In a nonparametric meta-analysis comparing the responses of their older adult participants to those of younger adults (age 18-30) to the same tasks, Levenson et al. (1991) reported responding was in the same direction for each respective emotion, but that older adults exhibited smaller autonomic changes. However, no analyses were conducted to determine whether there was a statistically significant difference between the age groups in their responding to each emotion-related task, limiting the interpretability of the results. The authors did conduct analyses on subjective reports of task difficulty and the intensity of target emotions felt by the participants. No statistically significant differences were noted during the "reliving" task, but on the facial configuration task, although there were no group differences on task difficulty ratings, older adults reported experiencing the target emotions less often than the younger adults, suggesting discrepant generalizability of the tasks. Levenson et al. (1991) also employed more than one task in their experimental protocol, but failed to counterbalance their 
tasks. Thus, reported findings may have been confounded by an order effect. Additional methodological concerns include the lack of exclusionary criteria other than the inability to control particular facial muscles (e.g., no medical condition, medication use, psychiatric condition, or premorbid anxiety level screening) and the lack of restriction of health behaviors that could impact cardiovascular and EDA reactivity (e.g., exercise, smoking).

Despite the existence of three psychophysiological studies that presented older adults with anxiety-evoking stimuli, it is still unclear as to how older adults would physiologically respond to an anxiety-evoking stimulus because the studies had methodological problems that limited the interpretability of their respective findings. Moreover, studies have found that anxious individuals respond differently to a stress- or anxiety-evoking stimulus than non-anxious individuals (Ehlers et al., 1988; Lader \& Wing, 1964; Rapee, 1985). In light of these findings, it is unknown whether results from psychophysiological studies that recruited non-anxious older adults could be replicated with an anxious population of older adults. Thus, it may be necessary to study anxious older adults as compared to non-anxious older adults in order to understand the relation between anxiety and physiological responses in older adults. Currently, there are no psychophysiological studies that have compared the physiological reactivity of anxious older adults to the physiological reactivity of non-anxious older adults.

\section{$\underline{\text { Statement of the Problem }}$}

Physiological arousal plays a vital role in various theories on the etiology and maintenance of anxiety (Barlow, 1988; Forsyth \& Eifert, 1996; Mower, 1939; see Lader \& Marks, 1971), and according to Lang's triple response model of anxiety, physiological arousal can affect the behavioral and cognitive presentation of anxiety (Lang, 1968; 1971; 1993). However, the population from which our empirical knowledge of anxiety is based is mostly 
comprised of individuals between the ages of 18 and 65 (Hersen et al., 1993). Therefore, one must question whether these data are applicable to individuals over the age of 65 because the general physiology of an individual changes over a lifetime. One might argue that the somatic consequences of these physiologic changes may affect the presentation of anxiety across the three response channels in older adults. If this is the case, then the question becomes: do developmental physiologic changes alter the experience and/or presentation of anxiety in older adults? The answer to this question may help explain the discrepancies in the prevalence rates of anxiety disorders between younger adults and older adults. For example, it may help explain why although generalized anxiety disorder (GAD) is "one of the least common anxiety disorders presenting to [clinicians]" (p. 110) and panic disorder is the most common anxiety disorder presenting to anxiety disorder clinics among younger adults (Rapee \& Barlow, 1993), GAD, an anxiety disorder with a significant cognitive component, is the most diagnosed anxiety disorder in older adults and panic disorder, a disorder with a significant physiological component, is the least diagnosed in older adults (Flint, 1994).

Studies have reported different physiological reactivity in HR, BP, and EDA to stressors between older adults and younger adults (see Anderson \& McNeilly, 1991). However, a closer inspection of these studies revealed methodological problems that limited the interpretability of each study. Of the studies that could be discussed with caution, older adults exhibited attenuated HR reactivity, faster HR and EDA (SCL, SCR) habituation to a stimulus, and more rapid SCR extinction to a CS than younger adults (Boutcher \& Stocker, 1996; Faucheux, Dupuis et al., 1983; Garwood et al., 1982; Jennings et al., 1990; Shmavonian et al., 1965, 1968, 1970). Equivocal findings were reported for BP and EDA (SPL, SCL, SCR) reactivity (Boutcher \& 
Stocker, 1996; Capriotti et al., 1981; Garwood et al., 1982; Jennings et al., 1990; Shmavonian et al., 1965, 1968).

It may be that in order to study the relation between anxiety and physiological responsivity in older adults, anxiety-evoking stimuli or the employment of fearful vs. control older adult participants may be necessary. Several studies found that older adult participants did not report standard laboratory stressors, like the Stroop challenge, to be anxiety-provoking (Barnes et al., 1982; Boutcher \& Stocker, 1996), and one study did not find a significant correlation between heart rate reactivity to a mental stressor task and anxiety measures in older adults (Faucheux, Baulon, et al., 1983). There are currently no psychophysiological studies that have investigated the responses of anxious vs. non-anxious older adults to anxiety-evoking stimuli. Moreover, there is a paucity of literature on the psychophysiological responses of older adults to anxiety-evoking stimuli. Only three psychophsyiological studies that employed an anxiety-evoking or fearful stimulus also used a sample group over the age of 55 (Ditto et al, 1987; Levenson et al., 1991; Silverman et al., 1958). However, each of these studies contained methodological problems that called into question the internal, external, and ecological validity of their respective results (e.g., use of a manipulation check; screening for psychiatric conditions, medication use, premorbid anxiety levels; use of anxious vs. non-anxious participants; controlling for health behaviors; counterbalancing of tasks). Thus, it is still unknown how older adults would physiologically respond to an anxiety-evoking stimulus as compared to younger adults. Moreover, there are currently no psychophysiology studies that employed both an anxiety-evoking stimulus and a standardized self-report measure of anxiety (i.e., STAI) to examine the relation between anxiety and psychophysiological reactivity in older adults. 
The purpose of this study was to clarify the relation between anxiety and physiologic responses in older adults as compared to younger adults by investigating the psychophysiological responses of older adults when presented with an anxiety-evoking stimulus. It also was an attempt clarify whether we can extrapolate from the findings of stressor-task studies how older adults will physiologically respond to an anxiety-evoking situation. The study will attempt to answer the following questions: a) How do older adults physiologically respond to an anxietyevoking stimulus in comparison to younger adults; b) Does premorbid anxiety level, or fear of the stimulus, affect how an older adult responds to an anxiety-evoking stimulus (vs. a control or non-fearful individual) in comparison to younger adults; and c) Does physiological reactivity to a standard mental stressor task differ from the physiological responses to an anxiety-evoking stimulus in older and younger adults

Because studies have reported that fears change with age, it is important to use an object that is equally fearful to both younger adults and older adults; such as the fear of snakes (Agras, Sylvester, \& Oliveau, 1969; Kogan, 1996; Lidell et al., 1991). Therefore, a snake will be utilized as the anxiety-evoking stimulus in this study. However, it would be difficult to guarantee a live snake would consistently and reliably behave in the same way with each subject (i.e, sleep during some sessions but thrash around in other sessions). Thus, in order to establish experimental control, the snake was presented in analogue form (e.g., videotape). In order to match experimental conditions and to accommodate possible developmental difficulties of older adult participants (e.g., hearing, motor abilities) a Stroop task was employed as the standard stressor task.

Based on past research, it was hypothesized that: (a) Older adults will exhibit reduced HR, SCL, and SCR in response to and faster recovery to stimuli as compared to younger adults 
regardless of fear condition (fearful vs. nonfearful); (b) Fearful individuals will exhibit greater cardiovascular (HR, SBP, DBP) and electrodermal activity (SCL, SCR) in response and delayed recovery to an anxiety-evoking stimulus as compared to a mental stressor task in comparison to nonfearful individuals; and (c) Fearful older adults would exhibit a similar but reduced physiological profile than fearful younger adults when exposed to an anxiety-evoking stimulusessentially responding with less reactivity but faster recovery to an anxiety-evoking stimulus.

In order to maximize the interpretability of this study, exclusionary criteria were employed to minimize possible confounding variables. More specifically, individuals using medications that act on the autonomic nervous system or have medical conditions that could potentially dampen arousal/responsivity (e.g., beta-blockers for hypertension, cardiac muscle damage from a myocardial infarction) or potentiate reactivity (e.g., stimulants, uncontrolled hypertension) were excluded from the study. In addition, only females were recruited for this study. Klorman, Weerts, Hastings, Melamed, and Lang (1974) and Bennett-Levy and Marteau (1984) found that females endorsed greater fear of snakes than males. Moreover, the prevalence rate for specific phobia, the animal and environment type, is significantly higher for females (7595\%; APA, 1994). Thus, in order to ensure an adequate size fearful sample, only females were included in this study.

\section{Method}

\section{$\underline{\text { Participants }}$}

Forty-six female younger adults (age 18-30) and 28 female older adults (age 65-80) out of an initial sample of approximately 450 volunteers were selected for participation in the experiment. The younger adults were recruited from undergraduate and graduate psychology courses at West Virginia University. The older adult participants were recruited from the local 
community through television and newspaper advertisements, senior citizen centers, churches, synagogues, health fairs, continuing education classes, VFW's, and a research pool in the Department of Psychology at West Virginia University. Participants were given extra credit or monetary compensation in exchange for their participation in the experiment.

Volunteers were excluded if they met any of the following exclusionary criteria: visual or color-vision impairment; current diagnosis of mood disorders, anxiety disorders, cognitive disorders, substance abuse/dependence, or psychotic disorders; history of CAD; or current use of beta-blockers (e.g., Atenolol, Toprol, Propranolol), ACE inhibitors (e.g., Cardizem, Zestril, Lotensin, Hyzaar, accupril, Avipro), calcium-channel blockers (e.g., Dynacirc, Procardia XL, Norvasc, Dihiazem hydrochloride, Calan SR), anti-arrhythmics (e.g., digoxin), coronary vasodilators (e.g., Dilacor, methyldopa), or benzodiazepines (e.g., Xanax).

Participants were separated into one of two fear groups based on their score on item 39 (snakes) on the Fear Survey Schedule-II (FSS: Geer, 1965). Individuals with a score between 1 and 3 were designated Low Fear and a score between 5 and 7 were designated High Fear. Thirty participants were categorized as Low Fear (19 young, 11 old) and 44 participants were categorized as High Fear (27 young, 17 old). Volunteers with a score of 4 ("some" fear) were not selected for participation in this experiment.

\section{$\underline{\text { Apparatus }}$}

Heart rate was measured continuously using a Grass Polygraph Model 79B, using 3 $\mathrm{Ag} / \mathrm{AgCl}$ electrodes and .05 molar NaCL electrode gel. A non-standard electrode placement was employed to avoid possible artifacts from limb movement. Regardless of handedness, two electrodes were placed subclavically (one on each side of the body) and a third electrode was placed on the right hip. Skin conductance level (SCL) was measured using a Grass Polygraph 
Model 79B, using two $2.5 \mathrm{~cm} \mathrm{Ag/AgCl}$ electrodes and .05 molar $\mathrm{NaCl}$ electrode gel. Bipolar placement on the medial phalanx of the second and third fingers of the non-dominant hand was employed to avoid possible artifacts from finger movement. Blood pressure was measured from the dominant arm using an IBS Corporation SD-700A Blood Pressure/Pulse Monitor to avoid interfering with SCL recordings. HR and SCL were recorded with a DATAQ DI-220 PGH/PGL data acquisition system. SCL data were printed out in order to calculate skin conductance responses (SCR). SCR's were defined as a change of .01 micromhos ( $\mu$ mhos) for SCL between 1-10 $\mu$ mhos and a change of .02 $\mu$ mhos for SCL greater than $10 \mu$ mhos (Andreassi, 1989).

Instructional prompts and a snake video were presented on a 20 " television monitor situated approximately 3 feet in front of the participant. An intercom was used as a means of communication between the participant and experimenter. Participants were observed via a oneway mirror throughout the experiment.

\section{Questionnaires}

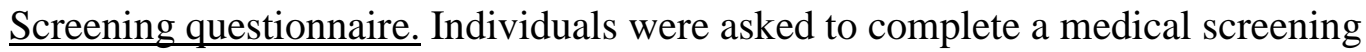
questionnaire created especially for this experiment. It screened for medical conditions, current medication use, psychiatric history, current health behaviors (i.e., drug, alcohol, nicotine, and caffeine use, exercise behaviors), and demographic information (i.e., age, race, education). A copy of the screening questionnaire is located in Appendix A.

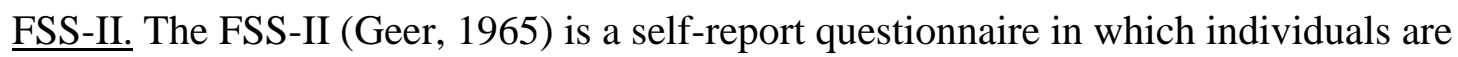
instructed to rate their level of fear on a Likert-type scale ranging from 1 (none) to 7 (terror) to 51 potentially fear-evoking situations and stimuli. The items on the FSS-II were derived from data collected on a sample of college students (Geer, 1965). The FSS-II has demonstrated high internal consistency and has been shown to be highly correlated with performance on behavior 
avoidance tests (Geer, 1965). Kogan (1996) validated the use of the FSS-II for older adults by demonstrating a relation between fear and interference with daily functioning and life satisfaction.

Beck Anxiety Inventory. The Beck Anxiety Inventory (BAI; Beck \& Steer, 1990) is a 21item questionnaire that assesses anxiety symptoms indicative of the presence of an anxiety disorder, with higher scores indicating greater anxiety. It has been found to have adequate validity and reliability (Frydrich, Dowdall, \& Chambless, 1992; Steer, Ranieri, Beck, \& Clark, 1993). Moreover, it has been psychometrically validated with a geriatric population (Kabacoff, Segal, Hersen, \& Van Hasselt, 1997). Therefore, the BAI was used to measure participants' premorbid level of anxiety.

State-Trait Anxiety Inventory. The State Trait Anxiety Inventory-State (STAI-S; Speilberger et al., 1970) is a 20-item self-report questionnaire that assesses an individual's anxiety state, with higher scores indicating greater anxiety. The STAI-S has been found to have adequate validity and reliability (see Spielberger, 1985). Instructions for the STAI-S were modified to clarify for which portion of the experiment they were completing the questionnaire (baseline, post-video, post-stroop).

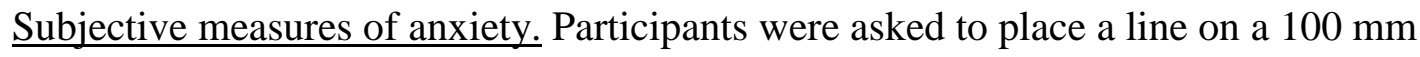
rating scale line $($ where $0=$ no feeling of anxiety/nervousness and $100=$ extremely strong feelings of anxiety/nervousness) indicating their level of anxiety following each task. The rating scale was superimposed on the bottom of the STAI-S questionnaire.

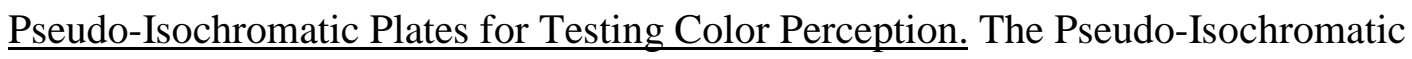
Plates for Testing Color Perception (American Optical Company, 1940) are comprised of 18 plates approved by the Inter-Society Color Council Subcommittee for color blindness studies. 
These plates have been shown to provide a valid screening test for defective color vision (Hardy, Rand, \& Rittler, 1946).

Snake Questionnaire. The Snake Questionnaire (SNAQ; Lang, Melamed, \& Hart, 1970) is a 30-item true-false questionnaire that measures an individual's fear of snakes. The SNAQ has been found to have adequate validity and reliability across several college samples (Klorman et al., 1974; Lang et al., 1970) but has not been normed with older adults.

$\underline{\text { Tasks }}$

$\underline{\text { Snake video. Participants watched a three-minute video on snakes, edited from a National }}$ Geographic video on snakes. The content of the video included approximately 30 -seconds of a boa-constrictor, 1-minute of coral and king snakes, 30-seconds of a side-winder, 30-seconds of a rattlesnake, and 1-minute inside the snake dens of rattlesnakes and gartersnakes. In order to discourage avoidance behavior when watching the snake video, participants were instructed to focus on the content of the video because they would be asked to answer several basic questions regarding the content of the video at the end of the experiment. Performance on the questionnaire was measured by counting the total number of correct responses. Correct responses were defined as answers that mentioned at least four types of snakes or an approximate frequency count greater than 25; indication that there were multiple colors/patterns from different snakes, or at least 3 of the 4 snake colors (brown, black, red, yellow); description of at least 3 of the 4 locales in the video (woods, desert, cave/den, rocks); and the description of the activities of at least 2 different snakes from the video. A copy of the questionnaire can be found in Appendix B. Analysis of performance on the questionnaire indicated that participants performed with at least $75 \%$ accuracy on the measure, with mean scores ranging from 3.7 to 4.0 (out of a possible 4.0). 


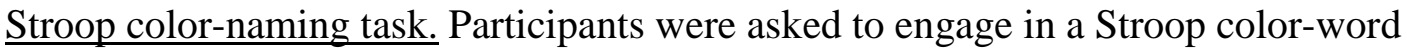
naming task. They were presented with a series of color names (e.g., red, green, blue) on a 9.5" x $12 "$ card in which the name of one color was printed in the ink of another color (e.g., the word "red" is printed in blue). Participants were asked to name the color of the ink in which each word was printed "as quickly and accurately as possible." They also were instructed not to correct themselves if they make a mistake but to go onto the next word. Participants were presented with 16 colored X's on a 9.5" x 12" card in order to practice the task. Following the practice session, participants engaged in the Stroop color-naming task for three-minutes. Each stimulus was presented randomly with respect to color and word order, with the exception that no color or word appeared consecutively. All Stroop performances were audiotaped and scored for errors. Performance on the Stroop task was measured by counting the ratio of errors to the total number of responses. Errors were defined as any response other than the correct color (e.g., naming the wrong color, a self-correction for a wrong response). Analysis of Stroop performance indicated all participants consistently engaged in the Stroop task for 3-minutes.

\section{$\underline{\text { Procedure }}$}

Volunteers completed the medical screening questionnaire, FSS-II, and BAI during the recruitment phase, and the exclusionary criteria were confirmed over the phone with potential participants. Individuals who qualified for the study were then scheduled for a laboratory session and asked to refrain from nicotine, caffeine, alcohol, other substance use, and strenuous exercise at least three hours before their scheduled laboratory session.

Upon arrival to the laboratory, participants were asked to read the first line of the consent form to assess for visual and reading impairment. Participants then read the entire consent form and signed it; no one declined to consent. Participants were then assessed for color-vision 
impairment with the Pseudo-Isochromatic Plates for Testing Color Perception (American Optical Company, 1940). Following verification of abstinence of the aforementioned health behaviors, participants were weighed and measured for height, and asked to complete the STAI-S.

The participant was then seated in a comfortable chair in front of a television monitor, and the electrodes and blood pressure cuff were placed as described above. The participant was asked to rest during a 10-minute baseline period. Following the baseline condition, the participant engaged in the two 3-minute activities: the Stroop color-naming task and the videoclip of snakes. The tasks were counterbalanced. All instructions were recorded in audiovisual form on video cassette and presented on the television monitor. Each task was followed by a 5-minute recovery period. During this period, participants were asked to sit back quietly and relax. At the end of the recovery period, they were asked to complete the STAI-S (Speilberger et al., 1970) and make a subjective anxiety rating reflecting how they felt "during the preceding task." After completing the anxiety measures following each task, participants underwent a 5-minute baseline period. During these periods, participants were again asked to sit back quietly and relax. Heart rate and skin conductance level were measured continuously throughout the experiment. Blood pressure readings were taken at minutes $1,3,5,7$, and 9 during the initial baseline period, minutes 1 and 3 during subsequent baseline periods, and minutes 1,3 , and 5 during the recovery periods. BP also was taken at the start and at minute 2 during the Stroop task and snake video.

Following the completion of the final baseline period, all electrodes and the blood pressure cuff were removed. Then, participants were asked to answer several simple questions regarding the content of the video and to complete the SNAQ. Participants completed the SNAQ at the end of the experimental session rather than the beginning of the session, in order to control 
for experimental expectations and also to prevent possibly increasing anticipatory anxiety and baseline arousal by high fear individuals. Finally, participants were debriefed and compensated for their participation.

$\underline{\text { Data reduction }}$

The second-by-second data initially obtained for HR and SCL were averaged into 30second epochs per baseline, task, and recovery periods. Means for each baseline and task period were calculated by averaging HR and SCL from the 30-second epochs for each baseline and task period. Means and standard deviations for SBP and DBP during baseline and task periods were obtained by averaging across the recordings taken during each respective period. For recovery data, a mean value was averaged for both HR and SCL for each minute within the recovery period. SCR was calculated as the total number of responses that occurred during each baseline and task period. For recovery data, SCR responses were counted for each minute within the recovery period.

$\underline{\text { Statistical analysis }}$

Health behaviors, SNAQ, BAI, FSS item 39 (snakes), measures of task performance, and baseline physiological measures were analyzed using 2 (Age: Young, Old) x 2 (Fear: Low, High) analyses of variance (ANOVAs). Group differences in demographic information for categorical data were explored using chi-square analyses. While subjective measures of anxiety were analyzed using a 2 (Age: Young, Old) x 2 (Fear: Low, High) x 2 (Task: Snake Video, Stroop Task) ANOVA, STAI-S and all physiological responses (HR, SCL, SCR, SBP, DBP) were analyzed using 2 (Age: Young, Old) x 2 (Fear: Low, High) x 2 (Task: Snake, Stroop) mixed factors analyses of covariance (ANCOVAs), covarying baseline level, with task treated as a within subjects variable. Recovery data for HR, SCL, and SCR were analyzed using a 2 (Age: 
Young, Old) x 2 (Fear: Low, High) x 5 (Interval: minutes 1, 2, 3, 4, 5) mixed factors design ANOVA while recovery data for SBP and DBP were analyzed using a 2 (Age: Young, Old) x 2 (Fear: Low, High) x 3 (Interval: minutes 1, 2, 3) mixed factors design ANOVA. With the exception of tests of Stroop task performance, a probability of $\leq .05$ was considered significant. Measures of Stroop task performance did not meet the assumption of equal variances. Because this study also employed unequal sample sizes, in order to minimize Type I Error, tests of Stroop task performance employed a more stringent significance level of $\leq .025$. Task order was initially included as a between-subjects variable in all reactivity and recovery analyses. However, as no significant order effects emerged, it was excluded from all analyses to increase power. Simple effect analyses and repeated contrasts were employed to clarify significant interaction effects. Summary tables for all ANOVA and ANCOVA analyses can be found in Appendix C.

Results

\section{$\underline{\text { Group demographics }}$}

No significant differences between fear groups were observed for age, race/ethnicity, body mass index, marital status, medical conditions, psychiatric history, prescription medication use, nonprescription drugs use, tobacco use, alcohol use, caffeine use, exercise, or daily liquid intake. See Table 1 for mean values for age and health behaviors. See Table 2 for categorical demographic information. See Table 3 for listing of medical and psychiatric conditions, medication and drugs used.

A significant main effect for Fear was observed for years of education, $\underline{F}(1,71)=4.86, \underline{p}$ $<.05, \eta^{2}=.069\left(\underline{\mathrm{M}}_{\text {low }}=14.5, \underline{\mathrm{M}}_{\mathrm{high}}=13.4\right)$. This main effect was qualified by a significant Age $\mathrm{x}$ Fear interaction, $\underline{\mathrm{F}}(1,68)=5.07, \underline{\mathrm{p}}<.05, \eta^{2}=.06$, with low fear older adults reporting more 
years of education than high fear older adults $(\mathrm{p}<.05)$ and low and high fear younger adults $(\mathrm{p}<$ .05). There was no fear effect of education for younger adults. See Figure 1.

Significant differences between age groups were observed for age, $\underline{\mathrm{F}}(1,73)=4061.08, \underline{\mathrm{p}}$ $<.001, \eta^{2}=.98 ;$ body mass index $(\mathrm{BMI}), \underline{\mathrm{F}}(1,73)=12.77, \underline{\mathrm{p}} \leq .001, \eta^{2}=.15 ;$ tobacco use, $\underline{\mathrm{F}}(1$, $70)=4.15, \underline{\mathrm{p}}<.05, \eta^{2}=.05$; alcohol use, $\underline{\mathrm{F}}(1,63)=8.92, \underline{\mathrm{p}}<.01, \eta^{2}=.12 ;$ marital status, $\chi^{2}(4$, $74)=66.44, \underline{p}<.001 ;$ medical conditions, $\chi^{2}(14,70)=26.79, \underline{p}<.05 ;$ and prescription medication use, $\chi^{2}(20,71)=41.1, \underline{p}<.01$, but not for race/ethnicity, psychiatric history, nonprescription drug use, caffeine use, exercise, and daily liquid intake. Relative to younger adults, older adults were significantly older, had greater BMI, and reported less tobacco and alcohol use, but reported having more medical conditions and endorsed greater prescription medication use. Also, more older adults were married than younger adults. See Tables 1, 2, and 3.

\section{$\underline{\text { Measures of fear and anxiety }}$}

FSS item 39 (snakes). Analysis of the score on item 39 of the FSS revealed a significant main effect for Fear, $\underline{\mathrm{F}}(1,73)=480.30, \underline{\mathrm{p}}<.001, \eta^{2}=.87$, with high fear individuals $(\underline{\mathrm{M}}=6.2)$ reporting higher scores than low fear individuals $(\underline{\mathrm{M}}=1.9)$. See Table 4.

SNAQ total score. The ANOVA on the SNAQ score also revealed a significant main effect for Fear, $\underline{F}(1,73)=69.22, \underline{p}<.001, \eta^{2}=.49$, with high fear individuals $(\underline{M}=17.2)$ reporting higher scores than low fear individuals $(\underline{\mathrm{M}}=5.7)$. See Table 4 .

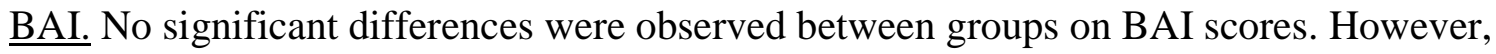
a main effect for Age approached significance, $\underline{\mathrm{F}}(1,73)=3.93, \underline{\mathrm{p}}=.051, \eta^{2}=.05$, with younger adults reporting somewhat higher anxiety $(\underline{M}=11.3)$ than older adults $(\underline{M}=8.4)$. See Table 4 . 
$\underline{\text { State Trait Anxiety Inventory-State. No significant differences were observed between }}$ groups on baseline STAI scores (Table 4). However, the Age x Fear x Task mixed factors design ANCOVA resulted in a significant main effect for Age, $\underline{\mathrm{F}}(1,69)=9.97, \underline{\mathrm{p}}<.01, \eta^{2}=.12$, with younger adults reporting higher adjusted state anxiety responses to the two tasks $(\underline{M}=40.0)$ than older adults $(\underline{\mathrm{M}}=33.6)$. There also was a significant main effect for Fear, $\underline{\mathrm{F}}(1,69)=12.16, \underline{\mathrm{p}} \leq$ $.001, \eta^{2}=.15$, with high fear individuals reporting higher state anxiety responses $(\underline{M}=40.4)$ than low fear individuals to both tasks $(\underline{\mathrm{M}}=33.2)$. Finally, the Age $\mathrm{x}$ Task interaction was significant, $\underline{\mathrm{F}}(1,69)=7.37, \underline{\mathrm{p}}<.01, \eta^{2}=.09$. See Figure 2 . Simple effects analyses revealed younger adults reported significantly higher STAI scores on the Stroop task than on the snake video $(\mathrm{p}<.001)$ while older adults reported similar STAI scores on both tasks. Younger adults also reported significantly higher STAI scores than older adults on the Stroop task $(p<.001)$. There was no significant difference for age on the Snake task. See Table 4.

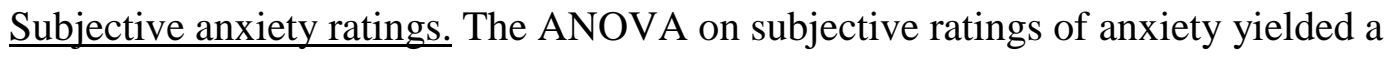
significant main effect for Fear, $\underline{\mathrm{F}}(1,70)=34.78, \underline{\mathrm{p}}<.001, \eta^{2}=.03$, with high fear individuals endorsing more anxiety $(\underline{M}=46.8 \mathrm{~mm})$ than low fear individuals $(\underline{\mathrm{M}}=19.7 \mathrm{~mm})$. The Age $\mathrm{x}$ Task, $\underline{\mathrm{F}}(1,70)=6.99, \underline{\mathrm{p}} \leq .01, \eta^{2}=.09$, and Fear $\mathrm{x}$ Task interactions were also significant, $\underline{\mathrm{F}}(1$, $70)=4.308, \underline{p}=.042, \eta^{2}=.05$. Follow-up simple effects analyses for the Age $\mathrm{x}$ Task interaction revealed that younger adults reported higher subjective anxiety than older adults on the Stroop task $(\underline{p}<.01)$ and younger adults reported higher subjective anxiety on the Stroop task than on the snake video $(\mathrm{p}<.001)$. There was no significant difference for age on the Snake task. See Figure 3. 
Follow-up simple effects analyses for the Fear x Task interaction revealed high fear individuals $(\underline{\mathrm{M}}=50.5 \mathrm{~mm})$ reported significantly greater subjective anxiety than low fear individuals $(\underline{\mathrm{M}}=30.1 \mathrm{~mm})$ during the Stroop task $(\mathrm{p} \leq .001)$ and during the snake video $(\underline{\mathrm{p}}<$ $\left..001 ; \underline{\mathrm{M}}_{\text {high }}=45.1 \mathrm{~mm}, \underline{\mathrm{M}}_{\text {low }}=11.9 \mathrm{~mm}\right)$. Low fear individuals also reported significantly greater subjective anxiety during the Stroop task than during the snake video $(\mathrm{p}<.001)$. High fear individuals reported similar subjective anxiety ratings for both tasks. See Figure 4. The main effect for Age approached significance, $\underline{F}(1,70)=3.88, \underline{p}=.053, \eta^{2}=.05$, with younger adults $(\underline{M}=37.8 \mathrm{~mm})$ reporting somewhat higher subjective anxiety than older adults $(\underline{\mathrm{M}}=28.7 \mathrm{~mm})$. See Table 4.

Task performance

Stroop task. The ANOVA performed on total number of responses to the Stroop task did not reveal significant main effects or interactions at the $\leq .025$ significance level. The ANOVA performed on number of errors revealed a significant main effect for Age, $\underline{F}(1,70)=5.72$, $\underline{p}<$ $.05, \eta^{2}=.07$, with older adults making more errors than younger adults. The main effect for Fear also was significant, $\underline{\mathrm{F}}(1,70)=8.35, \underline{\mathrm{p}}<.01, \eta^{2}=.11$, with high fear individuals making more errors $(\underline{M}=48.6)$ than low fear individuals $(\underline{M}=9.5)$. The Age $x$ Fear interaction approached significance, $\underline{\mathrm{F}}(1,70)=4.95, \underline{\mathrm{p}}<.05, \eta^{2}=.06$, with high fear older adults $(\underline{\mathrm{M}}=97.5)$ making significantly more errors than high and low fear younger adults $\left(\underline{\mathrm{M}}_{\mathrm{high}}=19.6, \underline{\mathrm{M}}_{\text {low }}=8.4 ; \underline{\mathrm{p}}<\right.$ $.01)$ and low fear older adults $(\underline{\mathrm{M}}=11.2 ; \underline{\mathrm{p}}<.05)$. See Table 5 .

Similarly, the ANOVA performed on error ratio also found a significant main effect for Age, $\underline{\mathrm{F}}(1,67)=11.14, \underline{\mathrm{p}} \leq .001, \eta^{2}=.002\left(\underline{\mathrm{M}}_{\text {old }}=.30, \underline{\mathrm{M}}_{\text {young }}=.07\right)$; for Fear, $\underline{\mathrm{F}}(1,67)=9.98, \underline{\mathrm{p}}$ $=.002, \eta^{2}=.14\left(\underline{\mathrm{M}}_{\text {low }}=.07, \underline{\mathrm{M}}_{\text {high }}=.21\right)$; as well as an Age $\mathrm{x}$ Fear interaction, $\underline{\mathrm{F}}(1,67)=6.16, \underline{\mathrm{p}}$ 
$<.05, \eta^{2}=.08$. Simple effects analyses revealed that high fear older adults $(\underline{\mathrm{M}}=.43)$ had a significantly greater mean error ratio than low fear older adults $(\underline{\mathrm{M}}=.09 ; \mathrm{p}<.05)$ and high and low fear younger adults $\left(\underline{\mathrm{M}}_{\mathrm{high}}=.10, \underline{\mathrm{M}}_{\mathrm{low}}=.05 ; \underline{\mathrm{p}} \leq .001\right)$. There was no fear effect on error ratio for younger adults. See Figure 5.

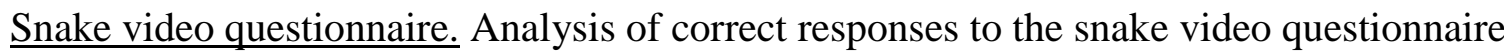
resulted in a significant Age $x$ Fear interaction, $\underline{\mathrm{F}}(1,70)=6.05, \underline{\mathrm{p}}<.05, \eta^{2}=.08$, with high fear older adults giving significantly fewer correct answers about the video than individuals from the other three groups. See Figure 6.

Baseline physiological measures

Mean baseline values for all physiological variables can be found in Table 6. No significant differences were observed regarding baseline HR, SCR, and SCL. However, a significant main effect for Age for baseline SBP, $\underline{\mathrm{F}}(1,69)=10.48, \underline{\mathrm{p}}<.01, \eta^{2}=.13$, as well as for baseline DBP, $\underline{\mathrm{F}}(1,69)=12.59, \underline{\mathrm{p}} \leq .001, \eta^{2}=.15$, was found, with older adults exhibiting higher baseline SBP and DBP than younger adults.

$\underline{\text { Physiological reactivity from pre-task baseline }}$

Paired t-tests were conducted to examine whether the tasks resulted in any change to each physiological measure. These analyses revealed significant increases during the Stroop task from pre-task baseline on HR, $\underline{\mathrm{t}}(72)=14.4, \underline{\mathrm{p}}<.001 ; \mathrm{SCL}, \underline{\mathrm{t}}(73)=14.2, \underline{\mathrm{p}}<.001 ; \mathrm{SCR}, \underline{\mathrm{t}}(71)=10.4$, $\underline{\mathrm{p}}<.001 ; \mathrm{SBP}, \underline{\mathrm{t}}(71)=12.2, \underline{\mathrm{p}}<.001 ;$ and DBP, $\underline{\mathrm{t}}(71)=8.5, \underline{\mathrm{p}}<.001$. However, none of the $\underline{\mathrm{t}}-$ tests conducted on physiological variables measured during the Snake video resulted in a statistically significant change from their respective pre-task baseline measures at the .05 significance level. 


\section{Physiological responses to tasks}

Mean adjusted response values for all physiological variables are reported in Table 6.

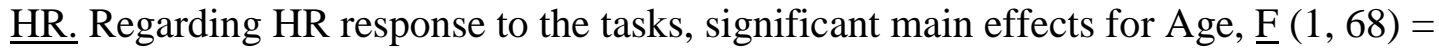
$10.74, \underline{\mathrm{p}}<.01\left(\underline{\mathrm{M}}_{\mathrm{young}}=79.4 \mathrm{bpm}, \underline{\mathrm{M}}_{\mathrm{old}}=76.8 \mathrm{bpm}\right)$, power $=.89 ;$ and Task, $\underline{\mathrm{F}}(1,68)=244.15$, $\underline{\mathrm{p}}<.001$, power $=1.0\left(\underline{\mathrm{M}}_{\text {stroop }}=83.6 \mathrm{bpm}, \underline{\mathrm{M}}_{\text {snake }}=74.0 \mathrm{bpm}\right) ;$ as well as an Age $\mathrm{x}$ Task interaction, $\underline{F}(1,68)=24.6, \underline{p}<.001$, power $=.99$, were found. Simple effects analyses on the Age $\mathrm{x}$ Task interaction revealed that younger adults exhibited greater adjusted mean HR response $(\underline{\mathrm{M}}=84.7 \mathrm{bpm})$ than older adults $(\underline{\mathrm{M}}=80.8 \mathrm{bpm})$ during the Stroop Task $(\underline{\mathrm{p}}<.01)$. Both younger and older adults exhibited significantly greater adjusted mean HR during the Stroop Task than during the snake video (young: $\underline{\mathrm{M}}_{\text {stroop }}=84.7 \mathrm{bpm}, \underline{\mathrm{M}}_{\text {snake }}=74.3 \mathrm{bpm}, \underline{\mathrm{p}}<$ .001 ; old: $\left.\underline{\mathrm{M}}_{\text {stroop }}=80.8 \mathrm{bpm}, \underline{\mathrm{M}}_{\text {snake }}=74.1 \mathrm{bpm}, \underline{\mathrm{p}}<.001\right)$. See Figure 7 . There were no significant age or fear group differences in HR response during the snake video.

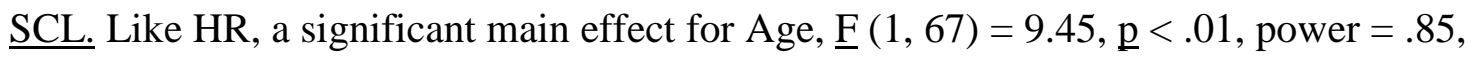
with younger adults exhibiting greater adjusted mean SCL than older adults $\left(\underline{\mathrm{M}}_{\text {young }}=8.13\right.$ $\left.\mu \mathrm{mhos}, \underline{\mathrm{M}}_{\mathrm{old}}=7.05 \mu \mathrm{mhos}\right)$; and Task, $\underline{\mathrm{F}}(1,67)=57.32, \underline{\mathrm{p}}<.001$, power $=1.0$, with participants evidencing significantly greater adjusted mean SCL responses to the Stroop task than the snake $\operatorname{video}\left(\underline{\mathrm{M}}_{\text {stroop }}=9.05 \mu \mathrm{mhos}, \underline{\mathrm{M}}_{\text {snake }}=5.77 \mu \mathrm{mhos}\right)$.

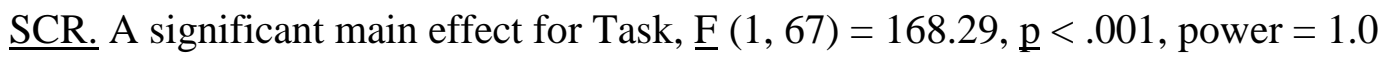
$\left(\underline{\mathrm{M}}_{\text {stroop }}=31.03, \underline{\mathrm{M}}_{\text {snake }}=9.92\right) ;$ and a significant Age $\mathrm{x}$ Task interaction, $\underline{\mathrm{F}}(1,67)=4.59, \underline{\mathrm{p}}<$ .05 , power $=.55$, were found. Similar to the simple effects analyses for the Age $\mathrm{x}$ Task interaction for HR, simple effects analyses showed younger adults $(\underline{\mathrm{M}}=33.88)$ exhibited more adjusted mean SCR than older adults $(\underline{\mathrm{M}}=28.07)$ during the Stroop Task $(\underline{\mathrm{p}}<.05)$ but no age differences emerged for the snake task. Moreover, both younger and older adults exhibited 
significantly more adjusted mean SCR during the Stroop Task than during the snake video

(young: $\underline{\mathrm{M}}_{\text {stroop }}=33.83, \underline{\mathrm{M}}_{\text {snake }}=8.69, \underline{\mathrm{p}}<.001 ;$ old: $\underline{\mathrm{M}}_{\text {stroop }}=28.24, \underline{\mathrm{M}}_{\text {snake }}=11.16, \underline{\mathrm{p}}<.001$ ). See Figure 8.

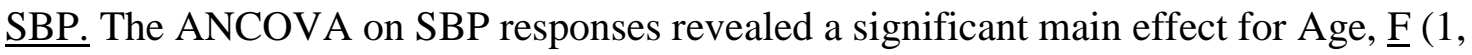
$67)=7.00, \underline{p} \leq .01$, power $=.73$, with older adults $(\underline{\mathrm{M}}=126.8 \mathrm{~mm} \mathrm{Hg})$ exhibiting higher adjusted mean SBP responses than younger adults $(\underline{\mathrm{M}}=122.8 \mathrm{~mm} \mathrm{Hg})$. A significant main effect for Task, $\underline{\mathrm{F}}(1,67)=109.75, \underline{\mathrm{p}}<.001$, power $=1.00$, was qualified by a significant Fear $\mathrm{x}$ Task interaction, $\underline{F}(1,66)=10.52, \underline{p}<.01$, power $=.89$. Simple effects analyses showed that both high and low fear individuals exhibited significantly higher adjusted mean SBP during the Stroop task than during the snake video (Low: $\underline{\mathbf{M}}_{\text {snake }}=119.0 \mathrm{~mm} \mathrm{Hg}, \underline{\mathbf{M}}_{\text {stroop }}=128.1 \mathrm{~mm} \mathrm{Hg}, \underline{p}$ $<.001$; High: $\left.\underline{\mathrm{M}}_{\text {snake }}=117.9 \mathrm{~mm} \mathrm{Hg}, \underline{\mathrm{M}}_{\text {stroop }}=132.1 \mathrm{~mm} \mathrm{Hg}, \mathrm{p}<.001\right)$, but that there was no significant group effect for fear on either task. See Figure 9.

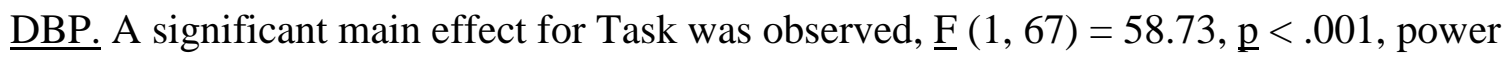
$=1.00$, with participants exhibiting significantly greater adjusted mean DBP responses during the Stroop task $(\underline{\mathrm{M}}=84.7 \mathrm{~mm} \mathrm{Hg})$ than during the snake video $(\underline{\mathrm{M}}=71.2 \mathrm{~mm} \mathrm{Hg})$. No other significant main effects or interactions were observed on DBP response during either the Stroop task or snake video.

Correlations between physiological measures and anxiety measures

Correlations between mean physiological measures (both baseline and reactivity) and anxiety measures were conducted to explore the relation dependent variables (see Table 8). The relation between baseline physiological measures and anxiety measures were investigated using bivariate correlations. The relation between reactivity data and anxiety measures were explored using partial correlations, partialing out pre-task baseline values. 
Heart rate. No significant correlations were found between HR measures and snake video subjective anxiety ratings, snake video STAI score, SNAQ total score, or BAI score. However, significant correlations were found between (a) baseline HR and Stroop STAI score, $\underline{\mathrm{r}}(72)=.25$, $\underline{\mathrm{p}}<.05$; and Stroop subjective anxiety rating, $\underline{\mathrm{r}}(72)=.23, \underline{\mathrm{p}}<.05$; and (b) mean Stroop HR response and Stroop STAI score, $\mathrm{pr}(70)=.27, \underline{\mathrm{p}}<.05$; and Stroop subjective anxiety rating, $\mathrm{pr}$ $(70)=.27, \underline{p}<.05$

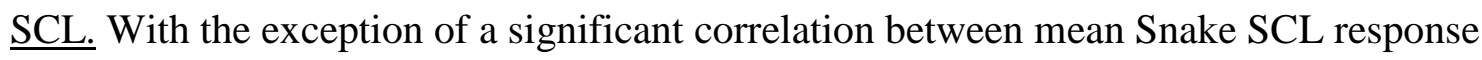
and BAI, pr $(69)=.34, \underline{p}<.01$, no other significant correlations were found between any other variable and baseline or reactivity SCLs. A positive correlation between mean Stroop SCL response and Stroop STAI score approached significance, $\mathrm{pr}(71)=.21, \mathrm{p}=.063$.

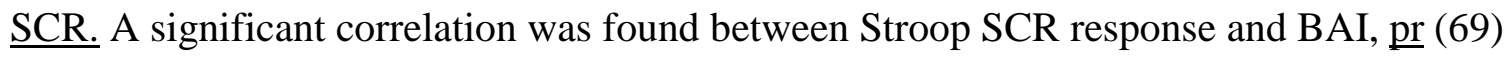
$=.24, \underline{p}<.05$. There were no significant correlations found between any other variable and SCR measures.

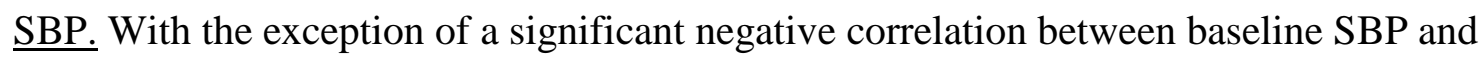
Stroop STAI score, $\underline{\mathrm{r}}(71)=-.29, \underline{\mathrm{p}}<.05$, there were no significant correlations found between reactivity SBP measures and other anxiety measures.

Diastolic blood pressure. With the exception of a significant negative correlation between baseline DBP and Stroop STAI score, $\underline{\mathrm{r}}(71)=-.24, \underline{\mathrm{p}}<.05$, no significant correlations were found between baseline or reactivity DBP measures and other anxiety measures. 


\section{$\underline{\text { Recovery data }}$}

Because no significant physiological responses were found during the snake video, only recovery data following the Stroop task were examined. See Table 7 for mean recovery values.

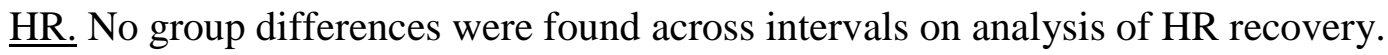

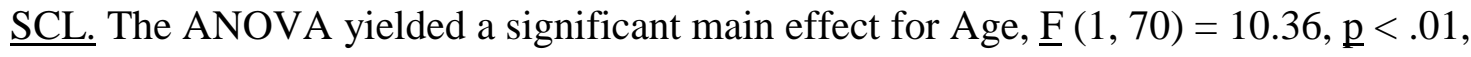
$\eta^{2}=.12$, with younger adults exhibiting higher $\operatorname{SCL}(\underline{\mathrm{M}}=8.09 \mu \mathrm{mhos})$ than older adults $(\underline{\mathrm{M}}=$ $5.21 \mu \mathrm{mhos})$; and Interval, $\underline{\mathrm{F}}(4,280)=76.01, \underline{\mathrm{p}}<.001, \eta^{2}=.52$. Repeated contrasts for the main effect of Interval revealed significant differences between minutes 1 and $2(\underline{p}<.001)$, minutes 2 and $3(\mathrm{p}<.001)$, minutes 3 and $4(\mathrm{p}<.001)$; and minutes 4 and $5(\mathrm{p}<.01)$. There also was a significant Age $x$ Interval interaction, $\underline{F}(4,280)=5.08, \underline{p} \leq .001, \eta^{2}=.06$. Repeated and difference contrasts indicated neither younger nor older adults reached baseline during recovery, but exhibited significantly smaller SCL's with each subsequent recovery interval. However, polynomial contrasts revealed an age-associated pattern in habituation rate, with younger adults exhibiting a quartic trend $(\mathrm{p}<.05)$ and older adults exhibiting a significant quadratic trend during recovery $(\mathrm{p}<.01)$. Although younger adults exhibited a more rapid decrease in SCL between minutes 2 and 3 relative to older adults, both younger and older adults evidenced a flattened but still significant trend towards baseline beginning at minute 3 . However, while older adults continued to maintain a reduced but still significant slope in recovery data between minutes 4 and 5, younger adults evidenced a steeper slope towards baseline between minutes 4 and 5 (see Figure 10).

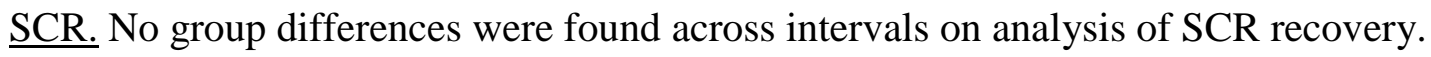
However, an Age $x$ Interval interaction approached significance, $\underline{F}(4,272)=2.32, \underline{p}=.056, \eta^{2}=$ .03. Simple effects analyses showed that although younger and older adults did not significantly 
differ in SCR's for each of the 5 intervals, younger adults exhibited a significant decline in SCR's between minutes 1 and $2(\underline{p}<.05)$ and minutes 2 and $3(\underline{p}<.05)$, and evidenced habituation by minute 3, while older adults showed a slight increase in SCR's between minutes 1 and 2 and a slight decrease between minutes 2 and 3, and did not show a significant decrease to baseline until between minutes 3 and $4(\mathrm{p}<.05)$. See Figure 11.

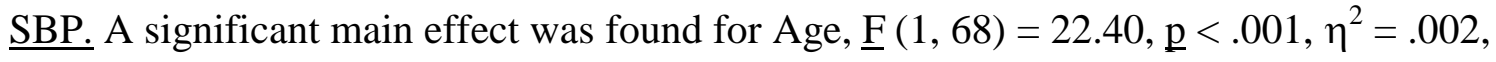
with older adults $(\underline{M}=127.3 \mathrm{~mm} \mathrm{Hg})$ exhibiting greater SBP during recovery than younger adults $(\underline{\mathrm{M}}=115.3 \mathrm{~mm} \mathrm{Hg})$. Significant interactions between Age x Interval, $\underline{\mathrm{F}}(2,136)=3.20$, $\underline{\mathrm{p}}$ $<.05, \eta^{2}=.07$; and for Fear $x$ Interval also were found, $\underline{\mathrm{F}}(2,136)=5.50, \underline{\mathrm{p}}<.01, \eta^{2}=.04$. These findings were qualified by a significant Age $x$ Fear $x$ Interval interaction, $\underline{F}(2,136)=$ $6.71, \underline{p}<.01, \eta^{2}=.09$. Simple effects analyses for the three-way interaction revealed that low fear older adults exhibited increased SBP during recovery intervals $(\underline{p}<.01)$ as compared to the trend towards decreased SBP or no change among the other groups during recovery (see Table 7). Closer inspection of the data revealed that while high fear younger adults showed a reduction in SBP to baseline at minute 5 post-Stroop task, high fear older adults returned to baseline by minute 3 post-Stroop task. Low fear younger adults showed immediate recovery to baseline following the stressor task whereas low fear older adults exhibited a progressive trend of increasing SBP throughout the recovery period. See Figure 12.

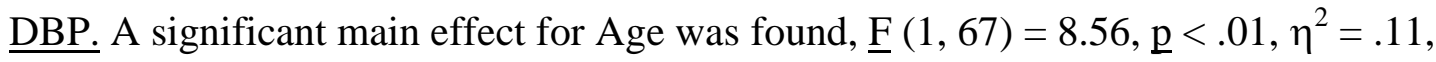
with older adults exhibiting increased DBP during recovery intervals $(\underline{M}=74.8 \mathrm{~mm} \mathrm{Hg})$ as compared to younger adults $(\underline{\mathrm{M}}=68.9 \mathrm{~mm} \mathrm{Hg})$. No other group differences were found across intervals for DBP during recovery. 


\section{Discussion}

The purpose of this study was to clarify the relation between anxiety and physiological responses in older adults as compared to younger adults. It also was an attempt to clarify whether we can infer from the findings of stressor-task studies how older adults respond physiologically to an anxiety-evoking situation. In comparison to younger adults, in general, this study revealed significant age and fear differences on select physiological and subjective responses. It found support to suggest that age-associated physiologic changes affected an individual's reactivity to a stressor task. It replicated the psychophysiological findings of stressor-task studies of older adults and yielded some evidence to suggest that stressor tasks may not evoke an emotional response sufficient enough to be considered an anxiety- or fear-evoking stimulus. It also found evidence to suggest that older adults exhibited greater desynchrony (physiologic responses vs. self-report) than younger adults to the Stroop task. The findings of this study also supported the necessity of employing methods of data collection that take into account age-associated changes in order to truly capture the experience/presentation of anxiety in older adults.

Hypothesis 1: Older adults will exhibit reduced physiological response and faster recovery to $\underline{\text { stimuli as compared to younger adults }}$

Consistent with previous research, younger and older adult participants did not differ in baseline measures of HR, SCL, or SCR (Capriotti et al., 1981; Faucheux, Dupuis, et al., 1983; Garwood et al., 1982; Jennings et al., 1990; Shmavonian, et al., 1970), but did differ in baseline blood pressure readings, with older adults exhibiting significantly greater blood pressure (systolic and diastolic) at baseline than younger adults (Boutcher \& Stocker, 1996; Garwood et al, 1982; Jennings et al., 1990). This latter finding supports literature suggesting the reduced plasticity of the arteries as a consequence of the aging process, resulting in greater peripheral 
resistance and higher resting blood pressure. Moreover, it is consonant with theories on HR and SCL stating that despite developmental changes in their respective physiology (i.e., hypertrophy of the heart, reduced density and frequency of active sweat glands), the consequences of these changes do not appear to affect resting levels of these parameters. Although both groups evidenced significant reactivity to the Stroop task, younger adults exhibited significantly greater HR and SCL reactivity than older adults during the Stroop task. Older adults also evidenced greater SBP responses than younger adults, but no significant age differences in DBP responses were observed during the Stroop task. Younger adults also exhibited significantly more SCR responding than older adults during the Stroop task. These findings replicate findings of earlier studies on the physiological responsivity of older and younger adults during laboratory stressor tasks (Boutcher \& Stocker, 1996; Faucheux, Dupuis, et al., 1983; Garwood et al, 1982; Jennings et al., 1990; Shmavonian et al., 1965; 1968; 1970).

No significant age differences in physiological responding were observed in response to the snake video. However, neither group exhibited significant physiological reactivity to the snake video. As is discussed in greater detail below, it appears the snake video was not considered particularly anxiety-evoking by participants, and therefore may have not provided a stimulus that was adequate to test the hypothesis of this study.

Contrary to the major hypothesis, recovery data on measures of skin conductance (SCL, SCR) following the Stroop task revealed delayed recovery in older adults as compared to younger adults. A trend analysis of the SCL recovery data suggested a faster rate of habituation in younger adults as compared to in older adults. Although both age groups evidenced a significant decline to baseline with each subsequent recovery interval, younger adults exhibited a "steeper slope" in recovery data as compared to the SCL responses of older adults. Moreover, 
while both younger and older adults exhibited an attenuation in SCL between minutes 3 and 4, older adults continued to exhibit a flattened but still significant decline to baseline in SCL from minutes 4 to 5 whereas younger adults evidenced a significant reversal in the trend, exhibiting a steeper decline to baseline between minute 4 to minute 5. Similarly, whereas younger adults evidenced a significant reduction in SCRs immediately following the end of the Stroop task and appeared to reach baseline by minute 3 , older adults did not show a significant reduction in SCR's until 3 minutes following the end of the Stroop task and appeared to reach baseline by minute 4.

The methodology employed to collect skin conductance measures may have influenced the EDA findings of this study. The definition for a SCR used for this study was much more liberal (SCL $\leq 10 \mu$ mhos, $\Delta \mathrm{SCL}=.01 \mu$ mhos; $\mathrm{SCL} \geq 11 \mu$ mhos, $\Delta \mathrm{SCL}=.02 \mu$ mhos) than the change score that is at present more popularly used in the skin conductance literature $(\Delta \mathrm{SCL} \geq$ $.05 \mu \mathrm{mhos})$. The reason for adopting a more liberal definition was in anticipation of dampened responding in older adult participants due to developmental changes to eccrine sweat glands. It also was an attempt to capture accurately the response profile of all participants rather than to capture patterns of responding as they conformed to definitions normalized with younger adult populations. Thus, it is telling that when using a lower threshold for defining SCRs, older adults exhibited a corresponding frequency of spontaneous skin fluctuations. It is possible that alternative assessment criteria may have resulted in differential age effects that need to be used to capture physiological events in older populations. Moreover, whereas studies employing a constant-current method consistently found decreased SCR magnitude and faster SCL habituation rate, studies employing a constant-voltage method did not find age-related differences in SCR magnitude or SCL habituation rate (see Catania et al.,1980). Because this 
study attempted to take into account age-associated physiologic changes and therefore employed a constant-voltage method for assessing EDA in addition to a more liberal definition of an SCR, the lack of significant age effects was not entirely surprising.

There also was a significant main effect for Age as well as a significant Age x Interval interaction for SBP during recovery that suggested that younger adults showed faster recovery to baseline than older adults, with younger adults exhibiting a trend towards baseline at 5-minutes post-completion of the Stroop task while older adults exhibited an increase in SBP during the same time interval. However, these findings were qualified by a significant Age x Fear $\mathrm{x}$ Interval interaction. Further analyses of the 3-way interaction revealed that while high fear older adults returned to baseline faster than high fear younger adults, younger low fear adults began to return to baseline during minute 5 of the recovery period while older low fear adults showed increasing SBP throughout the recovery period. These findings will be discussed in more detail later in the document, as it has implications for another major hypothesis.

Hypothesis 2: Fearful individuals will exhibit greater physiological responding to an anxiety$\underline{\text { evoking stimulus as compared to a mental stressor task in comparison to nonfearful individuals }}$

No significant differences for physiological measures were observed between high and low fear individuals when exposed to the snake video. There are a few possible explanations for these results: 1) the questionable validity of the stimulus to evoke adequate physiological responses; and 2) problems with the sample population. First, self-reported scores on the STAI-S and subjective anxiety rating following the snake video suggested that participants did not perceive the snake video as particularly fearful or anxiety-evoking. Although high fear individuals reported significantly higher anxiety scores than low fear individuals when exposed to the snake video (as well as to the Stroop task), the mean STAI-S score of the high fear group 
to the snake video only approached a score indicative of a stressful state (e.g., $\underline{M}=40.2)$. In a population of females between 50-69, the normative score on the STAI-S was $32.2(\underline{\mathrm{SD}}=8.67)$, and in a study in which college students underwent stressful and nonstressful conditions prior to filling out the STAI-S, female college students reported a mean score of $43.6(\underline{\mathrm{SD}}=11.59)$ under a mental stressor (e.g., test taking) condition. When exposed to an extremely unsettling stimulus (e.g., workshop accidents), female college students reported a mean score of $60.9(\underline{\mathrm{SD}}=11.99$; Spielberger, Gorush, \& Lushene, 1983). Thus, although the normative sample did not include individuals older than age 69, the mean score of the high fear group was only slightly higher than normal for females between age 50-69, and approached the mean score indicative of an acute stress response in younger adults but not a score indicative of extreme anxiety.

Similarly, although high fear individuals again reported being significantly more anxious than low fear individuals when providing a subjective anxiety rating following the snake video, the mean rating for high fear individuals was not qualitatively suggestive of being extremely anxious $-45 \mathrm{~mm} / 100 \mathrm{~mm}$ (see Table 2). It is possible that the upper anchor of the rating scale may have skewed self-reports away from extremely high ratings (i.e., $100 \mathrm{~mm}=$ most anxious ever). A more subtle description for the upper anchor (e.g., extremely/very anxious) may have encouraged participants to make higher ratings.

Another reason that no significant differences between fear groups were observed may be because the fear samples used were not comprised of extreme fear populations. Unlike other fear studies, we did not employ behavior avoidance tests to select participants nor did we use top scorers on a snake fear measure as the high fear group (e.g., top 6\%, Lumley \& Melamed, 1992; top 10\%, Lang, Levin, Miller, \& Kozak, 1983). Despite high fear individuals having a mean selfreported rating of being "very much" afraid of snakes on the FSS-II, their mean SNAQ total 
score $(\underline{M}=17)$ was not within the range of scores recognized as indicative of high snake fear individuals $(\underline{\mathrm{M}}>$ 19, Becker \& Costello, 1975; $\underline{\mathrm{M}}>$ 18, Klorman, 1974; May, 1977).

In support of this premise, although the sample size was too small to result in any meaningful interpretations, visual inspection of the physiological and subjective responses of the 20 individuals who scored greater than 20 on the SNAQ to the snake video was in the hypothesized direction. The reactivity of individuals who scored greater than 20 on the SNAQ was somewhat higher on SCL, SCR, and SBP as compared to high fear individuals who scored less than 19 on the SNAQ (SCL: $\underline{\mathrm{M}}_{20+}=7.05 \mu \mathrm{mhos}, \underline{\mathrm{M}}_{19-}=5.00 \mu \mathrm{mhos} ; \mathrm{SCR}: \underline{\mathrm{M}}_{20+}=11.15$, $\left.\underline{\mathrm{M}}_{19-}=9.0 ; \mathrm{SBP}: \underline{\mathrm{M}}_{20+}=117 \mathrm{~mm} \mathrm{Hg}, \underline{\mathrm{M}}_{19-}=116.3 \mathrm{~mm} \mathrm{Hg}\right)$. Moreover, scores on the STAI-S and subjective anxiety ratings by the former group $\left(\underline{\mathrm{M}}_{\mathrm{STAI}}=47.23 ; \underline{\mathrm{M}}_{\mathrm{rating}}=61.55 \mathrm{~mm}\right)$ suggested significantly greater anxiety in response to the snake video than the overall high fear group $\left(\underline{M}_{\mathrm{STAI}}=40.47 ; \underline{\mathrm{M}}_{\mathrm{rating}}=46.87 \mathrm{~mm}\right)$. Their subjective anxiety scores towards the snake video were somewhat higher than toward the Stroop task (Stroop task: $\underline{\mathrm{M}}_{\mathrm{STAI}}=44.62 ; \underline{\mathrm{M}}_{\mathrm{rating}}=$ $47.75 \mathrm{~mm})$. Correlations between self-report measures yielded a positive correlation between the SNAQ and the subjective anxiety measures completed following the snake video: (a) SNAQ and Snake STAI, $\underline{\mathrm{r}}(73)=.60, \underline{\mathrm{p}}<.001 ;$ and $(\mathrm{b})$ SNAQ and Snake subjective anxiety ratings, $\underline{\mathrm{r}}(73)=$ $.72, \mathrm{p}<.001$. These findings support the premise that the criteria by which this study screened for high snake fear individuals was not stringent enough to employ truly snake-fearful individuals.

Another problem with the sample population used in this study may explain the minimal response by the high fear individuals towards the snake video. Although high fear participants reported being fearful of snakes in general, the sample used may not have been homogenous in the contextual nature of their fear of snakes. More specifically, they may not all have been 
fearful of snakes in an analogue situation--they only may be fearful when in the physical presence of a snake but not of a pictorial representation of one. Indeed upon closer inspection of two particular items on the SNAQ that examined an individual's ability to tolerate pictorial representations of snakes, the data suggested that over half of the high fear sample would not be fearful of the snake video; only $40.1 \%$ of the high fear participants reported that "if a picture of a snake appear[ed] on the screen during a movie, I would turn my head" and $40.1 \%$ reported they "dislike[d] looking at pictures of snakes in a magazine."

Visual inspection of the physiological and subjective responses of the 18 individuals who self-reported avoidance behaviors towards video representations of snakes yielded some support for this hypothesis, with reactivity scores of self-reported avoidant individuals being somewhat higher on SCL, SCR and SBP as compared to individuals who self-reported the ability to watch a picture of a snake on the movie screen $\left(\mathrm{SCL}: \underline{\mathrm{M}}_{\mathrm{avoidant}}=6.72 \mu \mathrm{mhos}, \underline{\mathrm{M}}_{\text {not avoidant }}=5.38 \mu \mathrm{mhos}\right.$; $\mathrm{SCR}: \underline{\mathrm{M}}_{\text {avoidant }}=12.05, \underline{\mathrm{M}}_{\text {not avoidant }}=8.53 ; \mathrm{SBP}: \underline{\mathrm{M}}_{\text {avoidant }}=117.4 \mathrm{~mm} \mathrm{Hg}, \underline{\mathrm{M}}_{\text {not avoidant }}=116.1 \mathrm{~mm}$ Hg).. The subjective anxiety scores for self-reported avoidant individuals also were higher for the snake video $\left(\underline{\mathrm{M}}_{\mathrm{STAI}}=48.26, \underline{\mathrm{M}}_{\mathrm{rating}}=66.22 \mathrm{~mm}\right)$ than the Stroop task $\left(\underline{\mathrm{M}}_{\mathrm{STAI}}=43.02, \underline{\mathrm{M}}_{\mathrm{rating}}\right.$ $=46.94 \mathrm{~mm}$ ), in the hypothesized direction, and suggestive of greater anxiety towards the snake video stimulus. Although remote, it is possible that because the participants completed the SNAQ upon completion of the experiment, their responses for at least the item about turning their head at a snake on the movie screen was biased by their ability to watch the entire video clip without turning their head or engaging in other physically avoidant behaviors.

Although both fear groups evidenced significant reactivity to the Stroop task and there were slight trends in the direction of greater arousal among high fear individuals, no significant main effects for fear were found in physiological response to the Stroop task. These findings 
were not surprising given the fear groups were designated according to participants' self-reported fear of snakes rather than premorbid trait anxiety. Moreover, as was found with the age groups, closer inspection of the data from the anxiety measures also indicated that the Stroop task, while rated higher in subjective anxiety by high fear individuals, was not considered extremely anxiety-evoking $\left(\underline{\mathrm{M}}_{\mathrm{STAI}}=43.80 ; \underline{\mathrm{M}}_{\mathrm{rating}}=50.52 \mathrm{~mm}\right)$. Similarly, although in general rated significantly higher in anxiety relative to the snake video, the ratings for the Stroop task on the anxiety measures were not qualitatively suggestive of being extremely anxiety-evoking to participants $\left(\mathrm{STAI}-\mathrm{S}: \underline{\mathrm{M}}_{\text {stroop }}=41.06, \underline{\mathrm{M}}_{\text {snake }}=35.70\right.$; subjective anxiety ratings: $\underline{\mathrm{M}}_{\text {stroop }}=42.24$ $\left.\mathrm{mm}, \underline{\mathrm{M}}_{\mathrm{snake}}=31.68 \mathrm{~mm}\right)$.

While the STAI-S score of participants was indicative of an acute stress response in a normative sample $(\underline{\mathrm{M}}=43.69)$, the STAI-S scores did not approximate the mean score indicative of extreme anxiety/distress in a normative sample $(\underline{M}=60.94)$. Thus, although this study yields some data that the Stroop task was considered marginally more anxiety-evoking by high fear individuals in contrast to low fear counterparts, the evidence remains unconvincing that physiological responses to the Stroop task can generalize to physiological responses during anxiety-evoking situations.

Although it is curious that individuals with a high fear of snakes would experience the Stroop task as significantly more anxiety-evoking than individuals with a low fear of snakes, this finding may be related to the poorer performance observed on the Stroop task among high fear individuals. Although the direction of causality cannot be established, it would seem likely that the increased ratings of anxiety which were made after the task was completed were made in response to the poorer performance on the Stroop task that preceded the rating. In other words, since poor performance preceded the increased anxiety ratings, it seems likely poor performance 
led to increased ratings of anxiety. One must also consider the possibility that increased anxiety existed during the task and interfered with task performance (e.g., Yerkes-Dodson Law). It is also possible that because all participants were aware they would be exposed to a snake video during the course of the experiment, high fear individuals approached both stimuli as potentially threatening and responded according to experimental expectations.

Although high fear individuals endorsed experiencing significantly more anxiety when exposed to the snake video than low fear individuals, this was not accompanied by differential physiological responding to the snake video. Similarly, no significant correlations were observed between self-report and physiological responses to the snake video. This is likely due to the lack of reactivity to and restricted range of physiological responses that occurred during the snake video. However, there were significant positive correlations between BAI total score and EDA (SCL and SCR) response during the snake video. This finding tenuously supports a body of research in the anxiety literature that suggests individuals with high premorbid anxiety tend to exhibit greater physiological reactivity to a fearful stimulus. It also is congruous with previous research findings that suggest EDA to be a more reliable measure of anxiety relative to other psychophysiological variables. Another explanation for this finding, given there were no significant correlations between BAI scores and other physiological measures, is that participants in general evidenced a relatively greater range of scores on the BAI as well as in EDA responses during the snake video than any other physiological measure, making it possible for a positive relationship between BAI and EDA (SCL, SCR) responsivity to be detected.

A positive correlation between HR response and measures of anxiety (i.e., STAI-S, subjective anxiety ratings) during the Stroop task also was observed. This was likely due to the fact that physiological reactivity to the Stroop task was actually observed in contrast to the 
relatively benign snake video. Interestingly, there was a negative correlation between baseline SBP and DBP and Stroop STAI-S score. These findings are likely an artifact of age-related differences in physiology and self-report behavior. More specifically, younger adults exhibited significantly lower SBP and DBP throughout the experiment than older adults but also reported significantly higher STAI-S scores than older adults to the Stroop task. Thus, it is very likely the negative correlations would disappear if these analyses were conducted separately per age group. Indeed, when the correlations were run separately per age group, no significant correlations were found. Moreover, while only younger adults showed a slightly negative relationship between baseline SBP responses and Stroop STAI-S score, when partial correlations were conducted on SBP responses to the Stroop task, older adults exhibited a slightly negative relationship between SBP responses and Stroop STAI-S while younger adults exhibited a slightly positive relationship between these same variables. These findings are congruous with the theory that older adults tend to report lower subjective anxiety on self-report measures than younger adults.

Hypothesis 3: Fearful older adults would exhibit a similar but reduced physiological profile than fearful younger adults when exposed to an anxiety-evoking stimulus

This study did not find support for this hypothesis, as neither high fear younger adults nor high fear older adults exhibited significant reactivity to the snake video. However, again, these findings may be the consequence of problems with the stimulus and the defining characteristics of the sample rather than further support for physiological equivalence between younger and older adults during anxious-evoking situations.

Looking only at the physiological responses of young high and low fear participants, the findings from this study were inconsistent with the anxiety literature regarding baseline and recovery measures of physiological reactivity (Barlow et al., 1984; Bond et al., 1974; Lader \& 
Wing, 1964, 1966; Malmo et al., 1951; Rapee, 1985; Woods et al., 1987). In contrast to previous studies on phobic individuals (Antony et al., 1994; Ehlers et al., 1988; Geer, 1966; Woods et al., 1987), high fear younger adults did not exhibit significantly higher resting HR, SCL, SCR, SBP, or DBP or slower habituation to the fearful stimulus than low fear younger adults, nor were trends found in the hypothesized direction. However, it must be noted that this study did not employ individuals with diagnosed anxiety disorders. Although there is support for larger numbers of spontaneous skin fluctuations in response to anxiety-evoking stimuli in the literature, even in nonclinical fear samples (Geer, 1966; McGlynn, Puhr, Gaynor, \& Perry, 1973; Weerts \& Lang, 1978), the existing literature on increased magnitude of HR, SCL, SBP, and DBP reactivity to an anxiety-evoking stimulus in individuals under age 65 is equivocal. However, as was discussed in previous sections, problems with the fear sample and the questionable ability of the fear stimulus to evoke physiologic responses are likely explanations as to why the results of this study are discordant with the anxiety literature in younger adults.

Fearful older adults did not exhibit differential physiologic responding to the Stroop task than low fear older adults on HR, SCL, SCR, SBP, or DBP on baseline, reactivity, and recovery measures. However, there was a curious Age x Fear interaction in SBP during recovery from the Stroop task. Analyses of SBP during recovery revealed that at least in the high fear condition, older adults evidenced a faster rate of recovery than younger adults. However, in the low fear condition, whereas younger adults immediately returned to baseline levels of SBP, low fear older adults exhibited an increasing trend of increasing SBP during recovery. Examination of HR and DBP responses in low fear older adults during recovery did not correspond to this increase in SBP. Therefore, this finding was unique to SBP. 
The faster rate of recovery observed in older adults with high fear may be attributed to the fact that older adults exhibited a significantly greater SBP to the Stroop task. Because they reacted more than the younger adults, a greater drop in SBP was needed to recover from the task. It could also be argued that the vascular "stiffness" of the older adult sample may impact recovery, thus explaining the increasing trend in SBP observed among the low fear older adults. What cannot be explained is why only the high fear older adults recovered from the task and only the low fear older adults' SBPs increased during recovery.

\section{$\underline{\text { Task Performance }}$}

Interestingly, task performance on the Stroop task and the snake video questionnaire revealed high fear older adults gave poorer performances on both measures than individuals from other groups. It is possible that despite no evidence of obvious avoidance behaviors, high fear older adults may have appeared to watch the video but were not attending to the contents of the video. However, although high fear older adults provided statistically fewer correct responses about the snake video, qualitatively, their mean score (3.7 out of 4.0) did not suggest greater meaningful avoidance behavior in this group as compared to the other groups (with mean scores between 3.9-4.0).

An Age x Fear interaction also found that high fear older adults gave the most responses but also made the most errors on the Stroop task, yielding a significantly greater mean error ratio than any of the other three groups. Poorer performance on the Stroop task by high fear older adults as compared to the other groups can be explained by their faulty execution of the Stroop task. Despite their ability to perform the Stroop task correctly during practice trials, in general high fear older adults read the color name rather than naming the color ink in which the color name was printed during most of (if not throughout) the Stroop task. Thus, they produced the 
most responses but also made the most errors, yielding a significantly greater mean error ratio than any other group. That low fear older adults did not exhibit this inability to maintain an instructional set under testing conditions suggests that perhaps anxiety may have negatively influenced the high fear older adults to engage in the overlearned response set of reading in order to give the greatest number of responses instead of following task instruction.

Qualitative analyses of responding behavior during the Stroop task indicated that although several individuals in each of the other groups also exhibited an inability to maintain the instructional set under testing conditions, unlike high fear older adults, they were able to selfmonitor during the task and switch to correctly engaging in the Stroop task as previously instructed; high fear older adults did not exhibit self-corrective behavior. According to the Yerkes-Dodson Law, the increased anxiety in high fear older adults might interfere with cognitive functioning required to complete the Stroop task successfully. Interestingly, high fear older adults were, on average, the least educated participants in the study and low fear older adults were the most educated participants. Thus, it also is possible that a decline in cognitive functioning (age-associated or pathological) may account for the poorer performance among high fear older adults by negatively impacting their ability to self-monitor under distressing circumstances.

\section{$\underline{\text { Self-report behavior }}$}

Throughout the existing literature on anxiety in older adults, diagnostic interviews and scores on anxiety measures that depend on the self-report of fear, anxiety, or physical symptoms indicative of anxiety have yielded lower rates of anxiety among older adults as compared to younger adults; older adults tend to endorse fewer symptoms and report experiencing less subjective anxiety relative to younger adults (see Stanley, Beck, \& Zebb, 1996). Congruous with 
these findings, significantly lower scores on the BAI and the STAI indicate that age-associated differences in self-report behaviors were observed in this study, with older adults endorsing less anxiety than younger adults on self-report measures of anxiety. Also, this study found evidence of significant desynchrony between physiological responding and self-report behavior in older adults. Despite exhibiting significant HR, SCL, and SCR reactivity during the Stroop task and no difference in physiological responding during the snake video, older adults reported experiencing similar states of subjective anxiety during both task conditions on the STAI-S $\left(\underline{\mathrm{M}}_{\mathrm{stroop}}=34.12\right.$, $\left.\underline{\mathbf{M}}_{\text {snake }}=34.05\right)$ as well as on subjective anxiety ratings $\left(\underline{\mathrm{M}}_{\mathrm{stroop}}=30.46 \mathrm{~mm}, \underline{\mathrm{M}}_{\text {snake }}=33.03 \mathrm{~mm}\right)$; the STAI scores were not significantly different from baseline recordings $\left(\underline{M}_{\mathrm{STAI}}=31.58\right)$.

Although one might argue that a stressor task may not be considered anxiety-evoking, it is suspicious that younger adults did not exhibit the same pattern of desynchrony between physiological and self-report measures of anxiety. In other words, younger adults exhibited similar physiologic responses to the snake video as older adults and endorsed similar STAI-S scores and subjective anxiety ratings towards the snake video as older adults. However, whereas both younger and older adults exhibited greater physiologic reactivity to the Stroop task, only younger adults reported significantly greater subjective anxiety during the Stroop task on the STAI-S as well as on subjective anxiety ratings. Although the design of this study does not allow further investigation as to the causal reason for this difference in self-report behavior, the data support the theory posited that older adults tend to underreport subjective experiences that they relate to anxiety and fear. It is also possible that older adults just exhibit greater desynchrony than younger adults. 


\section{$\underline{\text { Limitations }}$}

There were problems with the fear sample and fear stimulus that limit the interpretability of this study as it relates to responses to the anxiety-evoking stimulus. Data from subjective and objective measures towards the study's anxiety-evoking stimulus (snake video) suggested that the stimulus did not evoke the responses typically seen in the literature and was not considered extremely anxiety-evoking to either high fear or low fear individuals. It should be noted, however, that the anxiety-evoking stimulus was comprised of a passive coping task (while the stressor task was an active-coping task), limiting the interpretability of the reactivity and recovery data; use of an anxiety-evoking stimulus that required an active coping strategy may have elicited more dynamic physiologic profiles.

There also were problems with the definition of high fear sample population. High fear individuals did not consistently endorse being highly fearful of snakes across two indices of snake fear (FSS item on fear of snakes, SNAQ), nor were they homogenous in the nature of their fear towards snakes, as evidenced by the majority response to two items on the SNAQ that assessed avoidance behavior towards pictorial representations of snakes. Data indicated that 59.9 percent of the high fear group reported not being fearful of a snake on a movie screen, precisely this study's method of presentation for the anxiety-evoking stimulus.

Also, a sampling bias may have inadvertently occurred between older and younger adults as a consequence of the exclusionary criteria, limiting the generalizability of the findings of this study. By excluding older adults with cardiac conditions and/or who used particular antihyptertensive medications, the findings from this study likely better represent a healthier older adult sample than the average older adult, of whom at least $85 \%$ have one chronic medical condition. It is also possible that the older adults recruited for the study were not as fearful as the 
younger adult participants. One of the reasons for the significant difference in sample size between older and younger adults was the difficulty in recruiting older adults to participate in the study as compared to the relative ease by which young adults in a university setting were recruited. For example, during the recruitment phase, more older adults refused to participate in the study because of the required exposure to the snake video than younger adults. Also, more older adults met the exclusionary criteria than younger adults. Given the positive relationship between anxiety and chronic medical conditions, it is possible that the high fear older adults who were included in this study (because they did not meet the exclusionary criteria) are not truly representative of anxious older adults in the general population.

\section{$\underline{\text { Conclusion }}$}

Although this study did not provide support for its major hypotheses, it was able to replicate some findings of other psychophysiological studies on the effects of age on physiological responses to a stressor task. In response to the Stroop task, there was evidence that older adults exhibited a similar but dampened reactivity profile relative to younger adults on HR, SCL, and SCR. There also was evidence of a slower rate of recovery in SCR for older adults than in younger adults. On measures SCL, older adults again exhibited a parallel but dampened pattern of responding during recovery from the stressor task. These preliminary data do call into question whether older adults may have more difficulty becoming physiologically conditioned to a fear stimulus and if they experience less physiological reactivity to conditioned fear responses.

The findings from this study also clearly indicate the need to be very careful about assessment criteria and methodology. The study yielded evidence that, as was suggested in previous literature, methodology will influence the outcome of psychophysiological studies in 
regards to age differences. It also was able to provide more evidence that older adults indeed exhibit different self-reporting behaviors on measures of anxiety.

Overall, this study was able to provide some data to support findings from previous studies and also to support the merit of further research to clarify the impact of aging on physiological responding. The data also provided some clinically relevant findings regarding age-appropriate assessment methodology and suggestions for future research. Hopefully, future research will address the questions left unanswered by this preliminary investigation by assessing the physiology of anxiety among older adults. 


\section{References}

Agras, S., Sylvester, D., \& Oliveau, D. (1969). The epidemiology of common fears and phobias. Comprehensive Psychiatry, 10, 151-156.

Alexopoulos, G. S. (1991). Anxiety and depression in the elderly. In C. Salzman \& B. D. Lebowitz (Eds.), Anxiety in the elderly: Treatment and research (pp. 63-77). New York: Springer.

American Psychiatric Association. (1994). Diagnostic and statistical manual of mental disorders (4th edition). Washington, D C: Author.

Anderson, N. B., \& McNeilly, M. (1991). Age, gender, and ethnicity as variables in psychophysiological assessment: Sociodemographics in context. Psychological Assessment, 3 , 376-384.

Andreassi, J. L. (1989). Psychophysiology: Human behavior and physiological response (2nd edition). London: Lawrence Erlbaum Associates.

Angst, J., Merikangas, K. R., \& Preisig, M. (1997). Subthreshold syndromes of depression and anxiety in the community. Journal of Clinical Psychiatry, 58, 6-10.

Antony, M. M., Meadows, E. A., Brown, T. A., \& Barlow, D. H. (1994). Cardiac awareness before and after cognitive behavioral treatment for panic disorder. Journal of Anxiety Disorders, 8, 341-350.

Asmundson, G. J. G., Norton, G. R., Wilson, K. G., \& Sandler, L. S. (1994). Subjective symptoms and cardiac reactivity to brief hyperventilation in individuals with high anxiety sensitivity, Behaviour Research and Therapy, 32, 237-241.

Barlow, D. H. (1988). Anxiety and its disorders. New York: Guilford. 
Barlow, D. H., Cohen, A. S., Waddell, M., Vermilyea, J. A., Klosko, J. S., Blanchard, E. B., \& Di Nardo, P. A. (1984). Panic and generalized anxiety disorders: Nature and treatment. Behavior Therapy, 15, 431-449.

Barnes, R. F., Raskind, M., Gumbrecht, G., \& Halter, J. B. (1982). The effects of age on the plasma catecholamine response to mental stress in man. Journal of Clinical Endocrinology and Metabolism, 54, 64-69.

Beck, A. T., \& Steer, R. A. (1990). Manual for the Beck Anxiety Invetory. San Antonio, TX: Psychological Corporation.

Becker, H. G. \& Costello, C. G. (1975). Effects of graduated exposure with feedback on snake phobias. Journal of Clinical and Counseling Psychology, 43, 478-484.

Bennett-Levy, J., \& Marteau, T. (1984). Fear of animals: What is prepared? British Journal of Psychology, 75, 37-42.

Bland, R. C., Orn, H., \& Newman, S. C. (1988). Prevalence of psychiatric disorders in the elderly in Edmonton. Acta Psychiatrica Scandinavia, 77, 57-63.

Blazer, D., George, L. K., \& Hughes, D. (1991). The epidemiology of anxiety disorders: An age comparison. In C. Salzman \& B. D. Lebowitz (Eds.), Anxiety in the elderly: Treatment and research (pp. 17-30). New York: Springer.

Bond, A. J., James, D. C., \& Lader, M. H. (1974). Physiological and psychological measures in anxious patients. Psychological Medicine, 4, 364-373.

Botwinick, J., \& Kornetsky, C. (1960). Age differences in the acquisition and extinction of the GSR. Journal of Gerontology, 15, 83-84.

Boutcher, S. H., \& Stocker, D. (1996). Cardiovascular response of young and older males to mental challenge. Journal of Gerontology, 51, P261-P267. 
Bruce, M. L., \& McNamara, R. (1992). Psychiatric status among the homebound elderly: An epidemiologic perspective. Journal of the American Geriatrics Society, 40, 561-566.

Capriotti, R., Garwood, M., \& Engel, B. T. (1981). Skin potential level: Age and recording site interactions. Journal of Gerontology, 36, 40-43.

Catania, J. J., Thompson, L. W., Michalewski, H. A., \& Bowman, T. E. (1980). Comparisons of sweat gland counts, electrodermal activity, and habituation behavior in young and old groups of subjects. Psychophysiology, 17, 146-152.

Cohen, G. D. (1991). Anxiety and general medical disorders. In C. Salzman \& B. D. Lebowitz (Eds.), Anxiety in the elderly: Treatment and research (pp. 47-62). New York: Springer.

Cone, J. D. (1979). Confounded comparisons in triple response mode assessment research. Behavioral Assessment, 1, 85-95.

Ditto, B., Miller, S., \& Maurice, S. (1987). Age differences in the consistency of cardiovascular response patterns in healthy women. Biological Psychology, 25, 23-31.

Ehlers, A., \& Breuer, P. (1992). Increased cardiac awareness in panic disorder. Journal of Abnormal Psychology, 101, 371-382.

Ehlers, A., Margraf, J., Roth, W. T., Taylor, C. B., \& Birbaumer, N. (1988). Anxiety induced by false heart rate feedback in patients with panic disorder. Behaviour Research and Therapy, 26, 1-11.

Ehlers, A., Margraf, J., Roth, W. T., Taylor, C. B., Maddock, R. J., Sheikh, J., Kopell, M. L., McClenahan, K. L., Gossard, D., Blowers, G. H., Agras, W. S., \& Kopell, B. S. (1986). Lactate infusions and panic attacks: Do patients and controls respond differently? Psychiatry Research, 17, 295-308. 
Eisdorfer, C., Doerr, H. O., \& Follette, W. (1980). Electrodermal reactivity: An analysis by age and sex. Journal of Human Stress, 6, 39-42.

Faucheux, B. A., Baulon, A., Poitrenaud, J., Lille, F., Moreaux, C., Dupuis, C., \& Bourliere, F. (1983). Heart rate, urinary catecholamines, and anxiety responses during mental stress in men in their fifties and seventies. Age and Ageing, 12, 144-150.

Faucheux, B. A., Bourleire, F., Baulon, A., \& Dupuis, C. (1981). The effects of psychosocial stress on urinary excretion of adrenaline and noradrenaline in 51- to 55- and 71and 74-year-old men. Gerontology, 27, 313-325.

Faucheux, B. A., Dupuis, C., Baulon, A., Lille, F., \& Bourliere, F. (1983). Heart rate reactivity during minor mental stress in men in their 50s and 70s. Gerontology, 29, 149-160.

Fisher, J. E., Zeiss, A. M., \& Carstensen, L. L. (1993). Psychopathology in the aged. In P. B. Sutker \& H. E. Adams (Eds.), Comprehensive handbook of psychopathology (2nd ed., pp. 815-842). New York: Plenum.

Flint, A. J. (1994). Epidemiology and comorbidity of anxiety disorders in the elderly. American Journal of Psychiatry, 151, 640-649.

Forsyth, J. P., \& Eifert, G. H. (1996). Systemic alarms in fear conditioning I: A reappraisal of what is being conditioned. Behavior Therapy, 27, 441-462.

Fredrikson, M. (1991). Physiological responses to stressors: Implications for clinical assessment. Psychological Assessment, 3, 350-355.

Fredrikson, M. \& Gunnarsson, R. (1992). Psychobiology of stage fright: The effect of public performance on neuroendocrine, cardiovascular and subjective reactions. Biological Psychology, 33, 51-61. 
Frydrich, T., Dowdall, D., \& Chambless, D. L. (1992). Reliability and validity of the Beck Anxiety Inventory. Journal of Anxiety Disorders, 6, 55-61.

Fuentes, K., \& Cox, B. J. (1997). Prevalence of anxiety disorders in elderly adults: A critical analysis. Journal of Behavior Research and Experimental Psychiatry, 28, 269-279.

Furchtgott, E., \& Busemeyer, J. K. (1979). Heart rate and skin conductance during cognitive processes as a function of age. Journal of Gerontology, 34, 183-190.

Garwood, M., Engel, B. T., \& Capriotti, R. (1982). Autonomic nervous system function and aging: Response specificity. Psychophysiology, 19, 378-385.

Geer, J. H. (1965). The development of a scale to measure fear. Behaviour Research and Therapy, 3, 45-53.

Geer, J. H. (1966). Fear and autnomic arousal. Journal of Abnormal Psychology, 71, 253255.

Gurian, B. S., \& Miner, J. H. (1991). Clinical presentation of anxiety in the elderly. Anxiety in the elderly: Treatment and research (pp. 31-44). New York: Springer.

Hardy, L. H., Rand, G., \& Rittler, C. (1946). A screening test for defective red-green vision. Journal of the Optical Society of America, 36, 610-614.

Hare, R. D. (1973). Orienting and defensive responses to visual stimuli. Psychophysiology, 9, 606-614.

Hassett, J. (1978). A primer of psychophysiology. San Francisco: W. H. Freeman and Company.

Hersen, M., Van Hasselt, V. B., \& Goreczney, A. J. (1993). Behavioral assessment of anxiety in older adults: Some comments. Behavior Modification, 17, 99-112. 
Himmelfarb, S., \& Murrell, S. A. (1984). Prevalence and correlates of anxiety symptoms in older adults. Journal of Psychology, 116, 159-167.

Hugahl, M. (1988). Psychophysiological aspects of phobic fears: An evaluative review. Neuropsychobiology, 20, 194-204.

Jennings, J. R., Brock, K., \& Nebes, R. (1990). Age and specific processing capacities: A cardiovascular analysis. Journal of Psychophysiology, 4, 51-64.

Johnstone, E. C., Bourne, R. C., Crow, T. J., Frith, C. D., Gamble, S., Lofthouse, R., Owen, F., Owens, D. G. C., Robinson, J., \& Stevens, M. (1981). The relationship between clinical response, psychophysiological variables and plasma levels of amitriptyline and diazepam in neurotic outpatients. Psychopharmacology, 72, 233-250.

Kabacoff, R. I., Segal, D. L., Hersen, M., \& Van Hasselt, V. B. (1997). Psychometric properties and diagnostic utility of the Beck Anxiety Inventory and the State-Trait Anxiety Inventory with older adult psychiatric patients. Journal of Anxiety Disorders, 11, 33-47.

Kelly, D. (1980). Anxiety and emotions. Springfield, IL: Charles C. Thomas.

Kelly, D., \& Martin, I. (1969). Autonomic reactivity, eyelid conditioning and their relationship to neuroticism and extroversion. Behaviour Research and Therapy, 7, 233.

Kilpatrick, D. R. (1984). Age, gender and patterns of common intense fears among adults. Behaviour Research and Therapy, 22, 141-150.

Klorman, R. (1974). Habituation of fear: Effects of intensity and stimulus order. Psychophysiology, 11, 15-26.

Klorman, R., Weerts, T. C., Hastings, J. E., Melamed, B. G., \& Lang, P. J. (1974). Psychometric description of some specific-fear questionnaires. Behavior Therapy, 5, 401-409. 
Kogan, J. N. (1996). Self-reported fear in middle-aged and older adults and its relation to daily functioning and satisfaction with life. Unpublished master's thesis, West Virginia University, Morgantown.

Krantz, D. S., Manuck S. B., \& Wing, R. R. (1986). Psychological stressors and task variables as elicitors of reactivity. In K. A. Matthews, S. M. Weiss, T. Detre, T. M. Dembroski, B. Falkner, S. B. Manuck, \& R. B. Williams, Jr. (Eds.), Handbook of stress, reactivity, and cardiovascular disease (pp. 85-107). New York: John Wiley and Sons.

Lader, M. H. (1967). Palmar skin conductance measures in anxiety and phobic states. Journal of Psychosomatic Research, 11, 271-281.

Lader, M. H., \& Marks, I. (1971). Clinical anxiety. New York: Grune \& Stratton. Lader, M. H., \& Wing, L. (1964). Habituation of the psycho-galvanic reflex in patients with anxiety states and in normal subjects. Journal of Neurology, Neurosurgery, and Psychiatry, 27, 210-218.

Lader, M. H., \& Wing, L. (1966). Physiological measures, sedative drugs and morbid anxiety. London: Oxford University Press.

Lakatta, E. G. (1990). Heart and circulation. In E. L. Schneider \& J. W. Rowe (Eds.), Handbook of the biology of aging (3rd ed., pp. 181-216). San Diego: Academic Press.

Lang, P. J. (1968). Fear reduction and fear behavior: Problems in treating a construct. In J. M. Shilieu (Ed.), Research in psychotherapy (Vol. III, pp. 90-102). Washington: American Psychological Association.

Lang, P. J. (1971). The application of psychophysiological methods to the study of psychotherapy and behavior modification. In A. E. Bergin \& S. L. Garfield (Eds.), Handbook of 
psychotherapy and behavior change: An empirical analysis (pp. 75-125). New York: John Wiley $\&$ Sons.

Lang, P. J. (1993). The three-system approach to emotion: Philosophical and theoretical problems. In N. Birbaumer \& A. Ohman (Eds.), The structure of emotion: Psychophysiological, cognitive, and clinical aspects (pp. 18-30). Seattle: Hogrefe \& Huber Publishers.

Lang, P. J., Levin, D. N., Miller, G. A., \& Kozak, M. J. (1983). Fear behavior, fear imagery, and the psychophysiology of emotion: The problem of affective response integration. Journal of Abnormal Psychology, 92, 276-306.

Lang, P. J., Melamed, B. G., \& Hart, J. (1970). A psychophysiological analysis of fear modification using an automated desensitization procedure. Journal of Abnormal Psychology, 76, 220-234.

Levenson, R. W., Carstensen, L. L., Friesen, W. V., \& Ekman, P. (1991). Emotion, physiology, and expression in old age. Psychology and Aging, 6, 28-35.

Levenson, R. W., Carstensen, L. L., \& Gottman, J. M. (1994). The influence of age and gender on affect, physiology, and their interrelations: A study of long-term marriages. Journal of Personality and Social Psychology, 67, 56-68.

Liddell, A., Locker, D., \& Burman, D. (1991). Self-reported fears (FSS-II) of subjects aged 50 years and over. Behaviour Research and Therapy, 29, 105-112.

Lumley, M. A., \& Melamed, B. G. (1992). Blood phobics and nonphobics: Psychological differences in affect during exposure. Behaviour Research and Therapy, 30, 425-434.

Magni, G., \& De Leo, D. (1984). Anxiety and depression in geriatric and adult medical inpatients: A comparison. Psychological Reports, 55, 607-612. 
Malmo, R. B., Shagass, C., \& Heslam, R. M. (1951). Blood pressure response to repeated brief stress in psychoneurosis: A study of adaptation. Canadian Journal of Psychology, 5, 167179.

Maple, S., Bradshaw, C. M., \& Szabadi, E. (1981). Pharmacological responsiveness of sweat glands in anxious patients and healthy volunteers. British Journal of Psychiatry, 141, 154161.

May, J. R. (1977). Psychophysiology of self-regulated phobic thoughts. Behavior Therapy, 8, 150-159.

McGlynn, F. D., Puhr, J. J., Gaynor, R., \& Perry, J. W. (1973). Skin conductance responses to real and imagined snakes among avoidant and non-avoidant college students. Behaviour Research and Therapy, 11, 417-426.

McGuinness, D. (1973). Cardiovascular responses during habituation and mental activity in anxious men and women. Biological Psychology, 1, 115-123.

Montagna, W. (1965). Morphology of the aging skin: The cutaneous appendages. In W. Montagna (Ed.), Advances in biology of skin: aging (pp. 1-16). New York: Pergammon.

Morris, J. D., \& Thompson, L. W. (1969). Heart rate changes in a reaction time experiment with young and aged subjects. Journal of Gerontology, 24, 269-277.

Mower, O. H. (1939). A stimulus-response analysis of anxiety and its role as a reinforcing agent. Psychological Review, 46, 553-565.

Myers, J.K., Weissman, M. M., Tischler, G. L., Holzer, C. E., Leaf, P. J., Orvaschel, H., Anthony, J. C., Boyd, J. H., Burke, J. D., Kramer, M., \& Stoltzman, R. (1984). Six-month prevalence of psychiatric disorders in three communities. Archives of General Psychiatry, 41, 959-967. 
Norris, A. H., Shock, N. W., \& Yiengst, M. J. (1953). Age changes in heart rate and blood pressure responses to tilting and standardized exercise. Circulation, 8, 521-526.

Papillo, J. F., Murphy, P. M., \& Gorman, J. M. (1988). Psychophysiology. In C. G. Last \& M. Hersen (Series E) \& A. P. Goldstein \& L. Krasner (Vol. E), Handbook of anxiety disorders: Vol. 151. Pergamon general psychology series (pp. 217-250). New York: Pergamon Press.

Pettijohn, T. F. (1992). Psychology: A concise introduction (3rd ed.). Guilford, CT: Dushkin Publishing.

Porges, S. W., \& Fox, N. A. (1986). Developmental Psychophysiology. In M. G. H. Coles, E. Donchin, \& S. W. Porges (Eds.), Psychophysiology: Systems, processes, and applications (pp. 611-625). New York: Guilford.

Powell, D. A., Milligan, W. L., \& Furchtgott, E. (1980). Peripheral autonomic changes accompanying learning and reaction time performance in older people. Journal of Gerontology, $\underline{35,}$ 57-65.

Rapee, R. (1985). A distinction between panic disorder and generalized anxiety disorder: Clinical presentation. Australian and New Zealand Journal of Psychiatry, 19, 227-232.

Rapee, R. (1986). Differential response to hyperventilation in panic disorder and generalized anxiety disorder. Journal of Abnormal Psychology, 95, 24-28.

Rapee, R., \& Barlow, D. H. (1993). Generalized anxiety disorder, panic disorder, and the phobias. In P. B. Sutker \& H. E. Adams (Eds.), Comprehensive handbook of psychopathology (2nd ed., pp. 109-127). New York: Plenum.

Regier, D. A., Boyd, J. H., Burke, J. D., Rae, D. S., Myers, J. K., Kramer,M., Robins, L. N., George, L. K., Karno, M., \& Locke, B. Z. (1988). One-month prevalence of mental disorders 
in the United States: Based on five epidemiologic catchment area sites. Archives of General Psychiatry, 45, 977-986.

Regier, D. A., Myers, J. K., Kramer, L. N., Robins, L. N., Blazer, D. G., Hough, R. L., Eaton, W. W., \& Locke, B. Z. (1984). The NIMH Epidemiologic Catchment Area program. Archives of General Psychiatry, 41, 934-941.

Rose, M. P., McGlynn, F. D., \& Lazarte, A. (1995). Control and attention influence snake phobics' arousal and fear during laboratory confrontations with caged snakes. Journal of Anxiety Disorders, 9, 293-302.

Sartory, G., Roth, W. T., \& Kopell, M. L. (1992). Psychophysiological assessment of driving phobia. Journal of Psychophysiology, 6, 311-320.

Shamoian, C. A. (1991). What is anxiety in the elderly. In C. Salzman \& B. D. Lebowitz (Eds.), Anxiety in the elderly: Treatment and research (pp. 3-15). New York: Springer.

Sheikh, J. I. (1991). Anxiety rating scales for the elderly. In C. Salzman \& B. D. Lebowitz (Eds.), Anxiety in the elderly: Treatment and research (pp. 251-265). New York: Springer.

Shmavonian, B. M., Miller, L. H., \& Cohen, S. I. (1968). Differences among age and sex groups in electro-dermal conditioning. Psychophysiology, 5, 119-131.

Shmavonian, B. M., Miller, L. H., \& Cohen, S. I. (1970). Differences among age and sex groups with respect to cardiovascular conditioning and reactivity. Psychophysiology, 5, 87-94.

Shmavonian, B. M., Yarmat, A. J., \& Cohen, S. I. (1965). Relationships between the autonomic nervous system and central nervous system in age differences in behavior. In A. T. Welford \& J. E. Birren (Eds.), Behavior, aging, and the nervous system: Biological determinants of speed of behavior and its changes with age (pp. 235-258). Springfield, IL: Charles C. Thomas. 
Silverman, A. J., Cohen, S. I., \& Shmavonian, B. M. (1958). Psychophysiological response specificity in the elderly, Journal of Gerontology, 13, 443.

Small, G. W. (1997). Recognizing and treating anxiety in the elderly. Journal of Clinical Psychiatry, 58, 41-47.

Spielberger, C. D. (1985). Assessment of state and trait anxiety: Conceptual and methodological issues. The Southern Psychologist, 2, 6-16.

Spielberger, C. D., Gorsuch, R. L., \& Lushene, R. E. (1970). Manual for the State-Trait Anxiety Inventory. Palo Alto: Consulting Psychologists Press.

Spielberger, C. D., Gorsuch, R. L., \& Lushene, R. E. (1983). Manual for the State-Trait Anxiety Inventory. Palo Alto: Consulting Psychologists Press.

Stanley, M. A., \& Beck, J. G. (1998). Anxiety disorders. In B. Edelstein (Vol. Ed.), Clinical geropsychology (Vol. 7): Comprehensive clinical psychology. Oxford, UK: Elsevier.

Stanley, M. A., Beck, J. G., \& Zebb, B. J. (1996). Psychometric properties of four anxiety measures in older adults. Behaviour Research and Therapy, 34, 827-838.

Steer, R. A., Ranieri, W. F., Beck, A. T., \& Clark, D. A. (1993). Further evidence for the validity of the Beck Anxiety Inventory with psychiatric outpatients. Journal of Anxiety Disorders, 7, 195-205.

Stern, R. M., Ray, W. J., Davis, C. M. (1980). Psychophysiological recording. New York: Oxford University Press.

Turner, J. R. (1994). Cardiovascular reactivity and stress: Patterns of physiological response. NY: Plenum Press.

Turner, S. M., Beidel, D. C., \& Nathan, R. S. (1985). Biological factors in obsessivecompulsive neurosis. Psychological Bulletin, 97, 451-461. 
Turpin, G. (1991). The psychophysiological assessment of anxiety disorders: Threesystems measurement and beyond. Psychological Assessment, 3, 366-375.

Weerts, T. C., \& Lang, P. J. (1978). Psychophysiology of fear imagery: Differences between focal phobia and social performance anxiety. Journal of Consulting and Clinical Psychology, 46, 1157-1159.

Woods, S. W., Charney, D. S., McPherson, C. A., Gradman, D. S., \& Heninger, G. R. (1987). Situational panic attacks: Behavioral, physiologic and biochemical characterization. Archives of General Psychiatry, 44, 365-375.

Yesavage, J. A., \& Taylor, B. (1991). Anxiety and dementia. In C. Salzman \& B. D. Lebowitz (Eds.), Anxiety in the elderly: Treatment and research (pp. 79-85). New York: Springer.

Zuckerman, M. (1991). Psychobiology of personality. Cambridge, MA: Cambridge University Press. 
Appendix A

Screening Questionnaire

$\underline{\text { Demographic Information }}$

Name

Date

Age

Gender: $M \quad F$

Marital/Relationship Status:

(1) Single

(4) Divorced

(2) Married

(5) Widowed

(3) Separated

(6) Live-in partner

Race/Ethnicity:

(1) White/Caucasian

(4) Asian

(2) Black

(5) Biracial (specify):

(3) Hispanic

Work status:(1) Working (3) Unemployed

(2) Retired

\section{Education level}

$\underline{\text { Medical Information }}$

1. Do you currently have any medical conditions? (specify)

2. Have you ever had a problem with your:

Heart

Blood pressure 
3. Are you currently taking any medication? (specify)

4. Have you ever been treated for a psychological/psychiatric problem? (specify)

5. Are you currently using drugs that aren't prescribed? (includes cold medication, marijuana....)

6. Height

Weight

7. (For females under age 50) Are you currently pregnant? $\quad \mathrm{Y} \quad \mathrm{N}$

$\underline{\text { Health Behaviors }}$

1. Do you smoke/chew? $\mathrm{Y} \quad \mathrm{N}$

If yes: How much per day?

2. On average, how much alcohol do you drink in a week's time?

3. On average, how much do you exercise in a week's time?

4. On average, how many cups of coffee do you drink per day?

how many cups of tea do you drink per day?

how many cans/cups of caffeinated soda do you drink per day?

5. Overall, how much liquid do you drink per day? 


\section{Appendix B}

Questions about the Video

1. How many snakes were on the video?

2. What color were the snakes?

3. Where were the snakes?(e.g. underground, in the desert, in the woods)

4. What were the snakes doing? 


\section{Appendix C}

\section{ANOVA and ANCOVA Summary Tables}

$\underline{\text { Table I1 }}$

$\underline{2 \text { (Age) }} \times 2$ (Fear) ANOVA Summary Table for Age of Subject.

\begin{tabular}{|r|r|r|r|r|r|}
\hline Source & Type III Sum of & df & Mean Square & $\mathrm{F}$ & Sig. \\
\hline Squares & & & & \\
\hline AGEGROUP & 45752.897 & 1 & 45752.897 & 4061.082 & .000 \\
\hline FEARGRP & 9.871 & 1 & 9.871 & .876 & .352 \\
\hline AGEGROUP * FEARGRP & .305 & 1 & .305 & .027 & .870 \\
\hline Error & 788.633 & 70 & 11.266 & & \\
\hline Total & 164872.000 & 74 & & & \\
\hline Corrected Total & 48384.216 & 73 & & & \\
\hline
\end{tabular}

Table I2

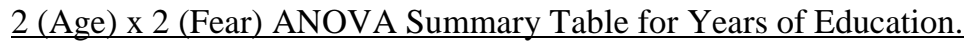

\begin{tabular}{|r|r|r|r|r|r|}
\hline Source & Type III Sum of & $\mathrm{df}$ & Mean Square & $\mathrm{F}$ & Sig. \\
& Squares & & & & \\
\hline AGEGROUP & 5.872 & 1 & 5.872 & 1.436 & .235 \\
\hline FEARGRP & 19.899 & 1 & 19.899 & 4.867 & .031 \\
\hline AGEGROUP * FEARGRP & 20.747 & 1 & 20.747 & 5.074 & .028 \\
\hline Error & 278.030 & 68 & 4.089 & & \\
\hline Total & 14202.000 & 72 & & & \\
\hline Corrected Total & 313.111 & 71 & & & \\
\hline
\end{tabular}

Table I3

$\underline{2 \text { (Age) } x ~} 2$ (Fear) ANOVA Summary Table for Body Mass Index

\begin{tabular}{|r|r|r|r|r|r|}
\hline Source & Type III Sum of & $\mathrm{df}$ & Mean Square & $\mathrm{F}$ & Sig. \\
& Squares & & & & \\
\hline AGEGROUP & 215.131 & 1 & 215.131 & 12.778 & .001 \\
\hline FEARGRP & 21.491 & 1 & 21.491 & 1.276 & .262 \\
\hline AGEGROUP $*$ FEARGRP & 11.247 & 1 & 11.247 & .668 & .417 \\
\hline Error & 1178.530 & 70 & 16.836 & & \\
\hline Total & 50552.040 & 74 & & & \\
\hline Corrected Total & 1407.075 & 73 & & & \\
\hline
\end{tabular}


Table I4

2 (Age) $\times 2$ (Fear) ANOVA Summary Table for Tobacco Use

\begin{tabular}{|r|r|r|r|r|r|}
\hline Source & $\begin{array}{r}\text { Type III Sum } \\
\text { of Squares }\end{array}$ & df & Mean Square & $\mathrm{F}$ & Sig. \\
\hline AGEGROUP & 184.331 & 1 & 184.331 & 4.154 & .045 \\
\hline FEARGRP & .807 & 1 & .807 & .018 & .893 \\
\hline AGEGROUP * FEARGRP & 34.373 & 1 & 34.373 & .775 & .382 \\
\hline Error & 2972.828 & 67 & 44.371 & & \\
\hline Total & 3718.000 & 71 & & & \\
\hline Corrected Total & 3176.930 & 70 & & & \\
\hline
\end{tabular}

Table I5

2 (Age) x 2 (Fear) ANOVA Summary Table for Alcohol Use

\begin{tabular}{|r|r|r|r|r|r|}
\hline Source & $\begin{array}{r}\text { Type III Sum } \\
\text { of Squares }\end{array}$ & df & $\begin{array}{r}\text { Mean } \\
\text { Square }\end{array}$ & $\mathrm{F}$ & Sig. \\
\hline AGEGROUP & 161.859 & 1 & 161.859 & 8.924 & .004 \\
\hline FEARGRP & .929 & 1 & .929 & .051 & .822 \\
\hline AGEGROUP * FEARGRP & 1.452 & 1 & 1.452 & .080 & .778 \\
\hline Error & 1088.254 & 60 & 18.138 & & \\
\hline Total & 1903.500 & 64 & & & \\
\hline Corrected Total & 1259.609 & 63 & & & \\
\hline
\end{tabular}

Table I6

2 (Age) $x 2$ (Fear) ANOVA Summary Table for Exercise

\begin{tabular}{|r|r|r|r|r|r|}
\hline Source & $\begin{array}{r}\text { Type III Sum } \\
\text { of Squares }\end{array}$ & df & Mean Square & F & Sig. \\
\hline AGEGROUP & 11.440 & 1 & 11.440 & .208 & .651 \\
\hline FEARGRP & 16.655 & 1 & 16.655 & .303 & .585 \\
\hline AGEGROUP * FEARGRP & 26.038 & 1 & 26.038 & .474 & .495 \\
\hline Error & 2252.947 & 41 & 54.950 & & \\
\hline Total & 3430.433 & 45 & & & \\
\hline Corrected Total & 2306.932 & 44 & & & \\
\hline
\end{tabular}


Table I7

2 (Age) x 2 (Fear) ANOVA Summary Table for Daily Liquid Intake

\begin{tabular}{|r|r|r|r|r|r|}
\hline Source & $\begin{array}{r}\text { Type III Sum } \\
\text { of Squares }\end{array}$ & df & Mean Square & F & Sig. \\
\hline AGEGROUP & 1.531 & 1 & 1.531 & .150 & .700 \\
\hline FEARGRP & .772 & 1 & .772 & .075 & .784 \\
\hline AGEGROUP * FEARGRP & 25.110 & 1 & 25.110 & 2.457 & .122 \\
\hline Error & 603.024 & 59 & 10.221 & & \\
\hline Total & 4549.000 & 63 & & & \\
\hline Corrected Total & 628.222 & 62 & & & \\
\hline
\end{tabular}

Table I8

2 (Age) x 2 (Fear) ANOVA Summary Table for Caffeine Use

\begin{tabular}{|r|r|r|r|r|r|}
\hline Source & $\begin{array}{r}\text { Type III Sum } \\
\text { of Squares }\end{array}$ & df & Mean Square & $\mathrm{F}$ & Sig. \\
\hline AGEGROUP & 6.793 & 1 & 6.793 & 2.153 & .147 \\
\hline FEARGRP & .253 & 1 & .253 & .080 & .778 \\
\hline AGEGROUP ${ }^{*}$ FEARGRP & $6.643 \mathrm{E}-02$ & 1 & $6.643 \mathrm{E}-02$ & .021 & .885 \\
\hline Error & 217.685 & 69 & 3.155 & & \\
\hline Total & 756.875 & 73 & & & \\
\hline Corrected Total & 225.245 & 72 & & & \\
\hline
\end{tabular}

Table 19

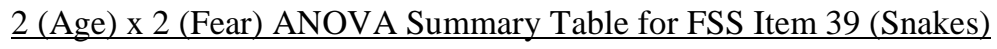

\begin{tabular}{|r|r|r|r|r|r|}
\hline Source & $\begin{array}{r}\text { Type III Sum } \\
\text { of Squares }\end{array}$ & df & $\begin{array}{r}\text { Mean } \\
\text { Square }\end{array}$ & F & Sig. \\
\hline AGEGROUP & .160 & 1 & .160 & .254 & .616 \\
\hline FEARGRP & 302.607 & 1 & 302.607 & 480.306 & .000 \\
\hline AGEGROUP * FEARGRP & 2.007 & 1 & 2.007 & 3.186 & .079 \\
\hline Error & 44.102 & 70 & .630 & & \\
\hline Total & 1890.000 & 74 & & & \\
\hline Corrected Total & 382.486 & 73 & & & \\
\hline
\end{tabular}


Table I10

$\underline{2 \text { (Age) } x ~} 2$ (Fear) ANOVA Summary Table for Snake Questionnaire

\begin{tabular}{|r|r|r|r|r|r|}
\hline Source & $\begin{array}{r}\text { Type III Sum } \\
\text { of Squares }\end{array}$ & df & Mean Square & F & Sig. \\
\hline AGEGROUP & .930 & 1 & .930 & .030 & .863 \\
\hline FEARGRP & 2154.941 & 1 & 2154.941 & 69.223 & .000 \\
\hline AGEGROUP * FEARGRP & 8.413 & 1 & 8.413 & .270 & .605 \\
\hline Error & 2179.138 & 70 & 31.131 & & \\
\hline Total & 16223.000 & 74 & & & \\
\hline Corrected Total & 4560.284 & 73 & & & \\
\hline
\end{tabular}

Table I11

2 (Age) x 2 (Fear) ANOVA Summary Table for Beck Anxiety Inventory

\begin{tabular}{|r|r|r|r|r|r|}
\hline Source & $\begin{array}{r}\text { Type III Sum } \\
\text { of Squares }\end{array}$ & df & Mean Square & F & Sig. \\
\hline AGEGROUP & 185.964 & 1 & 185.964 & 3.931 & .051 \\
\hline FEARGRP & 42.407 & 1 & 42.407 & .896 & .347 \\
\hline AGEGROUP * FEARGRP & 78.405 & 1 & 78.405 & 1.657 & .202 \\
\hline Error & 3311.349 & 70 & 47.305 & & \\
\hline Total & 11339.000 & 74 & & & \\
\hline Corrected Total & 3554.122 & 73 & & & \\
\hline
\end{tabular}

Table I12

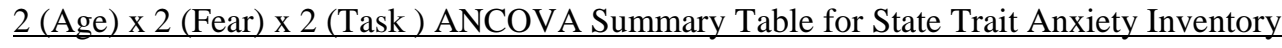

Tests of Within-Subjects Effects

\begin{tabular}{|r|r|r|r|r|r|}
\hline & $\begin{array}{r}\text { Type III } \\
\text { Sum of } \\
\text { Squares }\end{array}$ & df & $\begin{array}{r}\text { Mean } \\
\text { Square }\end{array}$ & F & Sig. \\
\hline TASK & 11.186 & 1 & 11.186 & .151 & .699 \\
\hline TASK * AGEGROUP & 546.512 & 1 & 546.512 & 7.371 & .008 \\
\hline TASK * FEARGRP & 186.216 & 1 & 186.216 & 2.512 & .118 \\
\hline TASK * AGEGROUP * FEARGRP & 20.961 & 1 & 20.961 & .283 & .597 \\
\hline Error(TASK) & 5115.615 & 69 & 74.139 & & \\
\hline
\end{tabular}

Tests of Between-Subjects Effects

\begin{tabular}{|r|r|r|r|r|r|}
\hline Source & $\begin{array}{r}\text { Type III Sum } \\
\text { of Squares }\end{array}$ & df & Mean Square & $\mathrm{F}$ & Sig. \\
\hline COVARIATE & 2926.669 & 1 & 2926.669 & 21.169 & .000 \\
\hline AGEGROUP & 1379.469 & 1 & 1379.469 & 9.978 & .002 \\
\hline FEARGRP & 1681.119 & 1 & 1681.119 & 12.160 & .001 \\
\hline AGEGROUP * FEARGRP & 305.996 & 1 & 305.996 & 2.213 & .141 \\
\hline Error & 9539.259 & 69 & 138.250 & & \\
\hline
\end{tabular}


Table I13

2 (Age) $\times 2$ (Fear) $\times 2$ (Task) ANOVA Summary Table for Subjective Anxiety Ratings

Tests of Within-Subjects Effects

\begin{tabular}{|r|r|r|r|r|r|}
\hline Source & $\begin{array}{r}\text { Type III } \\
\text { Sum of } \\
\text { Squares }\end{array}$ & df & $\begin{array}{r}\text { Mean } \\
\text { Square }\end{array}$ & F & Sig. \\
\hline TASK & 3049.223 & 1 & 3049.223 & 7.087 & .010 \\
\hline TASK * AGEGROUP & 3008.393 & 1 & 3008.393 & 6.992 & .010 \\
\hline TASK * FEARGRP & 1853.631 & 1 & 1853.631 & 4.308 & .042 \\
\hline TASK * AGEGROUP * FEARGRP & 786.574 & 1 & 786.574 & 1.828 & .181 \\
\hline Error(TASK) & 30118.988 & 70 & 430.271 & & \\
\hline
\end{tabular}

Tests of Between-Subjects Effects

\begin{tabular}{|r|r|r|r|r|r|}
\hline Source & $\begin{array}{r}\text { Type III Sum } \\
\text { of Squares }\end{array}$ & df & Mean Square & F & Sig. \\
\hline AGEGROUP & 2746.379 & 1 & 2746.379 & 3.882 & .053 \\
\hline FEARGRP & 24607.499 & 1 & 24607.499 & 34.786 & .000 \\
\hline AGEGROUP * FEARGRP & 12.094 & 1 & 12.094 & .017 & .896 \\
\hline Error & 49517.400 & 70 & 707.391 & & \\
\hline
\end{tabular}

Table I14

2 (Age) $x 2$ (Fear) ANOVA Summary Table for Stroop Total Number of Responses

\begin{tabular}{|r|r|r|r|r|r|}
\hline Source & $\begin{array}{r}\text { Type III Sum of } \\
\text { Squares }\end{array}$ & df & Mean Square & $\mathrm{F}$ & Sig. \\
\hline AGEGROUP & 9325.738 & 1 & 9325.738 & 3.701 & .059 \\
\hline FEARGRP & 10582.894 & 1 & 10582.894 & 4.200 & .044 \\
\hline AGEGROUP * FEARGRP & 3867.132 & 1 & 3867.132 & 1.535 & .220 \\
\hline Error & 168812.198 & 67 & 2519.585 & & \\
\hline Total & 2127571.000 & 71 & & & \\
\hline Corrected Total & 188651.437 & 70 & & & \\
\hline
\end{tabular}

Table I15

2 (Age) x 2 (Fear) ANOVA Summary Table for Stroop Task Errors

\begin{tabular}{|r|r|r|r|r|r|}
\hline Source & $\begin{array}{r}\text { Type III Sum of } \\
\text { Squares }\end{array}$ & df & Mean Square & F & Sig. \\
\hline AGEGROUP & 26124.972 & 1 & 26124.972 & 5.725 & .020 \\
\hline FEARGRP & 38125.343 & 1 & 38125.343 & 8.355 & .005 \\
\hline AGEGROUP * FEARGRP & 22622.340 & 1 & 22622.340 & 4.958 & .029 \\
\hline Error & 305730.355 & 67 & 4563.140 & & \\
\hline Total & 471086.000 & 71 & & & \\
\hline Corrected Total & 392640.930 & 70 & & & \\
\hline
\end{tabular}


Table 116

2 (Age) x 2 (Fear) ANOVA Summary Table for Stroop Task Error Ratio

\begin{tabular}{|r|r|r|r|r|r|}
\hline Source & $\begin{array}{r}\text { Type III Sum } \\
\text { of Squares }\end{array}$ & df & Mean Square & F & Sig. \\
\hline AGEGROUP & .619 & 1 & .619 & 11.140 & .001 \\
\hline FEARGRP & .555 & 1 & .555 & 9.982 & .002 \\
\hline AGEGROUP * FEARGRP & .342 & 1 & .342 & 6.161 & .016 \\
\hline Error & 3.723 & 67 & $5.557 \mathrm{E}-02$ & & \\
\hline Total & 7.130 & 71 & & & \\
\hline Corrected Total & 5.287 & 70 & & & \\
\hline
\end{tabular}

Table I17

2 (Age) x 2 (Fear) ANOVA Summary Table for Correct Responses on Snake Video Questionnaire

\begin{tabular}{|r|r|r|r|r|r|}
\hline Source & $\begin{array}{r}\text { Type III Sum } \\
\text { of Squares }\end{array}$ & df & Mean Square & $\mathrm{F}$ & Sig. \\
\hline AGEGROUP & .139 & 1 & .139 & 2.435 & .123 \\
\hline FEARGRP & .139 & 1 & .139 & 2.435 & .123 \\
\hline AGEGROUP * FEARGRP & .346 & 1 & .346 & 6.051 & .016 \\
\hline Error & 4.006 & 70 & $5.723 \mathrm{E}-02$ & & \\
\hline Total & 1149.000 & 74 & & & \\
\hline Corrected Total & 4.662 & 73 & & & \\
\hline
\end{tabular}

Table I18

$\underline{2 \text { (Age) } \times 2 \text { (Fear) } \times 2 \text { (Task) ANCOVA Summary Table for Heart Rate }}$

Tests of Within-Subjects Effects

\begin{tabular}{|r|r|r|r|r|r|}
\hline Source & $\begin{array}{r}\text { Type III } \\
\text { Sum of } \\
\text { Squares }\end{array}$ & df & $\begin{array}{r}\text { Mean } \\
\text { Square }\end{array}$ & F & Sig. \\
\hline COVARIATE & 187.88 & 1 & 187.88 & 17.11 & .000 \\
\hline TASK & 2680.83 & 1 & 2680.83 & 244.15 & .000 \\
\hline TASK * AGEGROUP & 270.08 & 1 & 270.08 & 24.60 & .000 \\
\hline TASK * FEARGRP & 13.46 & 1 & 13.46 & 1.23 & .272 \\
\hline TASK * AGEGROUP * FEARGRP & 1.21 & 1 & 1.21 & .11 & .741 \\
\hline Error(TASK) & 746.66 & 68 & 1.21 & & \\
\hline & & & & & \\
\hline
\end{tabular}

Tests of Between-Subjects Effects

\begin{tabular}{|r|r|r|r|r|r|}
\hline Source & $\begin{array}{r}\text { Type III Sum } \\
\text { of Squares }\end{array}$ & df & Mean Square & F & Sig. \\
\hline COVARIATE & 11981.18 & 1 & 11981.18 & 545.96 & .000 \\
\hline AGEGROUP & 235.75 & 1 & 235.75 & 10.74 & .002 \\
\hline FEARGRP & 4.58 & 1 & 4.58 & .21 & .649 \\
\hline AGEGROUP * FEARGRP & 3.72 & 1 & 3.72 & .17 & .682 \\
\hline Error & 1492.26 & 67 & 21.95 & & \\
\hline
\end{tabular}


Table I19

$\underline{2 \text { (Age) } \times 2 \text { (Fear) x } 2 \text { (Task) ANCOVA Summary Table for Skin Conductance Level }}$

Tests of Within-Subjects Effects

\begin{tabular}{|r|r|r|r|r|r|}
\hline Source & $\begin{array}{r}\text { Type III } \\
\text { Sum of } \\
\text { Squares }\end{array}$ & df & $\begin{array}{r}\text { Mean } \\
\text { Square }\end{array}$ & $\mathrm{F}$ & Sig. \\
\hline COVARIATE & 37.98 & 1 & 37.98 & 6.00 & .017 \\
\hline TASK & 362.59 & 1 & 362.59 & 57.32 & .000 \\
\hline TASK * AGEGROUP & 19.43 & 1 & 19.43 & 3.07 & .084 \\
\hline TASK * FEARGRP & .29 & 1 & .29 & .05 & .832 \\
\hline TASK * AGEGROUP * FEARGRP & 3.92 & 1 & 3.92 & .62 & .434 \\
\hline Error(TASK) & 423.79 & 67 & 6.33 & & \\
\hline
\end{tabular}

Tests of Between-Subjects Effects

\begin{tabular}{|r|r|r|r|r|r|}
\hline Source & $\begin{array}{r}\text { Type III Sum } \\
\text { of Squares }\end{array}$ & $\mathrm{df}$ & $\begin{array}{r}\text { Mean } \\
\text { Square }\end{array}$ & $\mathrm{F}$ & Sig. \\
\hline COVARIATE & 1373.14 & 1 & 1373.14 & 318.30 & .000 \\
\hline AGEGROUP & 40.75 & 1 & 40.75 & 9.45 & .003 \\
\hline FEARGRP & .39 & 1 & .39 & .09 & .765 \\
\hline AGEGROUP $*$ FEARGRP & 1.17 & 1 & 1.17 & .27 & .604 \\
\hline Error & 289.04 & 67 & 4.31 & & \\
\hline
\end{tabular}

Table I20

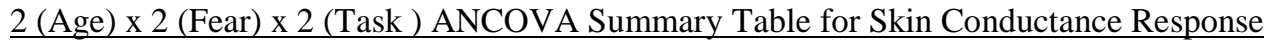

Tests of Within-Subjects Effects

\begin{tabular}{|r|r|r|r|r|r|}
\hline Source & $\begin{array}{r}\text { Type III Sum } \\
\text { of Squares }\end{array}$ & df & $\begin{array}{r}\text { Mean } \\
\text { Square }\end{array}$ & $\mathrm{F}$ & Sig. \\
\hline COVARIATE & .50 & 1 & .50 & .01 & .939 \\
\hline TASK & 14427.50 & 1 & 14427.50 & 168.29 & .000 \\
\hline TASK * AGEGROUP & 393.71 & 1 & 393.71 & 4.59 & .036 \\
\hline TASK * FEARGRP & 3.98 & 1 & 3.98 & .05 & .830 \\
\hline TASK * AGEGROUP * FEARGRP & 144.96 & 1 & 144.96 & 1.69 & .198 \\
\hline Error(TASK) & 5744.01 & 67 & 85.73 & & \\
\hline
\end{tabular}

Tests of Between-Subjects Effects

\begin{tabular}{|r|r|r|r|r|r|}
\hline Source & $\begin{array}{r}\text { Type III Sum } \\
\text { of Squares }\end{array}$ & df & Mean Square & F & Sig. \\
\hline COVARIATE & 3713.33 & 1 & 3713.33 & 30.98 & .000 \\
\hline AGEGROUP & 46.62 & 1 & 46.62 & .39 & .535 \\
\hline FEARGRP & 45.32 & 1 & 45.32 & .38 & .541 \\
\hline AGEGROUP $*$ FEARGRP & 71.88 & 1 & 71.88 & .60 & .441 \\
\hline Error & 8030.00 & 67 & 119.85 & & \\
\hline
\end{tabular}


Table I21

$\underline{2 \text { (Age) } x 2 \text { (Fear) x } 2 \text { (Task ) ANCOVA Summary Table for Systolic Blood Pressure }}$

Tests of Within-Subjects Effects

\begin{tabular}{|r|r|r|r|r|r|}
\hline & $\begin{array}{r}\text { Type III } \\
\text { Sum of } \\
\text { Squares }\end{array}$ & df & $\begin{array}{r}\text { Mean } \\
\text { Square }\end{array}$ & F & Sig. \\
\hline COVARIATE & 99.66 & 1 & 99.66 & 2.40 & .126 \\
\hline TASK & 4550.63 & 1 & 4550.63 & 109.75 & .000 \\
\hline TASK * AGEGROUP & 3.52 & 1 & 3.52 & .08 & .772 \\
\hline TASK * FEARGRP & 441.66 & 1 & 441.66 & 10.65 & .002 \\
\hline TASK * AGEGROUP * FEARGRP & 11.35 & 1 & 11.35 & .27 & .603 \\
\hline Error(TASK) & 2777.97 & 67 & 41.46 & & \\
\hline
\end{tabular}

Tests of Between-Subjects Effects

\begin{tabular}{|r|r|r|r|r|r|}
\hline Source & $\begin{array}{r}\text { Type III Sum } \\
\text { of Squares }\end{array}$ & df & Mean Square & F & Sig. \\
\hline COVARIATE & 12431.18 & 1 & 12431.18 & 207.31 & .000 \\
\hline AGEGROUP & 419.47 & 1 & 419.47 & 7.00 & .010 \\
\hline FEARGRP & 75.30 & 1 & 75.30 & 1.26 & .226 \\
\hline AGEGROUP $*$ FEARGRP & .19 & 1 & .19 & .00 & .956 \\
\hline Error & 4017.53 & 67 & 59.96 & & \\
\hline
\end{tabular}

Table I22

$\underline{2 \text { (Age) } \times 2 \text { (Fear) } \times 2 \text { (Task) ANCOVA Summary Table for Diastolic Blood Pressure }}$

Tests of Within-Subjects Effects

\begin{tabular}{|r|r|r|r|r|r|}
\hline & $\begin{array}{r}\text { Type III Sum } \\
\text { of Squares }\end{array}$ & $\mathrm{df}$ & $\begin{array}{r}\text { Mean } \\
\text { Square }\end{array}$ & $\mathrm{F}$ & Sig. \\
\hline COVARIATE & 8.06 & 1 & 8.06 & .09 & .764 \\
\hline TASK & 5200.16 & 1 & 5200.16 & 58.73 & .000 \\
\hline TASK * AGEGROUP & .28 & 1 & .28 & .00 & .955 \\
\hline TASK * FEARGRP & 245.53 & 1 & 245.53 & 2.77 & .101 \\
\hline TASK * AGEGROUP * FEARGRP & 27.58 & 1 & 27.58 & .31 & .579 \\
\hline Error(TASK) & 5932.06 & 67 & 88.54 & & \\
\hline
\end{tabular}

Tests of Between-Subjects Effects

\begin{tabular}{|r|r|r|r|r|r|}
\hline Source & Type III Sum of & df & Mean Square & F & Sig. \\
Squares & & & & \\
\hline COVARIATE & 3886.25 & 1 & 3886.25 & 32.79 & .000 \\
\hline AGEGROUP & 210.26 & 1 & 210.26 & 1.77 & .187 \\
\hline FEARGRP & 177.83 & 1 & 177.83 & 1.50 & .225 \\
\hline AGEGROUP * FEARGRP & 38.60 & 1 & 38.60 & .33 & .570 \\
\hline Error & 7144.175 & 66 & 108.245 & & \\
\hline
\end{tabular}


Table I23

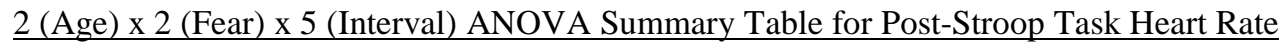

Tests of Within-Subjects Effects

\begin{tabular}{|r|r|r|r|r|r|}
\hline Source & $\begin{array}{r}\text { Type III } \\
\text { Sum of } \\
\text { Squares }\end{array}$ & df & $\begin{array}{r}\text { Mean } \\
\text { Square }\end{array}$ & F & Sig. \\
\hline RECOVERY & 140.326 & 4 & 35.082 & 1.915 & .108 \\
\hline RECOVERY * AGEGROUP & 96.691 & 4 & 24.173 & 1.319 & .263 \\
\hline RECOVERY * FEARGRP & 83.987 & 4 & 20.997 & 1.146 & .335 \\
\hline RECOVERY * AGEGROUP * FEARGRP & 84.754 & 4 & 21.189 & 1.157 & .330 \\
\hline Error(RECOVERY) & 5056.384 & 276 & 18.320 & & \\
\hline
\end{tabular}

Tests of Between-Subjects Effects

\begin{tabular}{|r|r|r|r|r|r|}
\hline Source & $\begin{array}{r}\text { Type III Sum } \\
\text { of Squares }\end{array}$ & df & Mean Square & F & Sig. \\
\hline AGEGROUP & 671.700 & 1 & 671.700 & 1.466 & .230 \\
\hline FEARGRP & 77.309 & 1 & 77.309 & .169 & .683 \\
\hline AGEGROUP $*$ FEARGRP & 104.170 & 1 & 104.170 & .227 & .635 \\
\hline Error & 31622.037 & 69 & 458.290 & & \\
\hline
\end{tabular}

Table I24

$\underline{2 \text { (Age) } \times 2 \text { (Fear) x } 5 \text { (Interval) ANOVA Summary Table for Post-Stroop Task Skin Conductance Level }}$

Tests of Within-Subjects Effects

\begin{tabular}{|r|r|r|r|r|r|}
\hline Source & $\begin{array}{r}\text { Type III } \\
\text { Sum of } \\
\text { Squares }\end{array}$ & df & $\begin{array}{r}\text { Mean } \\
\text { Square }\end{array}$ & F & Sig. \\
\hline RECOVERY & 321.344 & 4 & 80.336 & 76.017 & .000 \\
\hline RECOVERY * AGEGROUP & 21.500 & 4 & 5.375 & 5.086 & .001 \\
\hline RECOVERY * FEARGRP & 1.294 & 4 & .323 & .306 & .874 \\
\hline RECOVERY * AGEGROUP $*$ FEARGRP $^{*}$ & 4.020 & 4 & 1.005 & .951 & .435 \\
\hline Error(RECOVERY) & 295.909 & 280 & 1.057 & & \\
\hline
\end{tabular}

Tests of Between-Subjects Effects

\begin{tabular}{|r|r|r|r|r|r|}
\hline Source & $\begin{array}{r}\text { Type III Sum } \\
\text { of Squares }\end{array}$ & df & Mean Square & F & Sig. \\
\hline AGEGROUP & 138.822 & 1 & 138.822 & 10.361 & .002 \\
\hline FEARGRP & 12.803 & 1 & 12.803 & .956 & .332 \\
\hline AGEGROUP $*$ FEARGRP & 26.077 & 1 & 26.077 & 1.946 & .167 \\
\hline Error & 937.902 & 70 & 13.399 & & \\
\hline
\end{tabular}


Table I25

$\underline{2 \text { (Age) } \times 2 \text { (Fear) x } 5 \text { (Interval) ANOVA Summary Table for Post-Stroop Task Skin Conductance Responses }}$

Tests of Within-Subjects Effects

\begin{tabular}{|r|r|r|r|r|r|}
\hline Source & $\begin{array}{r}\text { Type III } \\
\text { Sum of } \\
\text { Squares }\end{array}$ & df & $\begin{array}{r}\text { Mean } \\
\text { Square }\end{array}$ & F & Sig. \\
\hline RECOVERY & 113.074 & 4 & 28.269 & 12.598 & .000 \\
\hline RECOVERY * AGEGROUP & 20.903 & 4 & 5.226 & 2.329 & .056 \\
\hline RECOVERY * FEARGRP & 2.536 & 4 & .634 & .283 & .889 \\
\hline RECOVERY * AGEGROUP * FEARGRP & 18.323 & 4 & 4.581 & 2.041 & .089 \\
\hline Error(RECOVERY) & 610.358 & 272 & 2.244 & & \\
\hline
\end{tabular}

Tests of Between-Subjects Effects

\begin{tabular}{|r|r|r|r|r|r|}
\hline Source & $\begin{array}{r}\text { Type III } \\
\text { Sum of } \\
\text { Squares }\end{array}$ & df & Mean Square & F & Sig. \\
\hline AGEGROUP & 1.207 & 1 & 1.207 & .246 & .621 \\
\hline FEARGRP & 7.178 & 1 & 7.178 & 1.466 & .230 \\
\hline AGEGROUP * FEARGRP & $9.041 \mathrm{E}-02$ & 1 & $9.041 \mathrm{E}-02$ & .018 & .892 \\
\hline Error & 332.912 & 68 & 4.896 & & \\
\hline
\end{tabular}

Table I26

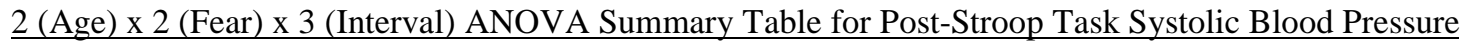

Tests of Within-Subjects Effects

\begin{tabular}{|r|r|r|r|r|r|}
\hline Source & $\begin{array}{r}\text { Type III Sum } \\
\text { of Squares }\end{array}$ & df & $\begin{array}{r}\text { Mean } \\
\text { Square }\end{array}$ & F & Sig. \\
\hline RECOVERY & 3.545 & 2 & 1.773 & .135 & .873 \\
\hline RECOVERY * AGEGROUP & 83.782 & 2 & 41.891 & 3.200 & .044 \\
\hline RECOVERY $*$ FEARGRP & 144.039 & 2 & 72.020 & 5.502 & .005 \\
\hline RECOVERY * AGEGROUP * FEARGRP & 175.821 & 2 & 87.910 & 6.716 & .002 \\
\hline Error(RECOVERY) & 1780.107 & 136 & 13.089 & & \\
\hline
\end{tabular}

Tests of Between-Subjects Effects

\begin{tabular}{|r|r|r|r|r|r|}
\hline Source & Type III Sum of & $\mathrm{df}$ & Mean Square & $\mathrm{F}$ & Sig. \\
& Square & & & & \\
\hline AGEGROUP & 7073.745 & 1 & 7073.745 & 22.409 & .000 \\
\hline FEARGRP & 42.924 & 1 & 42.924 & .136 & .713 \\
\hline AGEGROUP * FEARGRP & 245.870 & 1 & 245.870 & .779 & .381 \\
\hline Error & 21465.061 & 68 & 315.663 & & \\
\hline
\end{tabular}


Table I27

2 (Age) x 2 (Fear) x 3 (Interval) ANOVA Summary Table for Post-Stroop Task Diastolic Blood Pressure

Tests of Within-Subjects Effects

\begin{tabular}{|r|r|r|r|r|r|}
\hline Source & $\begin{array}{r}\text { Type III } \\
\text { Sum of } \\
\text { Squares }\end{array}$ & df & $\begin{array}{r}\text { Mean } \\
\text { Square }\end{array}$ & F & Sig. \\
\hline RECOVERY & 70.466 & 2 & 35.233 & 2.106 & .126 \\
\hline RECOVERY * AGEGROUP & 81.328 & 2 & 40.664 & 2.430 & .092 \\
\hline RECOVERY * FEARGRP & 42.967 & 2 & 21.484 & 1.284 & .280 \\
\hline RECOVERY * AGEGROUP * FEARGRP & 49.638 & 2 & 24.819 & 1.483 & .231 \\
\hline Error(RECOVERY) & 2242.222 & 134 & 16.733 & & \\
\hline
\end{tabular}

Tests of Between-Subjects Effects

\begin{tabular}{|r|r|r|r|r|r|}
\hline Source & $\begin{array}{r}\text { Type III Sum of } \\
\text { Squares }\end{array}$ & df & Mean Square & F & Sig. \\
\hline AGEGROUP & 1718.214 & 1 & 1718.214 & 8.561 & .005 \\
\hline FEARGRP & 211.583 & 1 & 211.583 & 1.054 & .308 \\
\hline AGEGROUP $*$ FEARGRP & 161.056 & 1 & 161.056 & .802 & .374 \\
\hline ERROR & 13446.874 & 67 & 200.700 & & \\
\hline
\end{tabular}


Table 1

$\underline{\text { Means (and Standard Deviations) for Age, Education, and Health Behaviors }}$

\begin{tabular}{|c|c|c|c|c|c|c|}
\hline & \multicolumn{3}{|c|}{ Younger Adults } & \multicolumn{3}{|c|}{ Older Adults } \\
\hline & $\begin{array}{l}\text { Low Fear } \\
(\mathrm{n}=19)\end{array}$ & $\begin{array}{l}\text { High Fear } \\
(\mathrm{n}=27)\end{array}$ & $\begin{array}{l}\text { Young } \\
(\mathrm{n}=46)\end{array}$ & $\begin{array}{l}\text { Low Fear } \\
(\mathrm{n}=11)\end{array}$ & $\begin{array}{l}\text { High Fear } \\
(\mathrm{n}=17)\end{array}$ & $\begin{array}{c}\text { Old } \\
(\mathrm{n}=28)\end{array}$ \\
\hline Age [yrs] & $\begin{array}{l}20.2 \\
(2.38)\end{array}$ & $\begin{array}{l}19.6 \\
(2.79)\end{array}$ & $\begin{array}{l}19.8^{\mathrm{e}} \\
(2.62)\end{array}$ & $\begin{array}{l}72.7 \\
(4.52)\end{array}$ & $\begin{array}{l}71.8 \\
(4.19)\end{array}$ & $\begin{array}{l}72.1^{f} \\
(4.26)\end{array}$ \\
\hline Education & 13.7 & 13.7 & 13.7 & 15.4 & 13.2 & 14.3 \\
\hline [yrs] & (1.37) & (1.39) & $(1.37)$ & $(2.25)$ & (3.03) & (1.90) \\
\hline Body Mass & 24.67 & 24.35 & $24.48^{\mathrm{e}}$ & 29.07 & 27.12 & $27.89^{f}$ \\
\hline Index $\left[\mathrm{kg} / \mathrm{m}^{2}\right]$ & $(4.57)$ & $(3.28)$ & $(3.82)$ & (4.07) & $(4.51)$ & $(4.51)$ \\
\hline Tobacco Use & 4.8 & 3.1 & $3.9^{\mathrm{a}}$ & 0.0 & 1.2 & $.77^{\mathrm{b}}$ \\
\hline [cigarettes/day] & (8.99) & $(6.76)$ & (7.73) & $(0.0)$ & $(5.00)$ & $(3.92)$ \\
\hline Alcohol Use & 4.4 & 4.5 & $4.4^{\mathrm{c}}$ & 1.4 & .89 & $1.1^{\mathrm{d}}$ \\
\hline [cups/week] & (6.11) & $(4.32)$ & $(5.05)$ & $(2.98)$ & $(1.50)$ & $(2.23)$ \\
\hline Exercise & 4.6 & 4.3 & 4.4 & 4.1 & 7.0 & 5.8 \\
\hline [hours/week] & (4.94) & $(6.35)$ & (5.74) & (3.13) & (12.04) & $(9.35)$ \\
\hline Caffeine Use & 2.4 & 2.4 & 2.4 & 3.0 & 3.1 & 3.1 \\
\hline [cups/day] & $(1.95)$ & $(1.60)$ & $(1.73)$ & (1.73) & (1.87) & (1.78) \\
\hline Liquid Intake & 8.5 & 7.4 & 7.9 & 6.9 & 8.4 & 7.8 \\
\hline [cups/day] & (3.34) & (2.87) & (3.09) & $(2.28)$ & (3.86) & (3.38) \\
\hline
\end{tabular}

Note. Significant main effects for Age are depicted by different superscripts. Means designated with ab superscripts represent significant group differences at $\mathrm{p} \leq .05$. Means designated with cd superscripts represent significant group differences at $\underline{p} \leq .01$. Means designated with ef superscripts represent significant group differences at $\mathrm{p} \leq .001$. 
Table 2

$\underline{\text { Frequencies (and Percentages) for Categorical Demographic Information }}$

\begin{tabular}{|c|c|c|c|c|c|c|}
\hline \multirow[b]{2}{*}{ Variables } & \multicolumn{3}{|c|}{ Younger Adults } & \multicolumn{3}{|c|}{ Older Adults } \\
\hline & $\begin{array}{l}\text { Low Fear } \\
(\mathrm{n}=19)\end{array}$ & $\begin{array}{c}\text { High Fear } \\
(\mathrm{n}=27)\end{array}$ & $\begin{array}{l}\text { Young } \\
(\mathrm{n}=46)\end{array}$ & $\begin{array}{l}\text { Low Fear } \\
(\mathrm{n}=11)\end{array}$ & $\begin{array}{c}\text { High Fear } \\
(\mathrm{n}=17)\end{array}$ & $\begin{array}{c}\text { Old } \\
(\mathrm{n}=28)\end{array}$ \\
\hline \multicolumn{7}{|l|}{ Race/Ethnicity } \\
\hline Caucasian & $\begin{array}{c}18 \\
(94.7 \%)\end{array}$ & $\begin{array}{c}23 \\
(85.2 \%)\end{array}$ & $\begin{array}{c}41 \\
(89.1 \%)\end{array}$ & $\begin{array}{c}11 \\
(100 \%)\end{array}$ & $\begin{array}{c}17 \\
(100 \%)\end{array}$ & $\begin{array}{c}28 \\
(100 \%)\end{array}$ \\
\hline Black & -- & $\begin{array}{c}3 \\
(11.1 \%)\end{array}$ & $\begin{array}{c}3 \\
(6.5 \%)\end{array}$ & -- & -- & -- \\
\hline Hispanic & -- & $\begin{array}{c}1 \\
(3.7 \%)\end{array}$ & $\begin{array}{c}1 \\
(2.2 \%)\end{array}$ & -- & -- & -- \\
\hline Asian & $\begin{array}{c}1 \\
(5.3 \%)\end{array}$ & -- & $\begin{array}{c}1 \\
(2.2 \%)\end{array}$ & -- & -- & -- \\
\hline \multicolumn{7}{|l|}{ Marital Status* } \\
\hline single & $\begin{array}{c}18 \\
(94.7 \%)\end{array}$ & $\begin{array}{c}25 \\
(92.6 \%)\end{array}$ & $\begin{array}{c}43 \\
(93.5 \%)\end{array}$ & -- & $\begin{array}{c}1 \\
(5.9 \%)\end{array}$ & $\begin{array}{c}1 \\
(3.6 \%)\end{array}$ \\
\hline married & -- & -- & -- & $\begin{array}{c}4 \\
(36.4 \%)\end{array}$ & $\begin{array}{c}10 \\
(58.8 \%)\end{array}$ & $\begin{array}{c}1 \\
(5.9 \%)\end{array}$ \\
\hline divorced & $\begin{array}{c}1 \\
(5.3 \%)\end{array}$ & -- & $\begin{array}{c}1 \\
(2.2 \%)\end{array}$ & $\begin{array}{c}3 \\
(27.3 \%)\end{array}$ & $\begin{array}{c}1 \\
(5.9 \%)\end{array}$ & $\begin{array}{c}4 \\
(14.3 \%)\end{array}$ \\
\hline widowed & -- & -- & -- & $\begin{array}{c}4 \\
(36.4 \%)\end{array}$ & $\begin{array}{c}5 \\
(29.4 \%)\end{array}$ & $\begin{array}{c}9 \\
(32.1 \%)\end{array}$ \\
\hline partnered & -- & $\begin{array}{c}2 \\
(7.4 \%)\end{array}$ & $\begin{array}{c}2 \\
(4.3 \%)\end{array}$ & -- & -- & -- \\
\hline
\end{tabular}

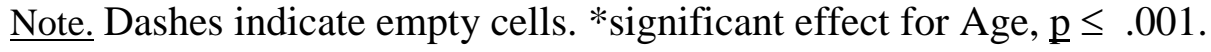


Table 3

Frequencies for Medical Conditions, Prescription Medications Use, Nonprescription Medication Use, and Psychiatric History.

\begin{tabular}{|c|c|c|c|c|c|c|}
\hline \multirow[b]{2}{*}{ Variables } & \multicolumn{3}{|c|}{ Younger Adults } & \multicolumn{3}{|c|}{ Older Adults } \\
\hline & $\begin{array}{l}\text { Low Fear } \\
(\mathrm{n}=19)\end{array}$ & $\begin{array}{l}\text { High Fear } \\
(\mathrm{n}=27)\end{array}$ & $\begin{array}{l}\text { Young } \\
(n=46)\end{array}$ & $\begin{array}{l}\text { Low Fear } \\
(\mathrm{n}=11)\end{array}$ & $\begin{array}{l}\text { High Fear } \\
(\mathrm{n}=17)\end{array}$ & $\begin{array}{c}\text { Old } \\
(\mathrm{n}=28)\end{array}$ \\
\hline \multicolumn{7}{|l|}{ Chronic Medical } \\
\hline \multicolumn{7}{|l|}{ Condition* } \\
\hline None & 17 & 24 & 41 & 5 & 7 & 12 \\
\hline Allergy & 1 & -- & 1 & -- & -- & -- \\
\hline Arthritis & -- & -- & -- & -- & 1 & 1 \\
\hline Asthma & 1 & 1 & 2 & -- & 1 & 1 \\
\hline Diabetes & -- & -- & -- & -- & 1 & 1 \\
\hline High Cholesterol & -- & -- & -- & -- & 1 & 1 \\
\hline Hodgkin's Disease & -- & 1 & 1 & -- & -- & -- \\
\hline Hypertension & -- & -- & -- & 2 & 2 & 4 \\
\hline Hypothyroidism & -- & 1 & 1 & 2 & 4 & 6 \\
\hline Parkinson's Disease & -- & -- & -- & 1 & -- & 1 \\
\hline Ulcer & -- & -- & -- & 1 & -- & 1 \\
\hline \multicolumn{7}{|l|}{ Prescription Medication** } \\
\hline None & 12 & 18 & 30 & 5 & 2 & 7 \\
\hline Diuretic (hydrothiazide, & -- & 1 & 1 & 2 & 2 & 4 \\
\hline
\end{tabular}




\begin{tabular}{|c|c|c|c|c|c|c|}
\hline \multirow[b]{2}{*}{ Variables } & \multicolumn{3}{|c|}{ Younger Adults } & \multicolumn{3}{|c|}{ Older Adults } \\
\hline & $\begin{array}{l}\text { Low Fear } \\
(\mathrm{n}=19)\end{array}$ & $\begin{array}{l}\text { High Fear } \\
(\mathrm{n}=27)\end{array}$ & $\begin{array}{l}\text { Young } \\
(\mathrm{n}=46)\end{array}$ & $\begin{array}{l}\text { Low Fear } \\
(\mathrm{n}=11)\end{array}$ & $\begin{array}{l}\text { High Fear } \\
(\mathrm{n}=17)\end{array}$ & $\begin{array}{c}\text { Old } \\
(n=28)\end{array}$ \\
\hline Birth Control/Estrogen & 7 & 5 & 12 & 1 & 3 & 4 \\
\hline $\begin{array}{l}\text { Allergy (Claritan, } \\
\text { Allegra) }\end{array}$ & 1 & 1 & 2 & -- & -- & -- \\
\hline Inhaler (asthma) & -- & 1 & 1 & -- & -- & -- \\
\hline $\begin{array}{l}\text { Synthroid } \\
\text { (hypothyroidism) }\end{array}$ & -- & 1 & 1 & 2 & 6 & 8 \\
\hline Anti-inflammatory & & & & & & \\
\hline $\begin{array}{l}\text { (Veldeeri, Plaquenel, } \\
\text { Arthrotec) }\end{array}$ & -- & -- & -- & -- & 1 & 1 \\
\hline $\begin{array}{l}\text { Gastrointestinal } \\
\text { (Prilosec, Sucralfate) }\end{array}$ & -- & -- & -- & 1 & -- & 1 \\
\hline $\begin{array}{l}\text { Fenofibrate } \\
\text { (cholesterol) }\end{array}$ & -- & -- & -- & -- & 1 & 1 \\
\hline Levodopa (Parkinsons & -- & -- & -- & 1 & -- & 1 \\
\hline Disease) & & & & & & \\
\hline Ambien, amitriptylin, & -- & -- & -- & -- & 4 & 4 \\
\hline Paxil, Celexa (for sleep) & & & & & & \\
\hline Nonprescription Medication & & & & & & \\
\hline None & 16 & 20 & 36 & 9 & 13 & 22 \\
\hline Metabolife (diet) & 1 & 1 & 2 & -- & -- & -- \\
\hline Cold medication & 1 & 2 & 3 & -- & 1 & 1 \\
\hline
\end{tabular}




\begin{tabular}{|c|c|c|c|c|c|c|}
\hline \multirow{2}{*}{ Variables } & \multicolumn{3}{|c|}{ Younger Adults } & \multicolumn{3}{|c|}{ Older Adults } \\
\hline & $\begin{array}{l}\text { Low Fear } \\
(\mathrm{n}=19)\end{array}$ & $\begin{array}{l}\text { High Fear } \\
(\mathrm{n}=27)\end{array}$ & $\begin{array}{l}\text { Young } \\
(n=46)\end{array}$ & $\begin{array}{l}\text { Low Fear } \\
(\mathrm{n}=11)\end{array}$ & $\begin{array}{c}\text { High Fear } \\
(\mathrm{n}=17)\end{array}$ & $\begin{array}{c}\text { Old } \\
(\mathrm{n}=28)\end{array}$ \\
\hline \multicolumn{7}{|l|}{ (Actifed, Tylenol PM, } \\
\hline Aspirin & -- & -- & -- & -- & 1 & 1 \\
\hline Allergy medication & -- & -- & -- & -- & 1 & 1 \\
\hline Gingko-biloba & -- & -- & -- & -- & 1 & 1 \\
\hline \multicolumn{7}{|l|}{ Psychiatric History } \\
\hline None & 17 & 27 & 44 & 10 & 15 & 25 \\
\hline Depression & 1 & -- & 1 & 1 & 1 & 2 \\
\hline Parent-child conflict & 1 & -- & 1 & -- & -- & -- \\
\hline
\end{tabular}

Note. Dashes indicates empty cells. Significant effects for age are noted with astericks. $* p \leq$ $.05 . * * \mathrm{p} \leq .01$. 
Table 4

Means for FSS Item 39 (snakes), BAI, STAI, SNAQ, and Subjective Measures of Anxiety Ratings

\begin{tabular}{|c|c|c|c|c|c|c|}
\hline & \multicolumn{3}{|c|}{ Younger Adults } & \multicolumn{3}{|c|}{ Older Adults } \\
\hline & $\begin{array}{l}\text { Low Fear } \\
(\mathrm{n}=19)\end{array}$ & $\begin{array}{l}\text { High Fear } \\
(\mathrm{n}=27)\end{array}$ & $\begin{array}{l}\text { Young } \\
(\mathrm{n}=46)\end{array}$ & $\begin{array}{l}\text { Low Fear } \\
(\mathrm{n}=11)\end{array}$ & $\begin{array}{l}\text { High Fear (n } \\
=17)\end{array}$ & $\begin{array}{c}\text { Old } \\
(\mathrm{n}=28)\end{array}$ \\
\hline FSS item 39 & 1.8 & 6.4 & 4.5 & 2.0 & 6.0 & 4.4 \\
\hline [snakes] & $(.76)$ & $(.70)$ & (2.4) & $(.83)$ & $(.94)$ & $(.82)$ \\
\hline \multirow[t]{2}{*}{ SNAQ } & 5.5 & 17.5 & 12.6 & 6.0 & 16.6 & 12.4 \\
\hline & $(4.57)$ & $(5.69)$ & (7.95) & $(2.68)$ & $(7.45)$ & (7.97) \\
\hline \multirow[t]{2}{*}{ BAI } & 11.6 & 11.1 & 11.3 & 6.1 & 9.9 & 8.4 \\
\hline & (7.38) & (7.07) & (7.13) & $(4.75)$ & (7.09) & $(6.45)$ \\
\hline \multicolumn{7}{|l|}{ STAI-State } \\
\hline \multirow[t]{2}{*}{ Baseline } & 31.2 & 31.9 & 31.6 & 29.0 & 33.2 & 31.5 \\
\hline & $(9.67)$ & $(6.50)$ & (7.87) & (7.64) & $(8.26)$ & (8.16) \\
\hline \multirow[t]{2}{*}{ Snake video } & 29.5 & 41.7 & 36.7 & 28.2 & 37.8 & 34.0 \\
\hline & $(8.96)$ & (13.43) & (13.15) & $(9.41)$ & $(9.70)$ & (10.55) \\
\hline \multirow[t]{2}{*}{ Stroop task } & 39.9 & 49.0 & 45.2 & 31.9 & 35.5 & 34.1 \\
\hline & (12.27) & (13.46) & $(13.60)$ & $(9.02)$ & $(7.26)$ & $(8.03)$ \\
\hline \multicolumn{7}{|c|}{ Subjective anxiety } \\
\hline \multicolumn{7}{|l|}{ ratings $[\mathrm{mm}]$} \\
\hline \multirow[t]{2}{*}{ Snake video } & 13.7 & 42.8 & 30.8 & 8.7 & 48.7 & 33.0 \\
\hline & $(16.67)$ & (29.12) & (28.48) & $(9.16)$ & (29.56) & $(30.75)$ \\
\hline \multirow[t]{2}{*}{ Stroop task } & 35.3 & 59.3 & 49.4 & 21.0 & 36.5 & 30.4 \\
\hline & (20.39) & (28.59) & (24.14) & (22.01) & (28.59) & (26.89) \\
\hline
\end{tabular}


Note. FSS = Fear Survey Schedule. SNAQ = Snake Questionnaire. BAI = Beck Anxiety Inventory. STAI $=$ State Trait Anxiety Inventory. 
Table 5

Means (and Standard Deviations) for Measures of Performance on the Stroop Task and Snake Video

\begin{tabular}{|c|c|c|c|c|c|c|}
\hline & \multicolumn{3}{|c|}{ Younger Adults } & \multicolumn{3}{|c|}{ Older Adults } \\
\hline & $\begin{array}{l}\text { Low Fear } \\
(\mathrm{n}=19)\end{array}$ & $\begin{array}{l}\text { High Fear } \\
(\mathrm{n}=27)\end{array}$ & $\begin{array}{l}\text { Young } \\
(\mathrm{n}=46)\end{array}$ & $\begin{array}{l}\text { Low Fear } \\
(\mathrm{n}=11)\end{array}$ & $\begin{array}{l}\text { High Fear } \\
(\mathrm{n}=17)\end{array}$ & $\begin{array}{c}\text { Old } \\
(\mathrm{n}=28)\end{array}$ \\
\hline \multicolumn{7}{|l|}{ Stroop Task } \\
\hline Total number & 167.1 & 177.3 & 173.4 & 127.5 & 168.7 & 151.9 \\
\hline of responses & $(26.55)$ & $(38.56)$ & $(34.45)$ & $(25.22)$ & $(86.61)$ & $(70.61)$ \\
\hline Total number & 8.4 & 19.6 & 15.3 & 11.2 & 97.5 & 62.4 \\
\hline of errors & $(5.48)$ & (51.25) & (40.37) & (11.43) & (125.34) & (104.79) \\
\hline \multirow[t]{2}{*}{ Error ratio } & .05 & .10 & .07 & .09 & .43 & .30 \\
\hline & $(.03)$ & (.13) & $(.09)$ & (.19) & $(.42)$ & $(.37)$ \\
\hline \multicolumn{7}{|l|}{ Snake video } \\
\hline Total correct & 3.9 & 4.0 & 3.9 & 4.0 & 3.7 & 3.8 \\
\hline responses & $(.22)$ & $(.00)$ & (.14) & $(.00)$ & (.43) & $(.35)$ \\
\hline
\end{tabular}

Note. Error ratio was calculated as (total number of responses)/(total number of errors), with lower scores signifying fewer errors. The maximum possible score for the Snake video questionnaire was 4. 
Table 6

Means (and Standard Deviations) for Baseline One and Estimated Means (and Standard Error) for

$\underline{\text { Reactivity to Snake Video and Stroop Task for Heart Rate, Skin Conductance Level, Skin Conductance }}$

Response, Systolic Blood Pressure, and Diastolic Blood Pressure

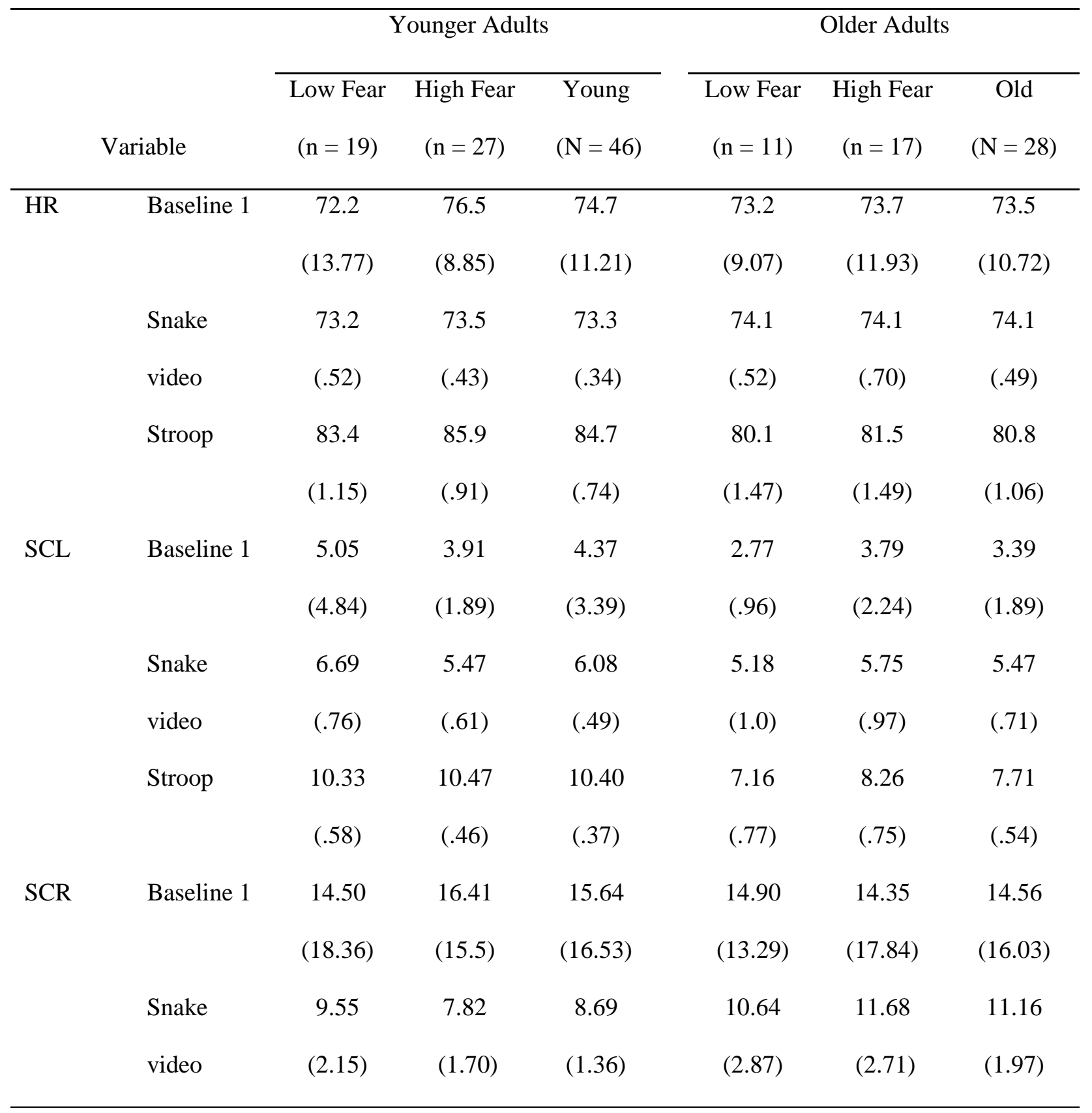




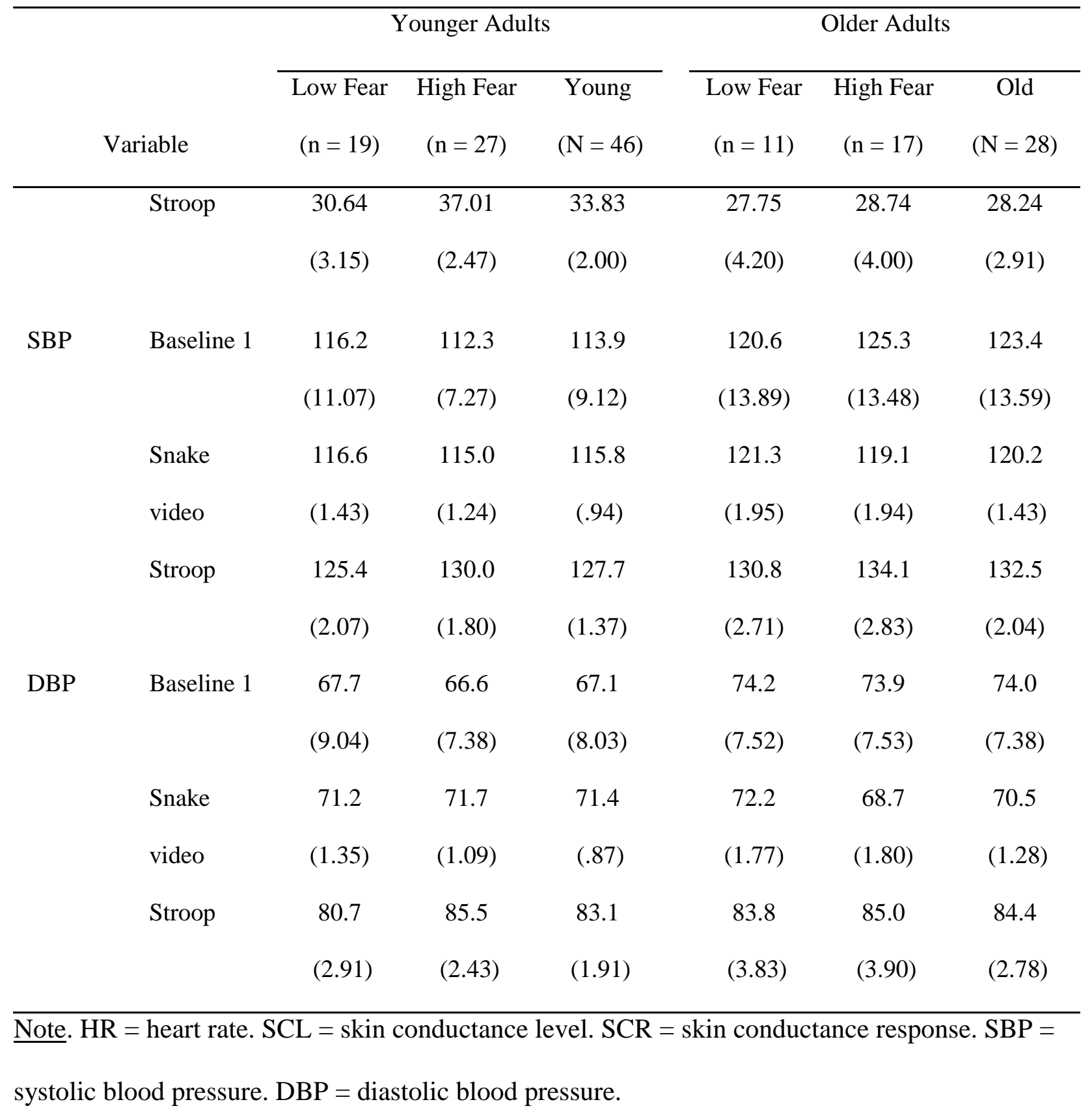




\section{Table 7}

Means (and Standard Deviations) for Heart Rate, Skin Conductance Level, Skin Conductance Response, $\underline{\text { Systolic Blood Pressure, and Diastolic Blood Pressure following Stroop Task and Snake Video }}$

\begin{tabular}{|c|c|c|c|c|c|c|c|}
\hline & & & ounger Adul & & & Older Adult & \\
\hline Variable & Interval & $\begin{array}{l}\text { Low Fear } \\
(\mathrm{n}=19)\end{array}$ & $\begin{array}{l}\text { High Fear } \\
(\mathrm{n}=27)\end{array}$ & $\begin{array}{l}\text { Young } \\
(\mathrm{N}=46)\end{array}$ & $\begin{array}{l}\text { Low Fear } \\
(\mathrm{n}=11)\end{array}$ & $\begin{array}{c}\text { High Fear } \\
(\mathrm{n}=17)\end{array}$ & $\begin{array}{c}\text { Old } \\
(\mathrm{N}=28)\end{array}$ \\
\hline HR & & & & & & & \\
\hline Snake video & minute 1 & $\begin{array}{c}74.1 \\
(12.16)\end{array}$ & $\begin{array}{c}77.2 \\
(8.86)\end{array}$ & $\begin{array}{c}75.9 \\
(10.34)\end{array}$ & $\begin{array}{l}72.5 \\
(7.95)\end{array}$ & $\begin{array}{c}72.8 \\
(11.83)\end{array}$ & $\begin{array}{c}72.7 \\
(10.32)\end{array}$ \\
\hline & minute 2 & $\begin{array}{c}74.1 \\
(12.22)\end{array}$ & $\begin{array}{l}76.7 \\
(8.70)\end{array}$ & $\begin{array}{c}75.6 \\
(10.26)\end{array}$ & $\begin{array}{l}71.9 \\
(7.90)\end{array}$ & $\begin{array}{c}72.7 \\
(11.78)\end{array}$ & $\begin{array}{c}72.4 \\
(10.27)\end{array}$ \\
\hline & minute 3 & 74.7 & 77.3 & 76.3 & 71.8 & 71.6 & 71.7 \\
\hline & & (12.60) & $(9.31)$ & (10.74) & $(8.07)$ & (11.99) & (10.45) \\
\hline & minute 4 & 74.2 & 77.0 & 75.9 & 72.2 & 72.0 & 72.1 \\
\hline & & (12.19) & $(9.47)$ & (10.65) & $(8.47)$ & (11.92) & $(10.52)$ \\
\hline & minute 5 & 74.5 & 76.8 & 75.8 & 72.2 & 71.7 & 71.9 \\
\hline & & (12.91) & $(9.08)$ & (10.75) & (8.09) & (11.92) & $(10.42)$ \\
\hline Stroop task & minute 1 & 71.1 & 76.2 & 74.1 & 72.6 & 72.3 & 72.4 \\
\hline & & (12.95) & $(9.93)$ & (11.38) & (7.74) & (11.91) & (10.31) \\
\hline & minute 2 & 74.8 & 76.3 & 75.7 & 72.8 & 72.8 & 72.8 \\
\hline & & (10.25) & $(8.55)$ & $(9.18)$ & (7.96) & (11.91) & (10.37) \\
\hline & minute 3 & 75.8 & 77.4 & 76.8 & 73.0 & 75.0 & 75.0 \\
\hline & & (11.09) & $(9.53)$ & (10.09) & (11.74) & $(9.92)$ & $(9.92)$ \\
\hline & minute 4 & 75.3 & 76.4 & 75.9 & 74.2 & 72.3 & 73.0 \\
\hline & & (11.11) & $(8.75)$ & $(9.65)$ & $(7.75)$ & (11.91) & (10.36) \\
\hline & minute 5 & 75.5 & 76.8 & 76.3 & 70.5 & 72.7 & 71.9 \\
\hline & & (10.57) & $(8.34)$ & $(9.20)$ & (12.93) & (11.66) & (11.99) \\
\hline
\end{tabular}




\begin{tabular}{|c|c|c|c|c|c|c|c|}
\hline \multirow[b]{2}{*}{ Variable } & \multirow[b]{2}{*}{ Interval } & \multicolumn{3}{|c|}{ Younger Adults } & \multicolumn{3}{|c|}{ Older Adults } \\
\hline & & $\begin{array}{l}\text { Low Fear } \\
\qquad(\mathrm{n}=19)\end{array}$ & $\begin{array}{l}\text { High Fear } \\
(\mathrm{n}=27)\end{array}$ & $\begin{array}{l}\text { Young } \\
(\mathrm{N}=46)\end{array}$ & $\begin{array}{l}\text { Low Fear } \\
\qquad(\mathrm{n}=11)\end{array}$ & $\begin{array}{l}\text { High Fear } \\
(\mathrm{n}=17)\end{array}$ & $\begin{array}{c}\text { Old } \\
(\mathrm{N}=28)\end{array}$ \\
\hline \multicolumn{8}{|l|}{ SCL } \\
\hline \multirow[t]{10}{*}{ Snake video } & minute 1 & 6.90 & 6.41 & 6.61 & 3.03 & 5.21 & 4.35 \\
\hline & & $(6.91)$ & $(3.74)$ & $(5.22)$ & $(1.52)$ & $(4.45)$ & $(3.71)$ \\
\hline & minute 2 & 6.50 & 5.76 & 6.07 & 2.77 & 4.91 & 4.07 \\
\hline & & $(6.45)$ & $(3.47)$ & $(4.87)$ & $(1.15)$ & $(4.06)$ & $(3.38)$ \\
\hline & minute 3 & 6.37 & 5.35 & 5.77 & 2.64 & 4.80 & 3.95 \\
\hline & & $(6.39)$ & $(3.35)$ & $(4.80)$ & $(1.15)$ & $(4.06)$ & $(3.38)$ \\
\hline & minute 4 & 6.23 & 5.16 & 5.60 & 2.66 & 4.64 & 3.86 \\
\hline & & $(6.55)$ & $(3.35)$ & $(4.89)$ & $(1.05)$ & $(3.64)$ & $(3.03)$ \\
\hline & minute 5 & 5.90 & 5.01 & 5.38 & 2.62 & 4.55 & 3.79 \\
\hline & & $(6.32)$ & $(3.28)$ & $(4.73)$ & $(1.04)$ & $(3.61)$ & $(3.01)$ \\
\hline \multirow[t]{10}{*}{ Stroop task } & minute 1 & 10.18 & 9.66 & 9.88 & 5.33 & 7.47 & 6.63 \\
\hline & & $(4.96)$ & $(3.76)$ & $(4.25)$ & $(2.66)$ & $(3.27)$ & $(3.18)$ \\
\hline & minute 2 & 9.19 & 8.69 & 8.90 & 4.47 & 6.80 & 5.89 \\
\hline & & $(5.29)$ & $(3.72)$ & $(4.39)$ & $(2.27)$ & $(3.17)$ & $(3.04)$ \\
\hline & minute 3 & 8.21 & 7.63 & 7.87 & 3.90 & 6.13 & 5.26 \\
\hline & & $(5.37)$ & $(3.51)$ & $(4.33)$ & $(1.75)$ & $(3.14)$ & $(2.87)$ \\
\hline & minute 4 & 7.50 & 6.95 & 7.18 & 3.65 & 5.65 & 4.87 \\
\hline & & $(5.26)$ & $(3.63)$ & $(4.33)$ & $(1.85)$ & $(3.11)$ & $(2.83)$ \\
\hline & minute 5 & 6.32 & 6.59 & 6.48 & 3.39 & 5.30 & 4.55 \\
\hline & & (3.60) & (3.73) & (3.64) & $(2.01)$ & (3.19) & $(2.90)$ \\
\hline \multicolumn{8}{|l|}{ SCR } \\
\hline \multirow[t]{2}{*}{ Snake video } & minute 1 & 1.94 & 2.48 & 2.27 & 1.60 & 2.35 & 2.07 \\
\hline & & (2.36) & $(2.65)$ & (2.53) & (1.58) & (3.57) & (2.98) \\
\hline
\end{tabular}




\begin{tabular}{|c|c|c|c|c|c|c|c|}
\hline \multirow[b]{2}{*}{ Variable } & \multirow[b]{2}{*}{ Interval } & \multicolumn{3}{|c|}{ Younger Adults } & \multicolumn{3}{|c|}{ Older Adults } \\
\hline & & $\begin{array}{l}\text { Low Fear } \\
(\mathrm{n}=19)\end{array}$ & $\begin{array}{l}\text { High Fear } \\
(\mathrm{n}=27)\end{array}$ & $\begin{array}{l}\text { Young } \\
(\mathrm{N}=46)\end{array}$ & $\begin{array}{l}\text { Low Fear } \\
(\mathrm{n}=11)\end{array}$ & $\begin{array}{l}\text { High Fear } \\
(\mathrm{n}=17)\end{array}$ & $\begin{array}{c}\text { Old } \\
(\mathrm{N}=28)\end{array}$ \\
\hline & minute 2 & $\begin{array}{c}1.72 \\
(1.99)\end{array}$ & $\begin{array}{c}2.33 \\
(2.62)\end{array}$ & $\begin{array}{c}2.09 \\
(2.38)\end{array}$ & $\begin{array}{c}1.50 \\
(1.78)\end{array}$ & $\begin{array}{l}2.18 \\
(2.92)\end{array}$ & $\begin{array}{c}1.93 \\
(2.54)\end{array}$ \\
\hline & minute 3 & 1.44 & 1.96 & 1.76 & 1.10 & 2.12 & 1.74 \\
\hline & & $(2.09)$ & $(2.17)$ & $(2.13)$ & (1.11) & $(3.50)$ & $(2.86)$ \\
\hline & minute 4 & 1.33 & 1.93 & 1.69 & 2.10 & 1.65 & 1.82 \\
\hline & & $(1.85)$ & $(2.32)$ & $(2.14)$ & (3.67) & $(2.98)$ & (3.19) \\
\hline & minute 5 & .78 & 1.70 & 1.33 & .80 & 1.65 & 1.33 \\
\hline & & $(1.44)$ & $(2.11)$ & $(1.91)$ & $(1.91)$ & $(2.96)$ & $(2.45)$ \\
\hline \multirow[t]{10}{*}{ Stroop task } & minute 1 & 2.61 & 2.44 & 2.51 & 1.50 & 3.29 & 2.63 \\
\hline & & $(2.28)$ & $(2.53)$ & $(2.41)$ & $(1.84)$ & $(4.07)$ & $(3.49)$ \\
\hline & minute 2 & 1.56 & 2.11 & 1.89 & 2.60 & 3.12 & 2.93 \\
\hline & & $(1.42)$ & $(2.24)$ & (1.96) & $(3.37)$ & $(5.01)$ & $(4.41)$ \\
\hline & minute 3 & .78 & 1.89 & 1.44 & 1.90 & 2.29 & 2.15 \\
\hline & & $(1.00)$ & $(2.71)$ & $(2.24)$ & $(2.38)$ & $(3.55)$ & $(3.12)$ \\
\hline & minute 4 & .83 & 1.63 & 1.31 & .60 & 1.53 & 1.19 \\
\hline & & (1.15) & (1.93) & (1.69) & $(.97)$ & $(3.57)$ & $(2.89)$ \\
\hline & minute 5 & .72 & 1.41 & 1.13 & .90 & 1.0 & .78 \\
\hline & & (1.18) & $(1.85)$ & $(1.63)$ & $(1.63)$ & $(1.91)$ & $(2.72)$ \\
\hline \multicolumn{8}{|l|}{ SBP } \\
\hline \multirow[t]{4}{*}{ Snake video } & minute 1 & 116.0 & 112.0 & 113.6 & 122.3 & 128.4 & 125.9 \\
\hline & & $(9.46)$ & $(8.69)$ & $(9.14)$ & (13.50) & (12.83) & $(13.20)$ \\
\hline & minute 2 & 114.3 & 113.2 & 113.7 & 122.2 & 126.5 & 124.8 \\
\hline & & (6.76) & $(8.89)$ & $(8.02)$ & (15.56) & (12.99) & (13.97) \\
\hline
\end{tabular}




\begin{tabular}{|c|c|c|c|c|c|c|c|}
\hline \multirow{2}{*}{ Variable } & \multirow[b]{2}{*}{ Interval } & \multicolumn{3}{|c|}{ Younger Adults } & \multicolumn{3}{|c|}{ Older Adults } \\
\hline & & $\begin{array}{c}\text { Low Fear } \\
(\mathrm{n}=19)\end{array}$ & $\begin{array}{l}\text { High Fear } \\
(\mathrm{n}=27)\end{array}$ & $\begin{array}{l}\text { Young } \\
(\mathrm{N}=46)\end{array}$ & $\begin{array}{l}\text { Low Fear } \\
(\mathrm{n}=11)\end{array}$ & $\begin{array}{l}\text { High Fear } \\
(\mathrm{n}=17)\end{array}$ & $\begin{array}{c}\text { Old } \\
(\mathrm{N}=28)\end{array}$ \\
\hline & minute 3 & $\begin{array}{c}114.4 \\
(10.15)\end{array}$ & $\begin{array}{c}109.8 \\
(12.77)\end{array}$ & $\begin{array}{l}111.7 \\
(11.86)\end{array}$ & $\begin{array}{c}122.8 \\
(13.14)\end{array}$ & $\begin{array}{c}129.1 \\
(13.61)\end{array}$ & $\begin{array}{l}126.5 \\
(13.54)\end{array}$ \\
\hline Stroop task & minute 1 & $\begin{array}{l}117.5 \\
(8.88)\end{array}$ & $\begin{array}{l}113.6 \\
(9.84)\end{array}$ & $\begin{array}{l}115.3 \\
(9.54)\end{array}$ & $\begin{array}{c}124.1 \\
(12.46)\end{array}$ & $\begin{array}{l}130.0 \\
(13.65)\end{array}$ & $\begin{array}{r}127.6 \\
(13.26)\end{array}$ \\
\hline & minute 2 & $\begin{array}{l}116.8 \\
(9.31)\end{array}$ & $\begin{array}{l}114.7 \\
(8.84)\end{array}$ & $\begin{array}{l}115.6 \\
(9.01)\end{array}$ & $\begin{array}{l}126.0 \\
(11.61)\end{array}$ & $\begin{array}{c}127.0 \\
(13.66)\end{array}$ & $\begin{array}{c}126.6 \\
(12.64)\end{array}$ \\
\hline & minute 3 & $\begin{array}{l}116.3 \\
(9.65)\end{array}$ & $\begin{array}{l}112.8 \\
(7.56)\end{array}$ & $\begin{array}{l}114.3 \\
(8.58)\end{array}$ & $\begin{array}{c}129.8 \\
(13.30)\end{array}$ & $\begin{array}{c}127.0 \\
(12.96)\end{array}$ & $\begin{array}{c}128.1 \\
(12.92)\end{array}$ \\
\hline DBP & & & & & & & \\
\hline Snake video & minute 1 & $\begin{array}{c}71.1 \\
(10.19)\end{array}$ & $\begin{array}{r}69.5 \\
(8.98)\end{array}$ & $\begin{array}{c}70.2 \\
(9.42)\end{array}$ & $\begin{array}{r}74.2 \\
(7.77)\end{array}$ & $\begin{array}{l}74.3 \\
(8.33)\end{array}$ & $\begin{array}{r}74.3 \\
(7.95)\end{array}$ \\
\hline & minute 2 & $\begin{array}{c}67.2 \\
(9.31)\end{array}$ & $\begin{array}{c}70.1 \\
(12.19)\end{array}$ & $\begin{array}{c}68.9 \\
(11.07)\end{array}$ & $\begin{array}{c}74.0 \\
(8.31)\end{array}$ & $\begin{array}{c}75.0 \\
(7.33)\end{array}$ & $\begin{array}{c}74.6 \\
(7.60)\end{array}$ \\
\hline & minute 3 & $\begin{array}{c}67.8 \\
(11.17)\end{array}$ & $\begin{array}{c}70.8 \\
(13.22)\end{array}$ & $\begin{array}{c}69.5 \\
(12.37)\end{array}$ & $\begin{array}{c}73.3 \\
(7.61)\end{array}$ & $\begin{array}{l}73.7 \\
(6.70)\end{array}$ & $\begin{array}{c}73.5 \\
(6.93)\end{array}$ \\
\hline Stroop task & minute 1 & $\begin{array}{l}69.4 \\
(7.61)\end{array}$ & $\begin{array}{c}69.0 \\
(8.06)\end{array}$ & $\begin{array}{c}69.1 \\
(7.79)\end{array}$ & $\begin{array}{c}74.5 \\
(6.86)\end{array}$ & $\begin{array}{l}73.3 \\
(7.48)\end{array}$ & $\begin{array}{c}73.8 \\
(7.13)\end{array}$ \\
\hline & minute 2 & $\begin{array}{c}70.5 \\
(9.34)\end{array}$ & $\begin{array}{c}69.6 \\
(10.37)\end{array}$ & $\begin{array}{c}70.0 \\
(9.85)\end{array}$ & $\begin{array}{c}78.0 \\
(8.65)\end{array}$ & $\begin{array}{c}72.8 \\
(8.52)\end{array}$ & $\begin{array}{c}74.9 \\
(8.79)\end{array}$ \\
\hline & minute 3 & $\begin{array}{l}67.3 \\
(9.12)\end{array}$ & $\begin{array}{c}67.7 \\
(8.60)\end{array}$ & $\begin{array}{c}67.5 \\
(8.71)\end{array}$ & $\begin{array}{c}78.0 \\
(7.44)\end{array}$ & $\begin{array}{c}72.6 \\
(10.96)\end{array}$ & $\begin{array}{r}74.8 \\
(9.89)\end{array}$ \\
\hline
\end{tabular}

Note. $\mathrm{HR}=$ heart rate. $\mathrm{SCL}=$ skin conductance level. $\mathrm{SCR}=$ skin conductance response. $\mathrm{SBP}=$ systolic blood pressure. $\mathrm{DBP}=$ diastolic blood pressure. 
Table 8

Correlations Between Mean Physiological Variables (Baseline and Reactivity) and Measures of Fear and Anxiety.

\begin{tabular}{|c|c|c|c|c|c|c|c|}
\hline & $\begin{array}{l}\text { STAI-S } \\
\text { Baseline }\end{array}$ & $\begin{array}{l}\text { STAI-S } \\
\text { Snake }\end{array}$ & $\begin{array}{l}\text { STAI-S } \\
\text { Stroop }\end{array}$ & $\begin{array}{c}\text { Subjective } \\
\text { Ratings-Snake }\end{array}$ & $\begin{array}{c}\text { Subjective } \\
\text { Ratings-Stroop }\end{array}$ & BAI & SNAQ \\
\hline \multicolumn{8}{|l|}{ HR } \\
\hline Baseline & $\begin{array}{c}\underline{r}=-.13 \\
n=74\end{array}$ & $\begin{array}{l}\underline{r}=.06 \\
n=74\end{array}$ & $\begin{array}{c}\underline{r}=.25^{*} \\
\mathrm{n}=74\end{array}$ & $\begin{array}{l}\underline{\mathrm{r}}=.04 \\
\mathrm{n}=74\end{array}$ & $\begin{array}{c}\underline{\mathrm{r}}=.23^{*} \\
\mathrm{n}=74\end{array}$ & $\begin{array}{c}\underline{r}=-.06 \\
n=74\end{array}$ & $\begin{array}{l}\underline{\mathrm{r}}=.17 \\
\mathrm{n}=74\end{array}$ \\
\hline Snake Video & $\begin{array}{c}\mathrm{pr}=-.02 \\
\mathrm{n}=71\end{array}$ & $\begin{array}{c}\underline{\mathrm{pr}}=-.06 \\
\mathrm{n}=71\end{array}$ & $\begin{array}{c}\underline{\mathrm{pr}}=.02 \\
\mathrm{n}=71\end{array}$ & $\begin{array}{c}\mathrm{pr}=-.07 \\
\mathrm{n}=71\end{array}$ & $\begin{array}{c}\underline{\mathrm{pr}}=.08 \\
\mathrm{n}=71\end{array}$ & $\begin{array}{c}\underline{\mathrm{pr}}=.02 \\
\mathrm{n}=71\end{array}$ & $\begin{array}{c}\underline{\mathrm{pr}}=-06 \\
\mathrm{n}=71\end{array}$ \\
\hline Stroop Task & $\begin{array}{c}\mathrm{pr}=.02 \\
\mathrm{n}=70\end{array}$ & $\begin{aligned} \mathrm{pr} & =.13 \\
\mathrm{n} & =70\end{aligned}$ & $\begin{aligned} \underline{\mathrm{pr}} & =.27 * \\
\mathrm{n} & =70\end{aligned}$ & $\begin{array}{c}\mathrm{pr}=.03 \\
\mathrm{n}=70\end{array}$ & $\begin{aligned} \underline{\mathrm{pr}} & =.27 * \\
\mathrm{n} & =70\end{aligned}$ & $\begin{array}{c}\mathrm{pr}=.08 \\
\mathrm{n}=70\end{array}$ & $\begin{array}{c}\mathrm{pr}=.04 \\
\mathrm{n}=70\end{array}$ \\
\hline SCL & & & & & & & \\
\hline Baseline & $\begin{array}{c}\underline{r}=-.17 \\
n=73\end{array}$ & $\begin{array}{c}\underline{r}=-.10 \\
n=73\end{array}$ & $\begin{array}{l}\underline{\mathrm{r}}=.00 \\
\mathrm{n}=73\end{array}$ & $\begin{array}{c}\underline{r}=-.17 \\
n=73\end{array}$ & $\begin{array}{c}\underline{r}=-.07 \\
n=73\end{array}$ & $\begin{array}{l}\underline{r}=.01 \\
n=73\end{array}$ & $\begin{array}{c}\underline{r}=-.07 \\
n=73\end{array}$ \\
\hline Snake Video & $\begin{aligned} \mathrm{pr} & =.07 \\
\mathrm{n} & =69\end{aligned}$ & $\begin{aligned} \mathrm{pr} & =-.07 \\
\mathrm{n} & =69\end{aligned}$ & $\begin{array}{c}\mathrm{pr}=.00 \\
\mathrm{n}=69\end{array}$ & $\begin{array}{c}\mathrm{pr}=-.11 \\
\mathrm{n}=69\end{array}$ & $\begin{array}{c}\mathrm{pr}=.01 \\
\mathrm{n}=69\end{array}$ & $\begin{aligned} \mathrm{pr} & =.34^{* *} \\
\mathrm{n} & =69\end{aligned}$ & $\begin{array}{c}\mathrm{pr}=.02 \\
\mathrm{n}=69\end{array}$ \\
\hline Stroop Task & $\begin{array}{c}\mathrm{pr}=.17 \\
\mathrm{n}=71\end{array}$ & $\begin{array}{c}\mathrm{pr}=.01 \\
\mathrm{n}=71\end{array}$ & $\begin{array}{c}\mathrm{pr}=.21 \\
\mathrm{n}=71\end{array}$ & $\begin{array}{c}\mathrm{pr}=.01 \\
\mathrm{n}=71\end{array}$ & $\begin{array}{c}\mathrm{pr}=.13 \\
\mathrm{n}=71\end{array}$ & $\begin{array}{c}\mathrm{pr}=.02 \\
\mathrm{n}=71\end{array}$ & $\begin{array}{c}\mathrm{pr}=.03 \\
\mathrm{n}=71\end{array}$ \\
\hline SCR & & & & & & & \\
\hline Baseline & $\begin{array}{c}\underline{r}=-.01 \\
n=72\end{array}$ & $\begin{array}{l}\underline{r}=-.01 \\
n=72\end{array}$ & $\begin{array}{l}\underline{\mathrm{r}}=.07 \\
\mathrm{n}=72\end{array}$ & $\begin{array}{l}\underline{\mathrm{r}}=.07 \\
\mathrm{n}=72\end{array}$ & $\begin{array}{l}\underline{\mathrm{r}}=.07 \\
\mathrm{n}=72\end{array}$ & $\begin{array}{l}\underline{r}=.03 \\
n=72\end{array}$ & $\begin{array}{l}\underline{\mathrm{r}}=.03 \\
\mathrm{n}=72\end{array}$ \\
\hline Snake Video & $\begin{aligned} \mathrm{pr} & =-.06 \\
\mathrm{n} & =69\end{aligned}$ & $\begin{aligned} \mathrm{pr} & =.08 \\
\mathrm{n} & =69\end{aligned}$ & $\begin{array}{c}\mathrm{pr}=-.04 \\
\mathrm{n}=69\end{array}$ & $\begin{aligned} \mathrm{pr} & =.00 \\
\mathrm{n} & =69\end{aligned}$ & $\begin{aligned} \mathrm{pr} & =-.05 \\
\mathrm{n} & =69\end{aligned}$ & $\begin{aligned} \mathrm{pr} & =.24^{*} \\
\mathrm{n} & =69\end{aligned}$ & $\begin{array}{c}\mathrm{pr}=-.01 \\
\mathrm{n}=69\end{array}$ \\
\hline Stroop Task & $\begin{aligned} \mathrm{pr} & =.07 \\
\mathrm{n} & =69\end{aligned}$ & $\begin{aligned} \mathrm{pr} & =.00 \\
\mathrm{n} & =69\end{aligned}$ & $\begin{aligned} \mathrm{pr} & =.202 \\
\mathrm{n} & =69\end{aligned}$ & $\begin{array}{c}\mathrm{pr}=-.02 \\
\mathrm{n}=69\end{array}$ & $\begin{aligned} \mathrm{pr} & =.08 \\
\mathrm{n} & =69\end{aligned}$ & $\begin{array}{c}\mathrm{pr}=-.05 \\
\mathrm{n}=69\end{array}$ & $\begin{array}{c}\mathrm{pr}=.02 \\
\mathrm{n}=69\end{array}$ \\
\hline
\end{tabular}




\begin{tabular}{|c|c|c|c|c|c|c|c|}
\hline & $\begin{array}{l}\text { STAI-S } \\
\text { Baseline }\end{array}$ & $\begin{array}{l}\text { STAI-S } \\
\text { Snake }\end{array}$ & $\begin{array}{l}\text { STAI-S } \\
\text { Stroop }\end{array}$ & $\begin{array}{c}\text { Subjective } \\
\text { Ratings-Snake }\end{array}$ & $\begin{array}{c}\text { Subjective } \\
\text { Ratings-Stroop }\end{array}$ & BAI & SNAQ \\
\hline \multicolumn{8}{|l|}{ SBP } \\
\hline Baseline & $\begin{array}{l}\underline{r}=.07 \\
n=73\end{array}$ & $\begin{array}{l}\underline{\mathrm{r}}=-.09 \\
\mathrm{n}=73\end{array}$ & $\begin{array}{c}\underline{r}=-.29 * \\
n=73\end{array}$ & $\begin{array}{l}\underline{r}=.00 \\
n=73\end{array}$ & $\begin{array}{l}\underline{r}=-.06 \\
n=73\end{array}$ & $\begin{array}{c}\underline{r}=-.13 \\
n=73\end{array}$ & $\begin{array}{l}\underline{r}=.03 \\
n=73\end{array}$ \\
\hline Snake Video & $\begin{aligned} \mathrm{pr} & =-.14 \\
\mathrm{n} & =70\end{aligned}$ & $\begin{array}{c}\mathrm{pr}=-.09 \\
\mathrm{n}=70\end{array}$ & $\begin{aligned} \mathrm{pr} & =-.09 \\
\mathrm{n} & =70\end{aligned}$ & $\begin{array}{c}\mathrm{pr}=-.11 \\
\mathrm{n}=70\end{array}$ & $\begin{array}{c}\mathrm{pr}=-.17 \\
\mathrm{n}=70\end{array}$ & $\begin{array}{c}\mathrm{pr}=-.08 \\
\mathrm{n}=70\end{array}$ & $\begin{aligned} \mathrm{pr} & =-.20 \\
\mathrm{n} & =70\end{aligned}$ \\
\hline Stroop Task & $\begin{aligned} \underline{\mathrm{pr}} & =.02 \\
\mathrm{n} & =69\end{aligned}$ & $\begin{aligned} \underline{\mathrm{pr}} & =.02 \\
\mathrm{n} & =69\end{aligned}$ & $\begin{array}{c}\underline{\mathrm{pr}}=-.08 \\
\mathrm{n}=69\end{array}$ & $\begin{array}{c}\underline{\mathrm{pr}}=-.14 \\
\mathrm{n}=69\end{array}$ & $\begin{array}{c}\mathrm{pr}=-.19 \\
\mathrm{n}=69\end{array}$ & $\begin{aligned} \underline{\mathrm{pr}} & =-.07 \\
\mathrm{n} & =69\end{aligned}$ & $\begin{array}{c}\underline{\mathrm{pr}}=.21 \\
\mathrm{n}=69\end{array}$ \\
\hline DBP & & & & & & & \\
\hline Baseline & $\begin{array}{l}\underline{r}=.02 \\
n=73\end{array}$ & $\begin{array}{c}\underline{r}=-.09 \\
n=73\end{array}$ & $\begin{array}{c}\underline{r}=-.24 * \\
n=73\end{array}$ & $\begin{array}{c}\underline{r}=-.17 \\
n=73\end{array}$ & $\begin{array}{c}\underline{r}=-.12 \\
n=73\end{array}$ & $\begin{array}{c}\underline{r}=-.15 \\
n=73\end{array}$ & $\begin{array}{c}\underline{r}=-.14 \\
n=73\end{array}$ \\
\hline Snake Video & $\begin{array}{c}\mathrm{pr}=-.12 \\
\mathrm{n}=70\end{array}$ & $\begin{aligned} \mathrm{pr} & =.01 \\
\mathrm{n} & =70\end{aligned}$ & $\begin{aligned} \mathrm{pr} & =.04 \\
\mathrm{n} & =70\end{aligned}$ & $\begin{array}{c}\mathrm{pr}=-.22 \\
\mathrm{n}=70\end{array}$ & $\begin{aligned} \mathrm{pr} & =.00 \\
\mathrm{n} & =70\end{aligned}$ & $\begin{aligned} \mathrm{pr} & =.00 \\
\mathrm{n} & =70\end{aligned}$ & $\begin{array}{c}\mathrm{pr}=-.04 \\
\mathrm{n}=70\end{array}$ \\
\hline Stroop Task & $\begin{aligned} \mathrm{pr} & =.01 \\
\mathrm{n} & =69\end{aligned}$ & $\begin{aligned} \mathrm{pr} & =.07 \\
\mathrm{n} & =69\end{aligned}$ & $\begin{aligned} \mathrm{pr} & =.00 \\
\mathrm{n} & =69\end{aligned}$ & $\begin{aligned} \mathrm{pr} & =.16 \\
\mathrm{n} & =69\end{aligned}$ & $\begin{aligned} \mathrm{pr} & =.18 \\
\mathrm{n} & =69\end{aligned}$ & $\begin{array}{c}\mathrm{pr}=-.06 \\
\mathrm{n}=69\end{array}$ & $\begin{aligned} \mathrm{pr} & =.16 \\
\mathrm{n} & =69\end{aligned}$ \\
\hline
\end{tabular}

Note. $\mathrm{HR}=$ Heart rate. $\mathrm{SCL}=$ Skin conductance level. $\mathrm{SCR}=$ Skin conductance response. $\mathrm{SBP}=$ Systolic

Blood Pressure. DBP = Diastolic Blood Pressure. STAI-S = State Trait Anxiety Inventory-State.

Subjective Ratings-Snake $=$ Subjective anxiety ratings during snake video. Subjective Ratings-Stroop $=$ Subjective anxiety ratings during Stroop task. BAI = Beck Anxiety Inventory. SNAQ $=$ Snake

Questionnaire. ${ }^{*} \mathrm{p} \leq .05 .{ }^{* *} \mathrm{p} \leq .01$. 


\section{Figure Captions}

Figure 1. Age x Fear Interaction for Years of Education

Figure 2. Age x Fear Interaction for State Trait Anxiety Inventory-State

Figure 3. Age x Task Interaction for Subjective Anxiety Ratings

Figure 4. Fear x Task Interaction for Subjective Anxiety Ratings

Figure 5. Age x Task Interaction for Snake Video Questionnaire

Figure 6. Age x Fear Interaction for Stroop Task Error Ratio

Figure 7. Age x Task Interaction for Heart Rate Responses During Tasks

Figure 8. Age x Task Interaction for SCR Responses

Figure 9. Fear x Task for Systolic Blood Pressure Responses During Tasks

Figure 10. Age x Interval Interaction for Post-Stroop Task Skin Conductance Level Recovery

Figure 11. Age x Interval Interaction for SCR Recovery following the Stroop Task

Figure 12. Age x Fear x Interval Interaction for SBP during Recovery 
Figure 1.

Age x Fear Interaction for Years of Education

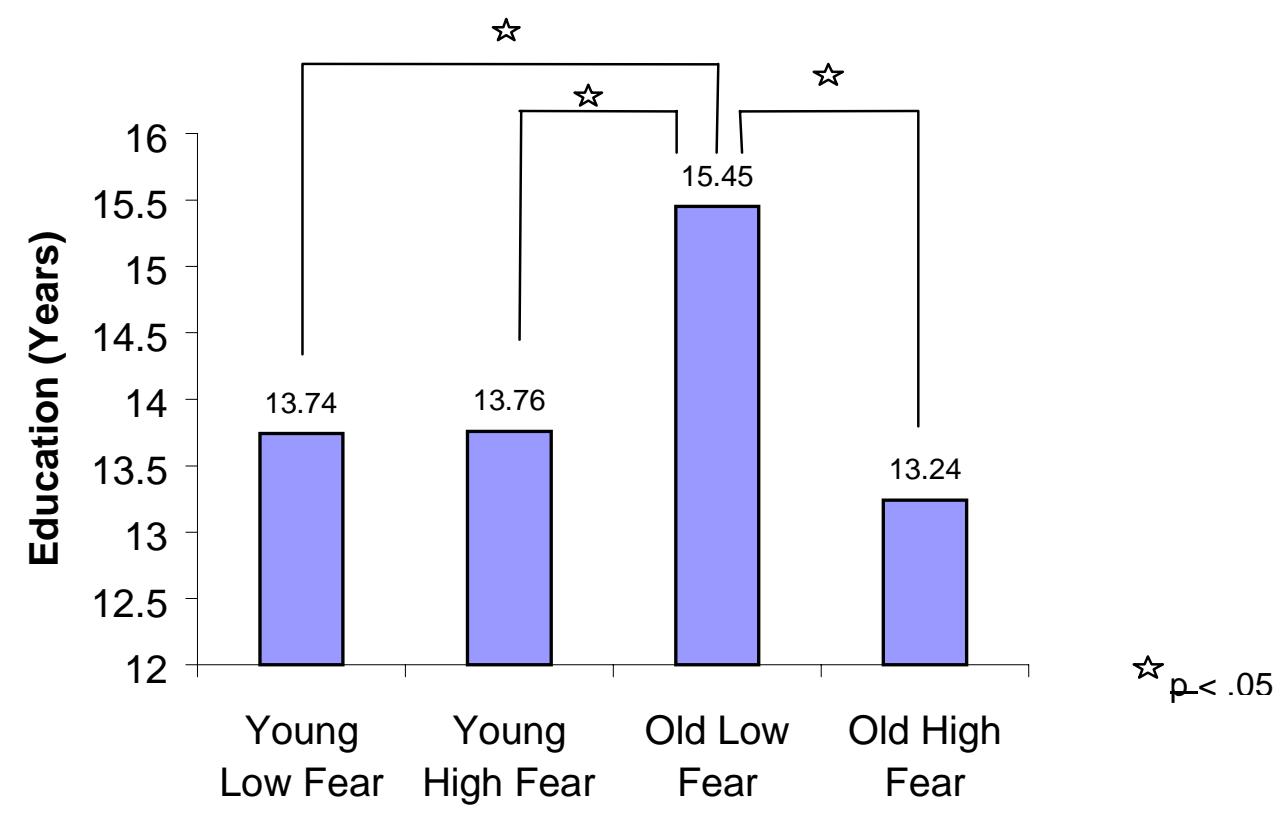


Figure 2.

$\underline{\text { Age } x \text { Task Interaction for State Trait Anxiety Inventory-State }}$

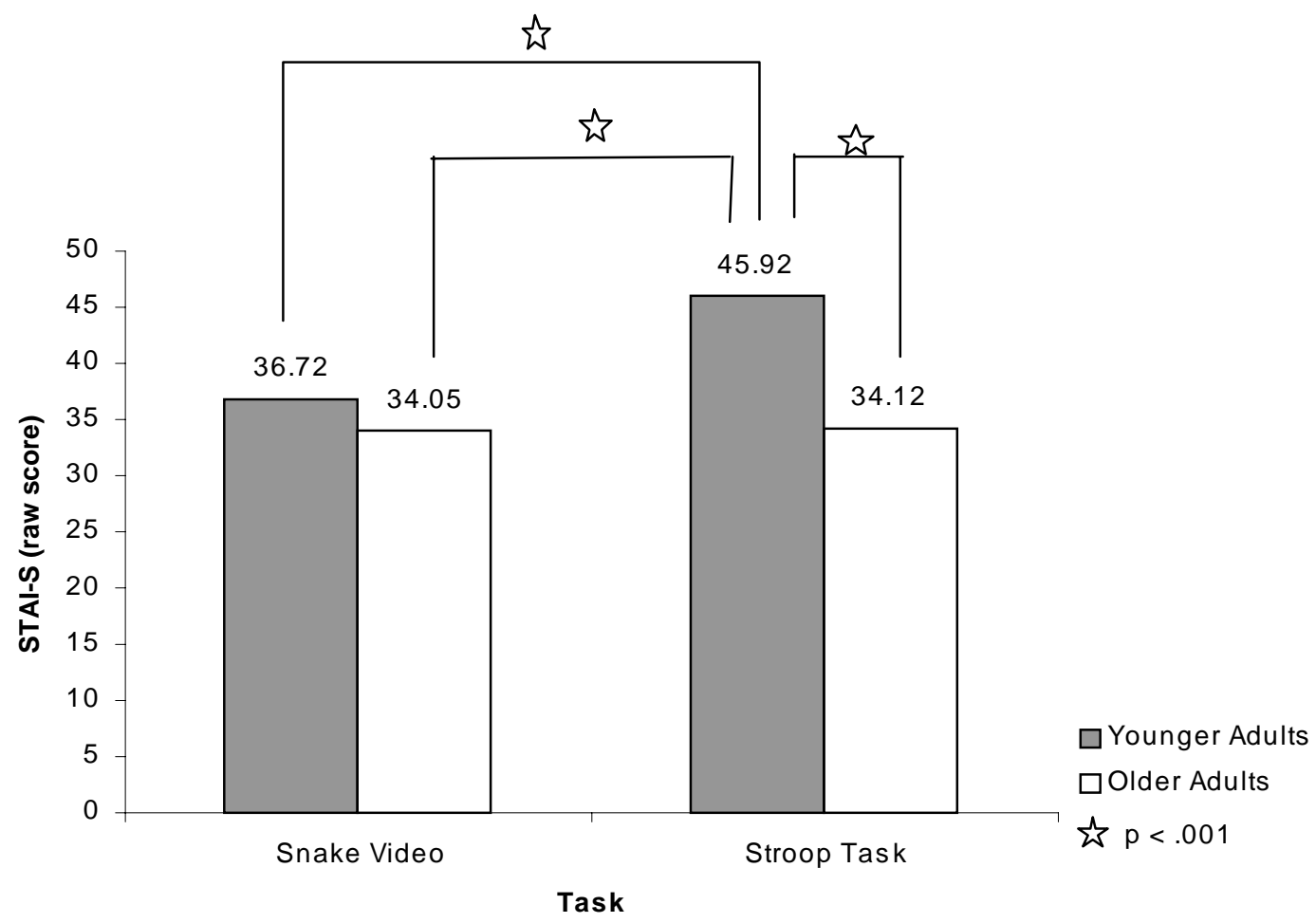


Figure 3.

Age x Task Interaction for Subjective Anxiety Ratings

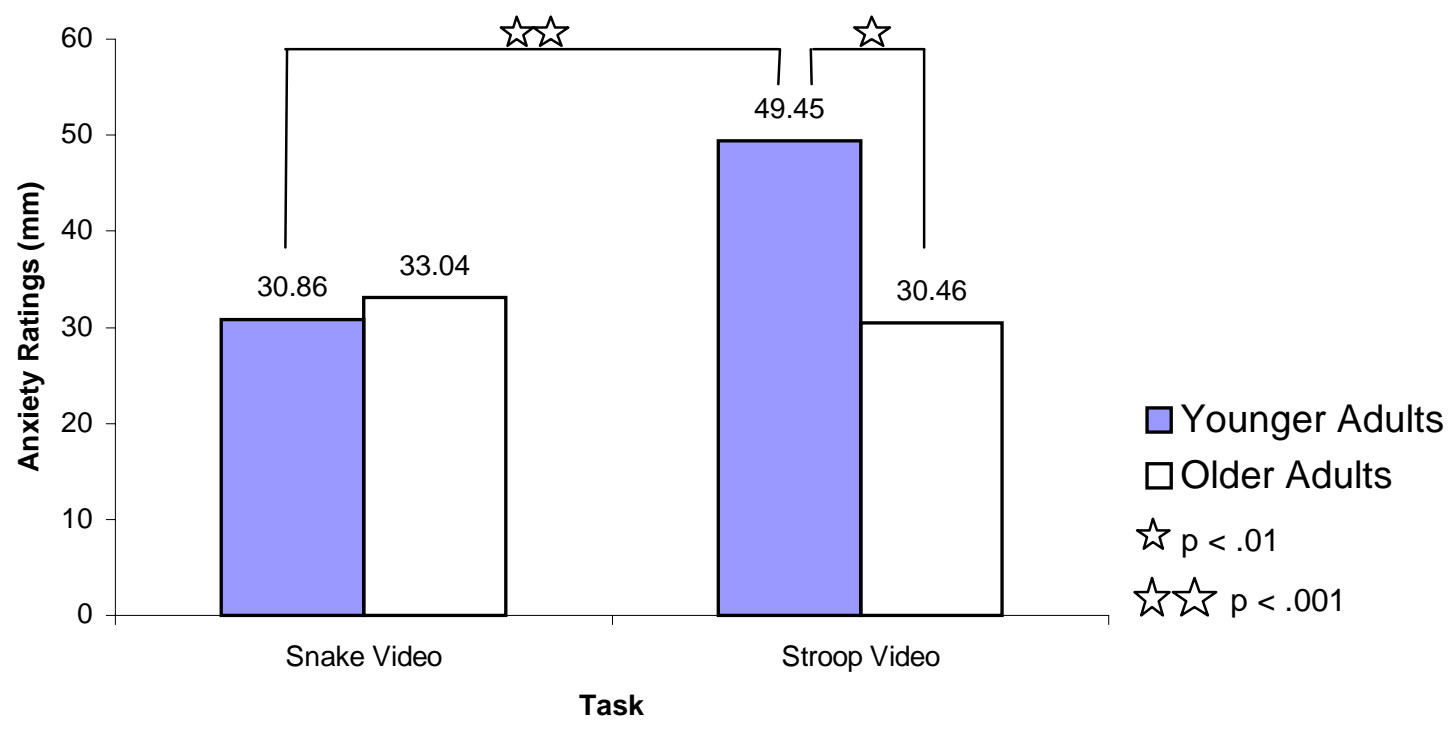


Figure 4.

Fear x Task Interaction for Subjective Anxiety Ratings

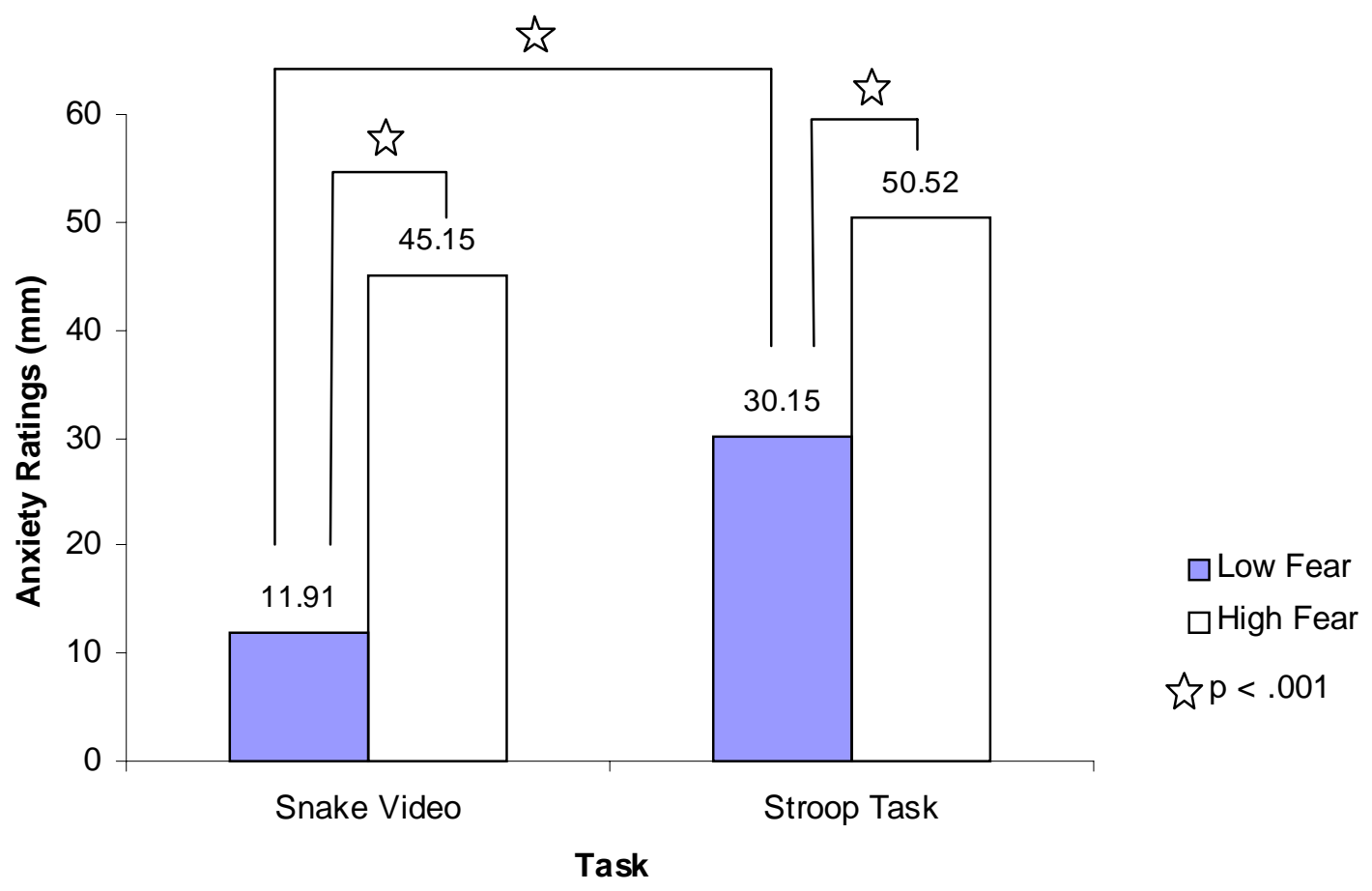


Figure 5.

$\underline{\text { Age x Fear Interaction for Stroop Task Error Ratio }}$

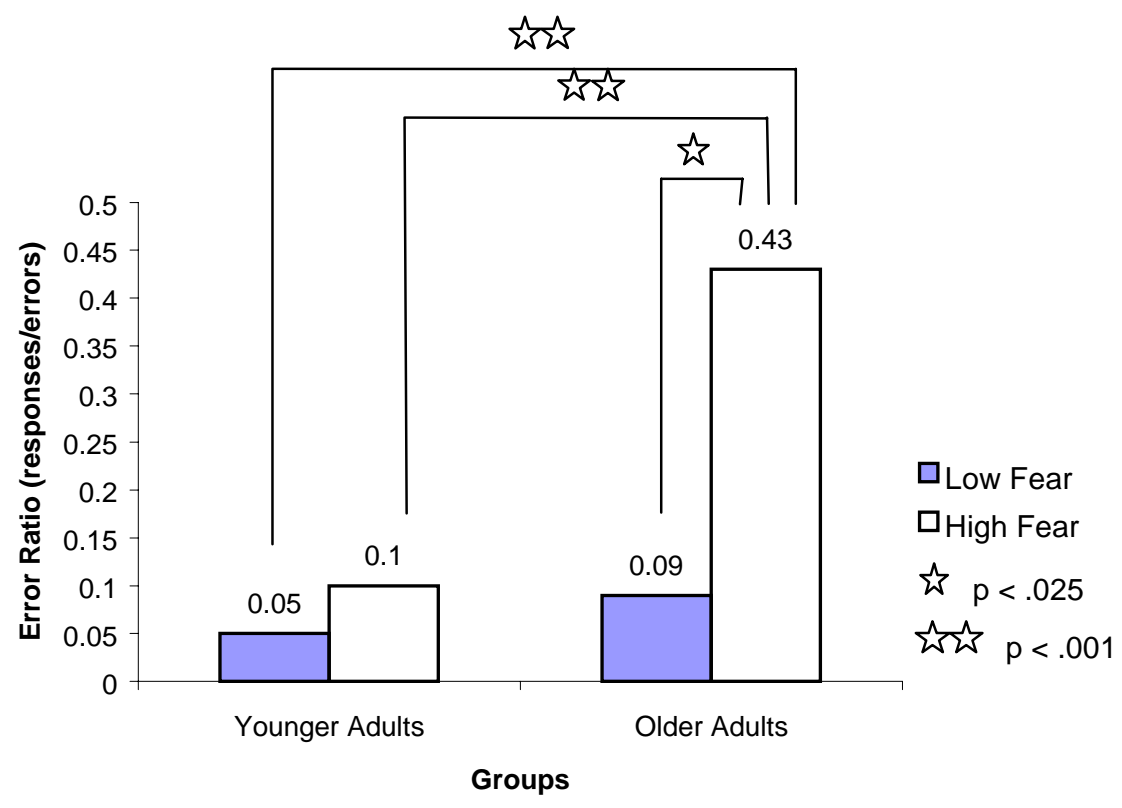


Figure 6.

Age x Fear Interaction for Snake Video Questionnaire

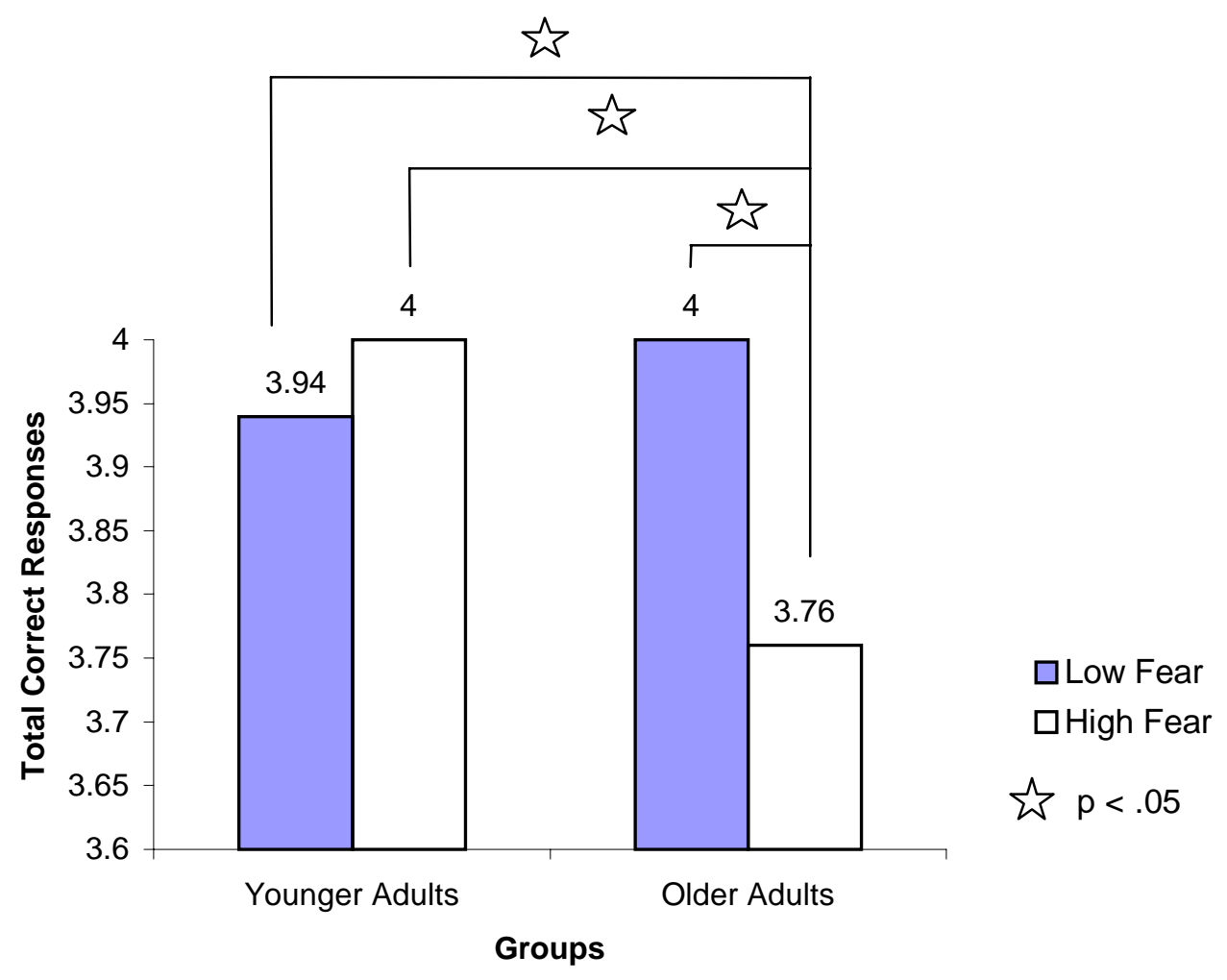


Figure 7.

Age x Task Interaction for Heart Rate Responses during Tasks

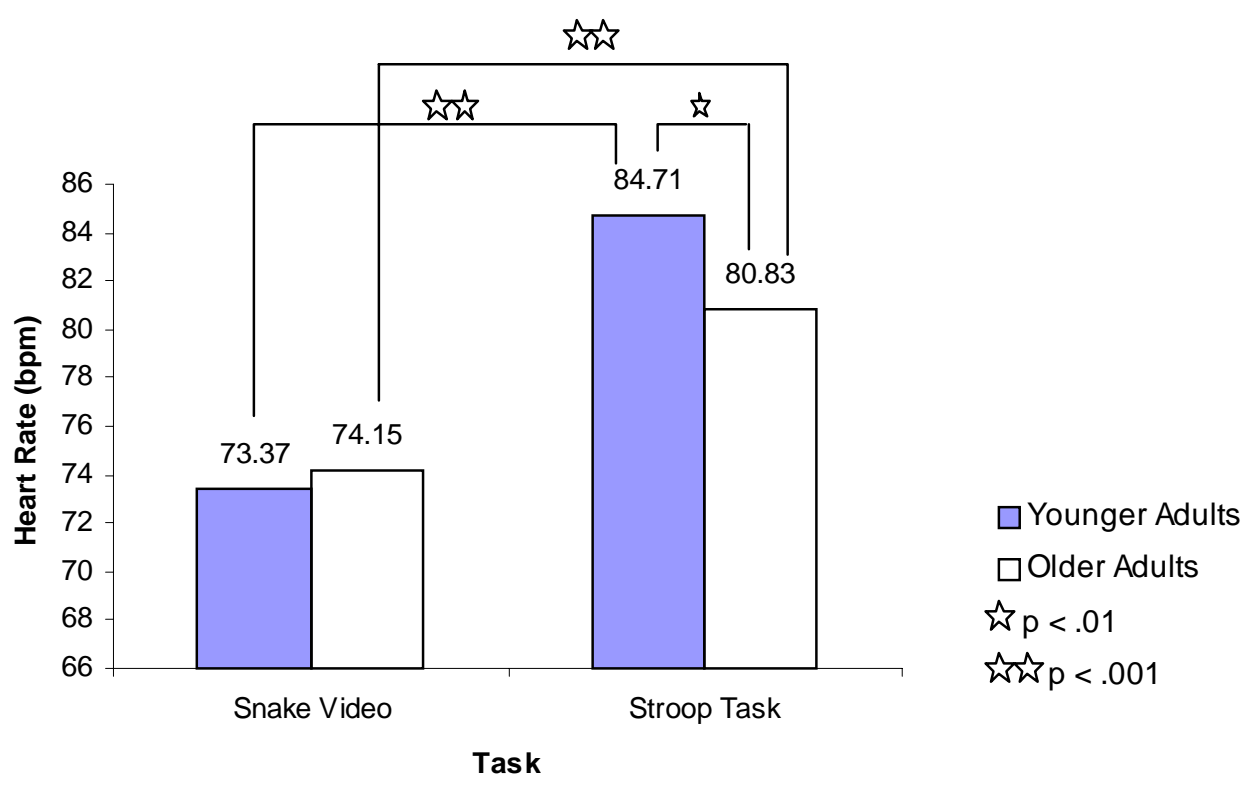


Figure 8.

$\underline{\text { Age x Task Interaction for SCR Responses during Tasks }}$

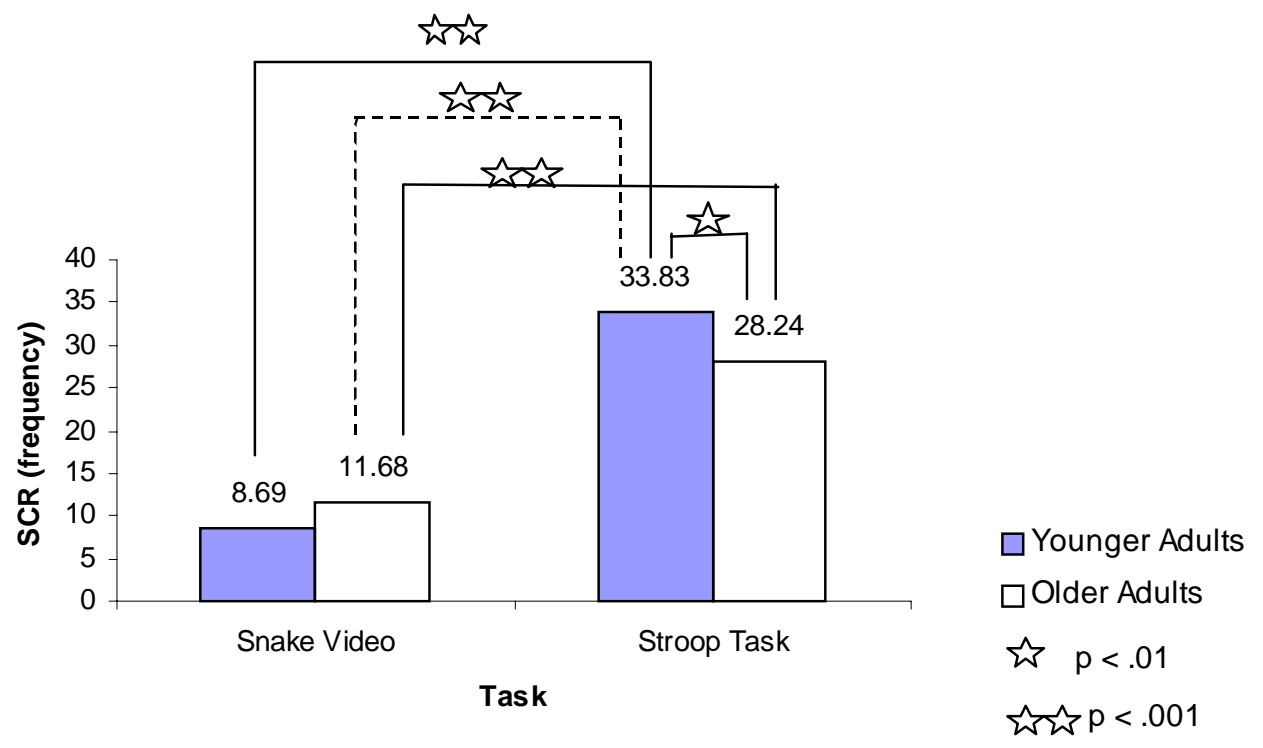


Figure 9.

Fear x Task Interaction for Systolic Blood Pressure Responses During Tasks

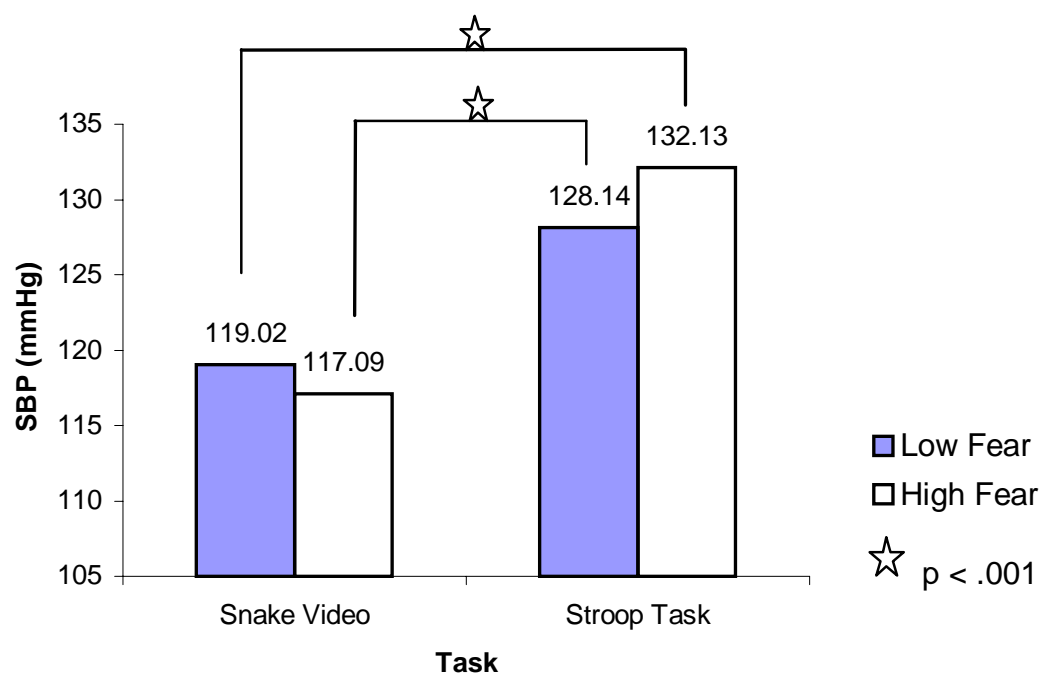


Figure 10.

Age x Interval Interaction for Post-Stroop Task Skin Conductance Level Recovery

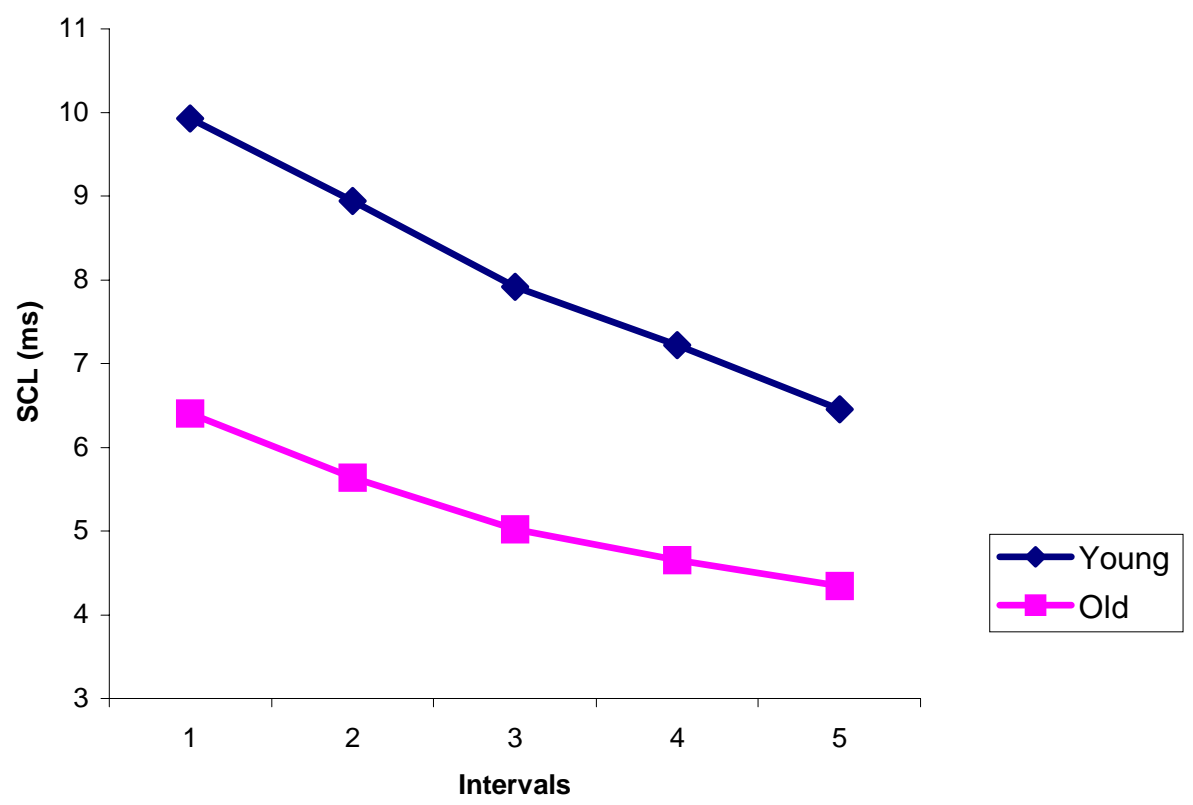


Figure 11.

Age x Interval Interaction for SCR Recovery following the Stroop Task

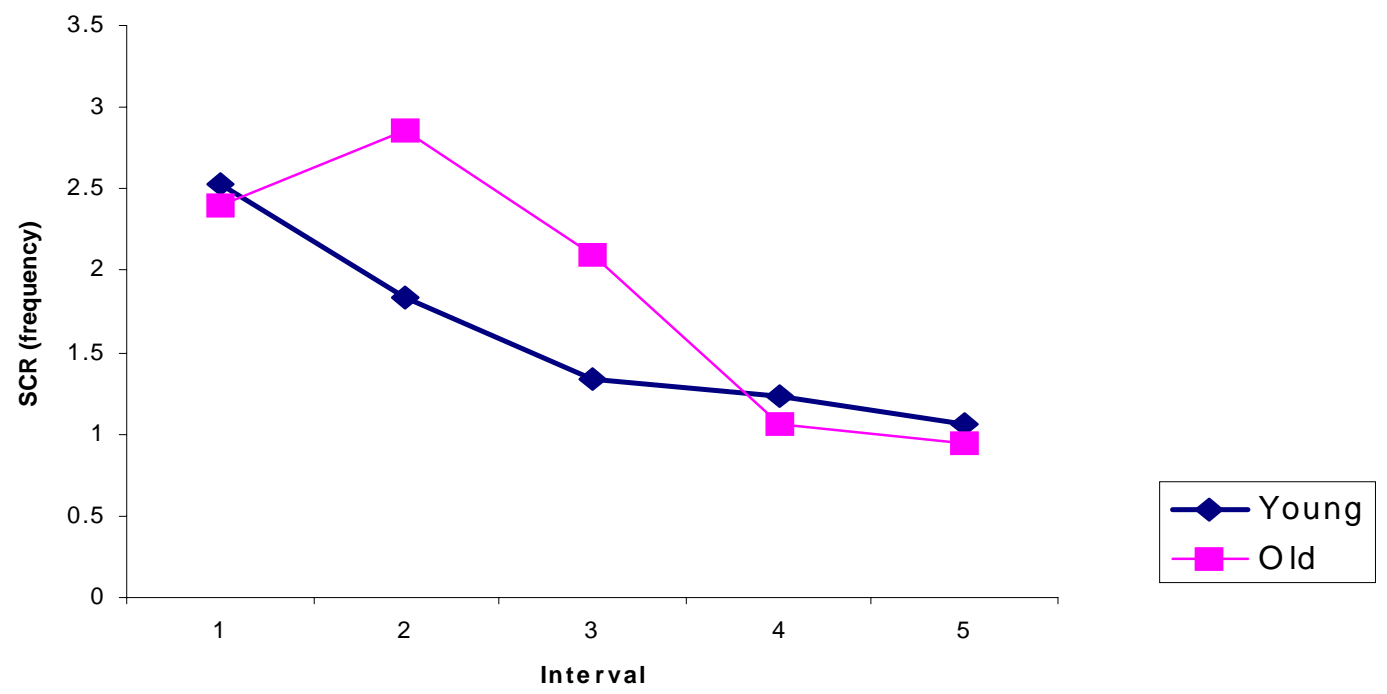


Figure 12.

Age x Fear x Interval Interaction for SBP during Recovery

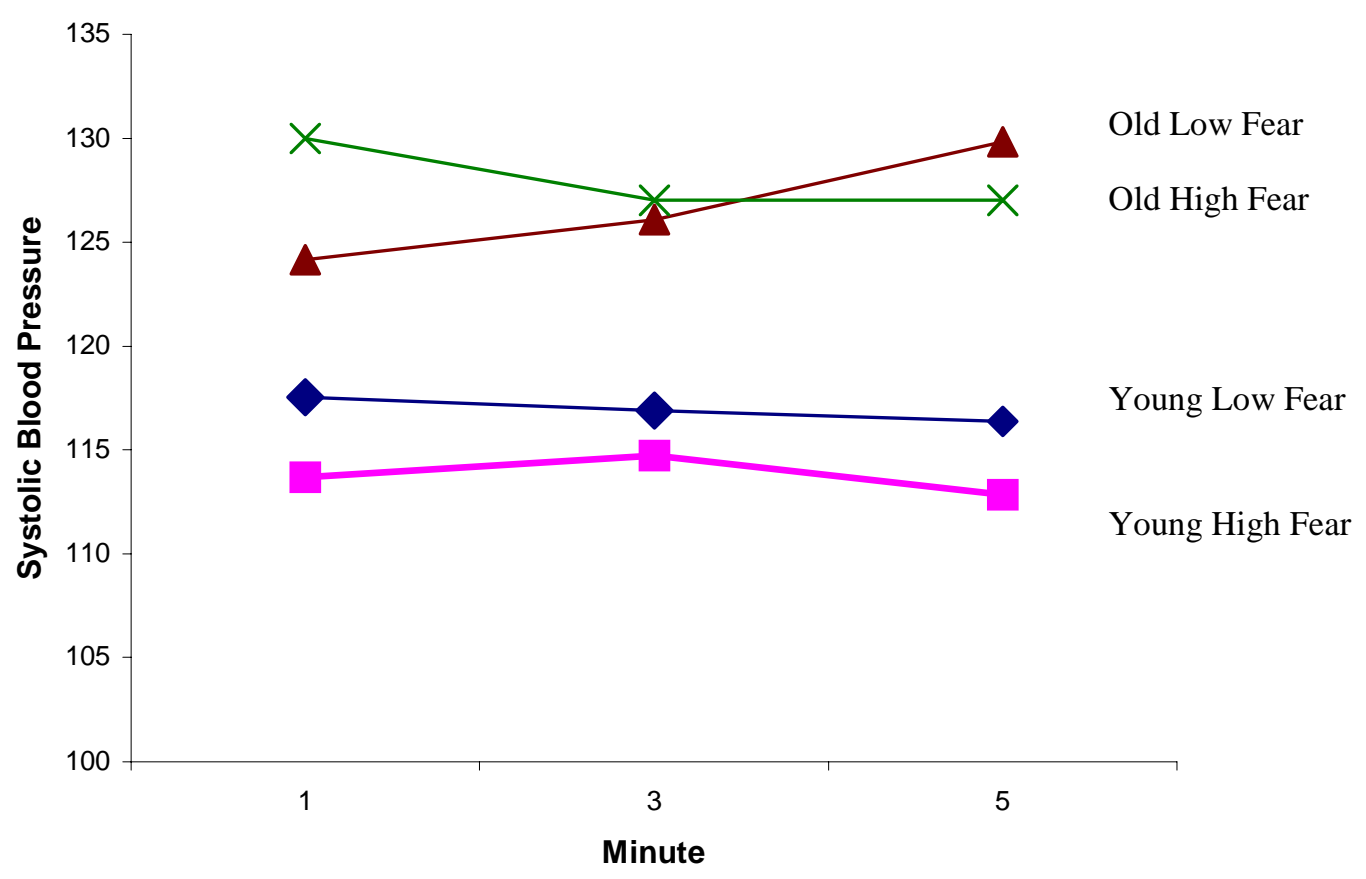

